\title{
Organic Tanks Safety Program: Advanced Organic Analysis FY 1996 Progress Report
}

Technical Task Leaders:

J. A. Campbell

K. L. Wahi

RECEIVED

Report Contributors:

S. A. Clauss

G. M. Mong

OCT 151996

K. E. Grant

J. Rau

V. Hoopes

R. Steele

September 1996

Prepared for the U.S. Department of Energy under Contract DE-AC06-76RLO 1830

Pacific Northwest National l.aboratory Operated for the U.S. Department of Energy by Battelle 


\section{DISCLAIMER}

This report was prepared as an account of work sponsored by an agericy of the United States Government. Neither the United States Government nor any agency thereof, nor Battelle Memorial Institute, nor any of their employees, makes any warranty, express or implied, o: assumes any legal liability or responsibility for the accuracy, completeness, or usefulness of any information, apparatus, product, or process disclosed, or represents that its use would not infringe privately owned rights. Reference herein to any specific commercial product, process, or service by trade name, trademark, manufacturer, or otherwise does not necessarily constitute or imply its endorsement, : recommendation, or favoring by the United States Government or any agency thereof, or Battelle Memorial Institute. The views and opinions of authors expressed herein do not necessarily state or reflect those of the United States Government or any agency. thereof.

\section{PACIFIC NORTHWEST NATIONAL LABORATORY operated by BATTELIE \\ for the \\ UNTTED STATES DEPARTMENT OFENERGY under Contract DE-AC06-76RLO 1830}

Printed in the United States of America

Available to DOE and DOE contractors from the

Office of Scientific and Technical Information, P. O. Box 62, Oak Ridge, TN 37831; prices available from (615) 576-8401.

Available to the public from the National Technical Information Service, U.S. Department of Commerce,5285-Port Royal Rd., Springfield, VA 22161

This document was printed on recycled paper. 


\section{DISCLAIMER}

Portions of this document may be illegible in electronic image products. Images are produced from the best available original document. 
PNNL-11309

UC-601

\section{Organic Tanks Safety Program: \\ Advanced Organic Analysis FY 1996 \\ Progress Report}

Technical Task Leader: J. A. Campbell and K. L. Wahl

Report contributors:

S. A. Clauss

K. E. Grant

V. Hoopes

G. M. Mong

J. Rau

R. Steele

September 1996

Prepared for the U.S. Department of Energy under Contract DE-AC06-76RLO 1830

Pacific Northwest National Laboratory

Operated for the U.S. Department of Energy

by Battelle 


\begin{abstract}
This report describes the work performed during FY 1996 by Pacific Northwest National Laboratory in optimizing analysis techniques for identifying organic components in Hanford waste tanks under the auspices of the Organic Tanks Safety Program. A major focus during the first portion of FY 1996 was to evaluate using organic functional group concentrations to screen for energetics. Organic functional group determination by Fourier transform infrared and Raman spectroscopy produced promising results. Fourier transform infrared and Raman spectroscopy would be useful screening tools for determining $\mathrm{C}-\mathrm{H}$ and $\mathrm{COO}$ - organic content in tank waste samples analyzed in a hot-cell-environment. These techniques were not truly quantitative and would be primarily used for identifying tanks of potential safety concern that may require further analysis.
\end{abstract}

Samples from Tanks 241-C-106 (Tank C-106) and 241-C-204 (C-204) were analyzed for organic constituents. The major organic component in C-106 was bis (2-ethylhexyl) phosphoric acid, and the major organic component identified in C-204 was tributyl phosphate.

Analyses of simulated wastes were also performed for the Waste Aging Studies Task (Don Camaioni, Task Leader) to determine the extent of organic degradation. Organic components . formed as a result of degradation have been identified, and the original starting components have been monitored quantitatively. Sample analysis is not routine and required considerable methods adaptation and optimization.

Several techniques have been evaluated for directly analyzing chelator and chelator fragments in tank wastes: matrix-assisted laser desorption/ionization time-of-flight mass spectrometry and liquid chromatography with ultraviolet detection using copper complexation. Although not directly funded by the Tanks Safety Program, the success of these technologies has implications for both the Flammable Gas and Organic Tanks Safety Programs. 



\section{Summary}

Samples taken from Tank 241-C-204 (C-204) in May 1995 were analyzed during FY 1996. The major organic component present in the samples delivered to Pacific Northwest National Laboratory (PNNL) was tributyl phosphate (TBP), $0.18 \mathrm{~g}$ of carbon/g of wet weight. This corresponds to $0.33 \mathrm{~g}$ of $\mathrm{TBP} / \mathrm{g}$ of wet weight sample as delivered to the hot cell. Relatively small amounts of dibutyl phosphate (DBP) were present in the water-soluble materials, representing about $2000 \mu \mathrm{g}$ of carbon/g of original tank sample. No monobutyl phosphate (MBP) was found to be present in the extracts presented for analysis. Acetate and formate were also present in the tank waste in very minor amounts (analysis by ion chromatography (IC). (Campbell and Mong 1996).

The samples obtained by oil samples centrifuged from C-106 sludge were submitted to PNNL for organic speciation. Using a combination of infrared (IR), gas chromatography/mass spectrometry (GC/MS), and liquid chromatography (LC), approximately $80 \%$ of the total organic carbon (TOC) was identified. The principal constituent of the oil was the compound bis(2-ethylhexyl) phosphoric acid (D2EHP), existing as the sodium salt in the waste. Minor amounts of TBP, normal paraffin hydrocarbon (NPH), transesterification products of D2EHP, and butyl alcohol were also identified. Methylene chloride extracts of the oil obtained by centrifugation were also analyzed.

Analyses of simulated wastes to determine the extent of organic degradation have been performed for the Waste Aging Studies (Don Camaioni, Task Leader). Many samples have been analyzed, and efforts during FY 1996 have focused on improving detection capabilities for degradation products. Modifications to IC and LC separations afforded advances in detection of the lower-concentrated degradation products formed during the aging studies. As a result, the analyses were not routine and required considerable methods optimization.

During the middle of FY 1995 and extending into FY 1996, efforts were redirected at the request of Westinghouse Hanford Company (WHC). More emphasis was placed on developing analytical techniques for functional group analysis. In some cases, functional-group information, instead of complete organic speciation, may be sufficient to determine tank safety. Fourier transform infrared and Raman spectroscopy were evaluated for analyzing functional groups. Promising results were obtained for analyzing liquid and solid simulant waste samples (Wahl et al. 1996). However, further development is required before implementing these techniques as a screening tool for rapidly determining organic functional groups for energy estimation.

A test plan was written to detail the efforts to determine the organic species present in Hanford tanks which are currently on or could potentially be included on the Organic Tanks Watch List. The test plan discussed the analytical methodology and prospective tank waste samples and was a joint effort of staff from PNNL and WHC (see Carlson et al. in Appendix A). The test plan is in the final stages of review.

To estimate the extent of degradation of organics in the tanks, fill histories have been compared with actual analyses. The results vary widely, indicating that chemical processes over time have changed the chemistry of the tanks. For example, the fill history of SY-101 indicates that 0.008 $\mathrm{mg} / \mathrm{g}$ of oxalic acid, a common degradation product, was initially in the tank, but analysis results revealed approximately $15 \mathrm{mg} / \mathrm{g}$. For ethylenediaminetetraacetic acid (EDTA), the fill history lists a concentration of $12 \mathrm{mg} / \mathrm{g}$; the concentration determined by analysis was $4.2 \mathrm{mg} / \mathrm{g}$. Further comparisons between the fill history and actual analysis are needed to estimate the amount of degradation of the organic constituents. 
Because derivatization gas chromatography/flame ionization detection (which was used for chelator analyses) is time-consuming, expensive, and heavily dependent of the nature of the dried material, ion-pair liquid chromatography with ultraviolet detection as the copper complex is being evaluated for analyzing tank waste directly. Studies with simulated wastes looked very promising and were expanded to include actual wastes. Preliminary results show that the typical chelators, such as EDTA, N-(2-hydroxyethyl)ethylenediaminetriacetic acid (HEDTA), nitrilotriacetic acid (NTA), and iminodiacetic acid (IDA) can be separated. Another technique evaluated for direct analysis of chelators and chelator fragments is matrix-assisted laser desorption/ionization time-of-flight mass spectrometry. This technique has the advantage of very little sample preparation, small sample size, and little or no additional waste produced, but is still in the early stages of development.

\section{References}

Campbell, JA and GM Mong. 1996. Letter Report. Tank 241-C-204 Analyses. PNNLOT:032596. Pacific Northwest National Laboratory, Richland, Washington.

Wahl, KL, JA Campbell, IE Burgeson, SA Bryan, DM Camaioni, RT Hallen, BD Lerner, and RD Scheele. 1996. Use of Organic Functional Group Concentrations as a Means of Screening for Energetics. PNNL-10883, Pacific Northwest National Laboratory, Richland, Washington. 


\section{Acknowledgments}

The support of Westinghouse Hanford Company for the real waste analysis is gratefully acknowledged. The authors would also like to thank G. K. Ruebsamen for patience and diligence in compiling this report and W. C. Cosby for editorial assistance. In addition, the authors would like to thank Dr. Harry Babad of WHC for his assistance, support, and thought-provoking dialogue. Pacific Northwest National Laboratory is operated for the U.S. Department of Energy by Battelle under Contract DE-AC06-76RLO 1830. 


\section{Glossary}

\begin{tabular}{|c|c|}
\hline $\mathrm{BF}_{3}$ & boron trifluoride \\
\hline BuD2EHP & butyl bis(2-ethylhexyl) phosphate \\
\hline Bu2EHP & butyl (2-ethylhexyl) phosphate \\
\hline $\mathrm{CE}$ & capillary electrophoresis \\
\hline $\mathrm{CI}$ & chemical ionization \\
\hline DBP & dibutyl phosphate \\
\hline D2EHP & bis(2-ethylhexyl) phosphate \\
\hline $\mathrm{DSC}$ & differential scanning calorimetry \\
\hline ED3A & ethylenediaminetriacetic acid \\
\hline EDTA & ethylenediaminetetraacetic acid \\
\hline EI & electron impact \\
\hline ESI & electrospray ionization \\
\hline FID & flame ionization detection \\
\hline FT & Fourier transform \\
\hline FY & fiscal year \\
\hline GCIMS & gas chromatography/mass spectrometry \\
\hline HEDTA & $\mathrm{N}$-(2-hydroxyethyl)ethylenediaminetriacetic acid \\
\hline $\mathrm{HP}$ & Hewlett-Packard \\
\hline HPLC & high performance liquid chromatography \\
\hline IC & ion chromatography \\
\hline IDA & iminodiacetic acid \\
\hline IR & infrared \\
\hline LC & liquid chromatography \\
\hline LC/MS & liquid chromatography/mass spectrometry \\
\hline MALDI-TOF & matrix-assisted laser desorption/ionization time-of -flight \\
\hline MBP & monobutyl phosphate \\
\hline MS & mass spectrometry \\
\hline MSD & mass selective detector \\
\hline $\mathrm{m} / \mathrm{z}$ & mass-to-charge \\
\hline NTA & nitrilotriacetic acid \\
\hline NPH & normal paraffin hydrocarbon \\
\hline PFTBA & perfluorotributylamine \\
\hline PNNL & Pacific Northwest National Laboratory \\
\hline S-EDDA & symmetrical ethylenediaminediacetic aciḍ \\
\hline SFC & supercritical fluid chromatography \\
\hline TBP & tributyl phosphate \\
\hline T2EHP & tris(2-ethylhexyl) phosphate \\
\hline TIC & total inorganic carbon \\
\hline TOC & total organic carbon \\
\hline U-EDDA & unsymmetrical ethylenediaminediacetic acid \\
\hline UV & ultraviolet \\
\hline WHC & Westinghouse Hanford Company \\
\hline
\end{tabular}





\section{Contents}

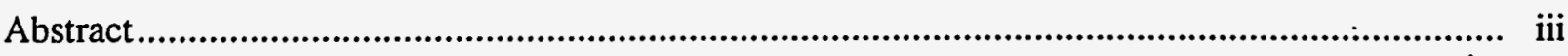

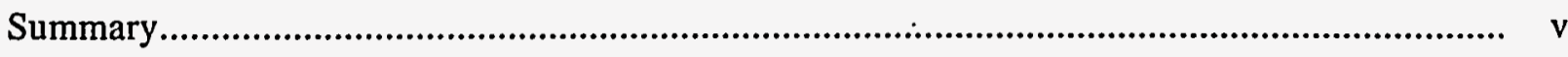

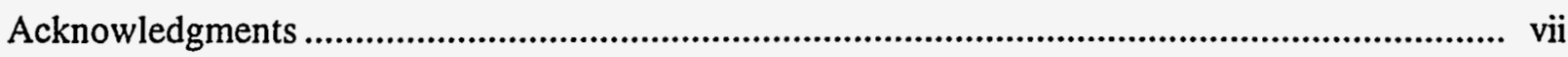

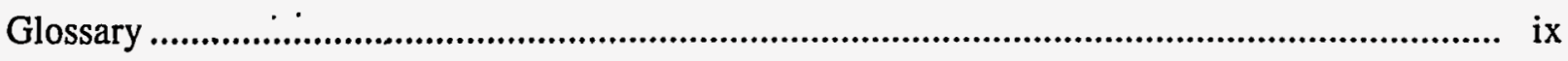

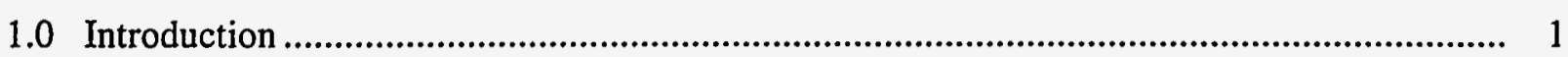

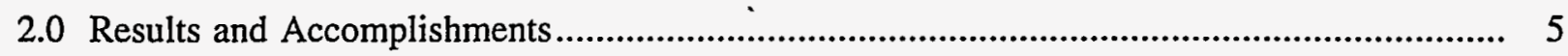

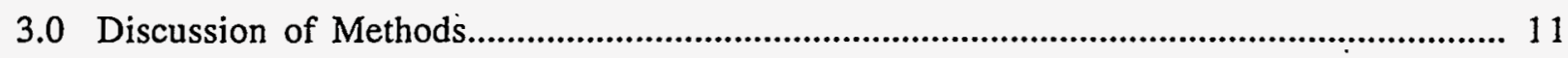

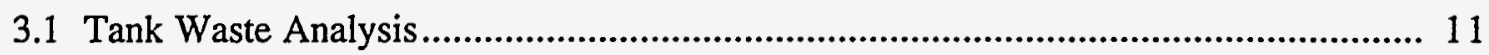

3.1.1 Analysis of Samples from Tank 241-C-204 ......................................... 11

. $\quad 3.1 .2$ Analysis of Tank C-106 Centrifuged Oil Samples ................................... 14

3.2 Analyses of Simulant Wastes for Waste Aging Studies........................................ 22

3.3 Organic Functional Group Screening Development ........................................... 25

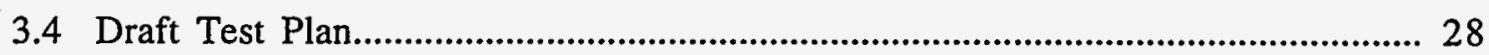

3.5 Alternative Methods Being Developed .............................................................. 28

3.5.1 Matrix-Assisted Laser Desorption/Ionixzation Time-of-Flight MS............. 29

3.5.2 Ion-Pair Chromatography for Chelators and Chelator Fragments.............. 35

3.5.3 Ion-Pair Chromatography of Dibutyl Phosphate.................................... 36

3.6. Degradation of Organics in Flammable Gas Tanks............................................. 46

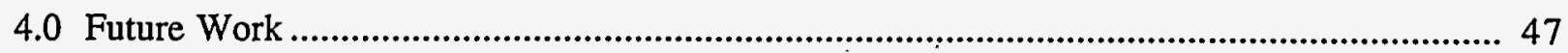

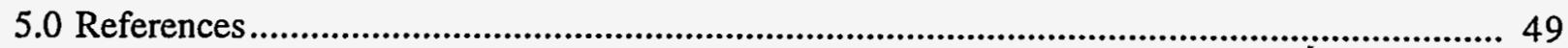

Appendix A Test Plan for the Speciation of Organics in Actual Tank Wastes to Support Verification of Solubility and Aging Assumptions...............................A.1

Appendix B Preprint of Determination of Monobutyl Phosphate and Dibutyl Phosphate in Mixed Hazardous Wastes by Ion-Pair Chromatography 


\section{Figures}

3.1 Total Ion Chromatogram (GC/MS-EI Mode) of Diazomethane

Derivatized Tank Sample C-204 and the Mass Spectrum of the Only

Major Component Tributyl Phosphate.

3.2 Total Ion Chromatogram (GC/MS-EI Mode) of Diazomethane Derivatized

Tank C-106 Centrifuged Oil Sample and the Associated Mass Spectra of

the Major Components

3.3 Total Ion Chromatogram (GC/MS-CI Mode) of Diazomethane Derivatized

Tank C-106 Centrifuged Oil Sample and the Associated CI Mass Spectra of

the Major Components

3.4 Mass Spectral Fragmentation Pattern for Tributyl Phosphate...................................... 20

3.5 Reanalysis of Tank C-103 Sample by GC/MS ..................................................... 23

3.6 Schematic of Organic Analysis Scheme of SIM-PAS-95-1a

Waste Aging Samples.

3.7 Ion Chromatogram of Organic Acid Standards with AS-11

Column (Dionex).

3.8. Ion Chromatogram of Organic Acid Standards with AS-6 Column (Dionex)

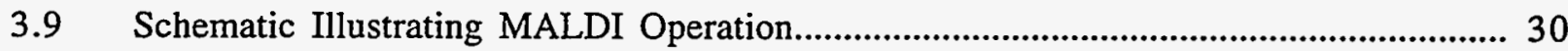

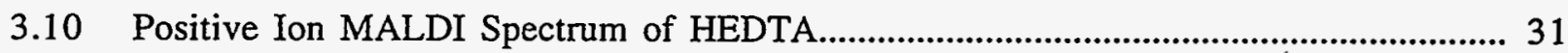

3.11 Positive Ion MALDI Spectrum of EDTA .............................................................. 32

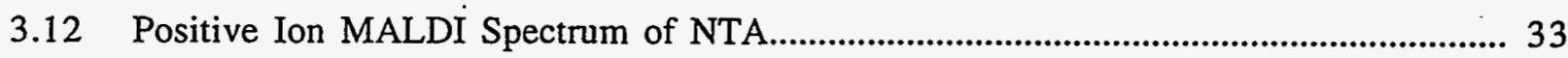

3.13 Negative Ion MALDI Mass Spectrum of Citric Acid with Gentisic Acid Matrix.............. 34

3.14 Ion-Pair Chromatogram of Chelator Standards ................................................. 37

3.15 Ion-Pair Chromatogram of Simulated Waste ........................................................ 38

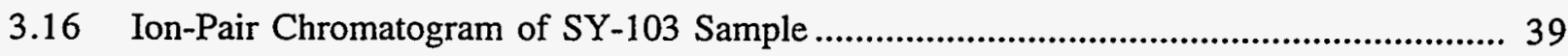

3:17 Ion-Pair Chromatogram of Heated Sample from SY-103 ...................................... 40

3.18 Ion-Pair Chromatography of MBP and DBP Standards with

Refractive Index Detection

3.19. Calibration Curve for Dibutyl Phosphate in Standard Solutions. 
3.20 Ion-Pair Chromatography of Inorganic Simulant Spiked with $\mathrm{DBP}$ and MBP

3.21 Ion-Pair Chromatography with Preconcentration Clean-up of a Simulant Waste Sample Spiked with DBP and MBP

3.22 Ion-Pair Chromatogram of a Waste Simulant Containing MBP, DBP, and TBP 44

3.23 Ion-Pair Chromatogram of a Waste Sample from Tank 241-C-204... 45 


\section{Tables}

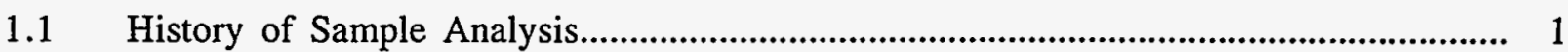

2.1 Results of Analyses of Oil Released by Sludge Centrifugation from C-106 Samples ................................................................................................

3.1 Analytical Methods Used for Support of Aging .................................................... 24

3.2 Retention Times of Organic Acid Standards with Two Different Ion Chromatography Columns and Separation Schemes

3.3 Ions Observed for the Analytes by MALDI-TOF MS in the Positive or Negative Ion Mode. 


\subsection{Introduction}

During FY 1994, the Advanced Organic Analysis task was initiated as part of the Organic Tanks Safety Project under the direction of Westinghouse Hanford Company (WHC). The work under this task was performed by Pacific Northwest National Laboratory (PNNL) for WHC to develop and improve analysis techniques that could be used to quantitatively identify organic species in tankwaste samples under the auspices of the Organic Tanks Safety Program. Methods development efforts that started during FY 1994 were continued at the beginning of FY 1995. During the second half of FY 1995, WHC redirected the task towards more functional group determinations. The task was changed to reduce efforts in new development work and place more emphasis on actual waste analysis. Tank waste samples analyzed during FY 1994, 1995 and 1996 are listed in Table 1.1.

Table 1.1 History of Sample Analysis

Fiscal Year

1994

1995

1996
Samples Analyzed

C-103

C-102, C-103, BY-108

C-204, C-106

Early efforts were focused on developing new analytical techniques that could be used to analyze organics in tank wastes. Originally, emphasis was placed on organic speciation to identify what compounds were actually in the tank waste. Therefore, most of the initial development focused on ways to determine specific organic components in complex inorganic matrices typical of tank waste. Accounting for total organic carbon (TOC) can determine the effectiveness of organic speciation efforts. Initial (1993) attempts at analyzing organics in tank waste produced only about $20 \%$ TOC accountability. Accountability for TOC increased to $80-90 \%$ by improving methods for preparing and analyzing samples (Campbell et al. 1994a). Information gained from organic analyses of tank waste (Campbell et al. 1994a) has been used to develop tank-waste simulants used for other research projects related to organic-tanks safety. For example, these simulants were used to study waste-aging processes (Camaioni et al. 1994 and 1995) and organic concentration mechanisms (Gerber 1994).

Methods currently used to analyze tank-waste samples for organics include derivatization gas chromatography/mass spectrometry (GC/MS), high-performance liquid chromatography (HPLC), and liquid chromatography/mass spectrometry (LC/MS) (Campbell et al. 1994a and 1994b). While these analysis techniques provide valuable information about the organic components in the waste samples, they are, in general, time-consuming, generate a substantial amount of secondary laboratory waste, and can introduce interferences or artifacts because of the derivatization-based side reactions associated with GC/MS procedures. Therefore, it was a goal during FY 1994 to identify and test alternative analytical methods that could make organic analysis of tank wastes more efficient and cost effective. The techniques tested during FY 1994 were electrospray ionization mass spectrometry (ESI/MS) for direct MS analysis of non-volatile components, capillary electrophoresis (CE) for separations with minimal mobile phase waste generation, supercritical fluid extraction (SFE) for waste minimization during sample handling, and Raman spectroscopy for functional group determinations (Campbell et al. 1994c). Preliminary results for all of these techniques showed potential for 
improving the efficiency of organic analysis, but were never fully developed for real tank waste analysis due to priority changes and funding restraints.

Ion chromatography (IC), developed under the Flammable Gas Safety Program (Campbell et al. 1995a), has proven very effective for low-molecular weight acids analysis. This technique has been effective in monitoring starting components in simulant aging studies, as well as identifying degradation products (Camaioni et al. 1995, 1996). As with any new technique, there were still some obstacles to implementing this technique. For example, a problem of co-eluting species with the initial separation protocol existed. Alternative separations methods are under development to solve this problem.

Coupling ion chromatography to mass spectrometry was another concept that was only partially developed prior to re-direction of efforts to functional group analysis techniques. The mass spectrometric detection method envisioned was atmospheric pressure chemical ionization, ideally suited for small-molecule analysis and relatively tolerant of matrix components. Preliminary results of this technique were presented (Wahl et al. 1995). However, further efforts toward implementation have been reduced because of shifting priorities.

Also during FY 1995, two separations methods (ion-pair chromatography with refractiveindex detection and capillary isotachophoresis with ultraviolet detection) were pursued to improve capabilities for analyzing and quantitating dibutyl phosphate (DBP) in the presence of large concentrations of nitrate and nitrite. Capillary isotachophoresis is a form of electrophoresis where separations are performed based on differences in mobility of charged analytes in an electric field. Dibutyl phosphate is a fuel-rich organic compound of concern that is present in many waste tanks. It is a safety concern due to its high-enthalpy in waste mixtures. Preliminary results from efforts to find a robust analysis technique for DBP were promising.

Another major effort of this task during FY 1995 was completing a Test Plan for analyzing waste samples from Tanks 241-C-102 (C-102), C-103, and BY-108 in support of resolving a safety concern regarding the entrainment of organic solvents and other chemicals in waste solids. The Test Plan was a joint effort of staff from PNNL and WHC; analyses were scheduled to be a joint effort as well. Analyses and results obtained to date were performed by WHC, with the direction and assistance of PNNL. Preliminary results and details of the Test Plan have been published (Campbell et al. 1995b).

To support the shift in emphasis away from complete organic speciation for tank wastes, development of a functional-group screening tool based on Raman and infrared (IR) spectrometry began near the end of FY 1995 and extended into FY 1996. This was complemented by differential scanning calorimetry (DSC) and TOC analyses to obtain a good estimate of the enthalpy of organics present in waste. The goal was to obtain approximate organic energetics information with rapid, costeffective screening tools. When necessary to resolve a safety issue or interpret conflicting data from other characterization efforts, the more expensive complete organic speciation would be performed to gain more detailed information on the organic content of the tanks. This screening-tool development was scheduled to continue during FY 1996, and a report on this development was prepared and published in FY 1996 (Wahl et al. 1996). Preliminary results from the early stages of development of this screening tool were encouraging.

Additional tank samples need to be analyzed to determine the applicability of the analytical methods being used to analyze waste. Although efforts to date have been extremely successful in 
determining organics present in tank samples analyzed, minor adjustments of analytical methods will most likely be required to account for inevitable changes in the sample matrix. Therefore, continuous efforts to improve the robustness of organic-analysis techniques are warranted.

This report will discuss the results from analyses of samples from C-204 and C-106, and the analytical procedures used to analyze simulant waste samples for organics degradation to support the Waste Aging Organic Safety Task (Camaioni et al. 1996). In addition, the state of optimization of organic analysis methods and a summary of the results from the organic functional group screening development will be discussed. Preliminary data from evaluating alternative methods to analyze chelator and chelator fragments directly, requiring no derivatization before analysis will also be discussed. The method optimization was not directly funded by the Organics Tanks Safety Program; however, the results have important implications for the entire Tank Safety Program. If successful, the cost of analyses would be greatly reduced. 


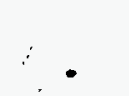




\subsection{Results and Accomplishments}

\section{Real Waste Analysis}

Two auger samples were taken from C-204 and delivered to PNNL in 1996 for analysis. The major organic component present in the samples delivered to PNNL was tributyl phosphate (TBP), $0.18 \mathrm{~g}$ of carbon/g of wet weight. Analyses were performed using GC/FID and GC/MS. This represents $0.33 \mathrm{~g}$ of $\mathrm{TBP} / \mathrm{g}$ of wet weight sample as delivered to the hot cell. Relatively small amounts of DBP were in the water-soluble materials, approximately $2000 \mu \mathrm{g}$ of carbon/g of original tank sample. No MBP was found in the extracts presented for analysis. However, the assay for DBP and MBP may be incomplete; studies must be undertaken to be certain that these materials are not left behind in the.necessary ion-exchange step used to reduce the radioactivity of the final matrix material. Acetate and formate were also in the tank waste in very minor amounts (analysis by IC). Chelators such as EDTA, NTA, IDA, and ethylenediaminetriacetic acid (ED3A) were not detected in the C-204 samples.

Tank C-106 is a high heat tank and questions arose concerning the safety of transferring solids from C-106 to AY-102. The C-106 Grab Sampling and Analysis Plan (Schreiber 1996) identified the overall characterization objectives for sample collection, laboratory analytical evaluation, and reporting requirements for the sampling events. To maximize information obtained from the samples recovered from C-106, an extensive dewatering step was built into the laboratory test plans (Schreiber 1996). The staff of the 222-S laboratory were asked to dewater the sludge using a fritted disk or filter cone to maximize separation of water-soluble from water-insoluble waste components. This separation step was designed to avoid the anomalies sometimes observed when samples containing significant amounts of water are analyzed. Errors in analysis results were of particular concern when a waste sample contained analytes that may partition into both the aqueous and solid phases. Standard centrifugation separated a phase that was sludge associated organic oil that floated on the aqueous waste layer. The results of speciation with C-106-derived sludge oil are summarized in Table 2.1. The two samples were taken from different risers.

The major organic component detected in the sludge oil samples was bis(2-ethylhexyl) phosphate which has the following structure. Both samples have basically the same organic<smiles>CCCCOP(=O)(O)O</smiles>

composition. Bis(2-ethylhexyl) phosphate is a viscous, yellow to amber liquid, and is a versatile cation exchanger, which, by proper adjustment of conditions, could be used to extract practically all of the actinide and fission product elements of interest in the Waste Management Program.

Two samples of a methylene chloride extract of sludge oil (C-106) were provided by WHC. They were identified as sample 3133 and sample 3132. Samples 3133 and 3132 were extracted from oil from sludge samples $6 \mathrm{C}-96-14$ and $6 \mathrm{C}-96-8$, respectively. These samples were very similar in composition to the oils centrifuged from the $\mathrm{C}-106$ sludges described previously. The major constituent in sample 3133 was D2EHP. However, methylene chloride extraction samples were contaminated with bis(2-ethylhexyl) phthalate, a material (e.g., phthalates) usually associated with 
Table 2.1 Results of Analyses of Oil Released by Sludge Centrifugation from C-106 Samples

Sample 7SA:

$\begin{array}{lll}\text { Component } & \text { mg/g } & \text { mg Carbon/g } \\ \text { D2EHP } & 0.66 & 0.37 \\ \text { BúD2EHP } & 0.07 & 0.043 \\ \text { T2EHP } & 0.01 & 0.005 \\ \text { TBP } & 0.05 & 0.027 \\ \text { Bu2EHP } & 0.03 & 0.015 \\ \text { Total } & 0.82 & 0.46\end{array}$

Sample 13-3:

\begin{tabular}{|c|c|c|}
\hline Component & $\underline{\mathrm{mg} / \mathrm{g}}$ & mg Carbon/g \\
\hline D2EHP & 0.54 & 0.30 \\
\hline BuD2EHP & 0.08 & 0.047 \\
\hline T2EHP & 0.005 & 0.003 \\
\hline TBP & 0.06 & 0.030 \\
\hline Bu2EHP & 0.02 & 0.011 \\
\hline Total & 0.70 & 0.391 \\
\hline $\begin{array}{l}\text { D2EHP = bi } \\
\text { BuD2EHP = } \\
\text { T2EHP = tri } \\
\text { Bu2EHP = }\end{array}$ & $\begin{array}{l}\text { (2-exyl) } \\
\text { hexyl) } \\
\text { thylhe }\end{array}$ & 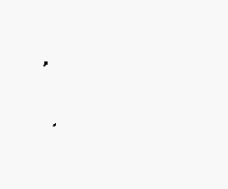 \\
\hline
\end{tabular}

plasticizers. Sample 3132 contained approximately the same amount of D2EHP as sample 3133, but about 3 times as much bis(2-ethylhexyl) phthalate. This may be due simply to contamination from plasticizers in the plastic centrifuge tubes used in the 222-S Laboratory. Both samples were delivered in similar containers and were treated identically by PNNL scientists. Although phthalate esters are clearly an artifact of laboratory handling, the cause of the contamination will be pursued since WHC will be checking other sludge waste samples for extractable organics, making avoidance of such potential contamination a requirement. Quantitation and carbon balance are in progress.

A C-103 sample (received 1994) was retrieved from storage and a-30-mg aliquot taken of the organic layer present in the sample. This aliquot was dissolved in $2 \mathrm{~mL}$ methylene chloride and treated with an additional $2 \mathrm{~mL}$ diethyl ether that had been previously saturated with hydrochloric acid. This treatment appears to quantitatively transform sodium bis(2-ethylhexyl) phosphate in the sample into the free acid form; as evidenced by copious amounts of white precipitate $(\mathrm{NaCl})$ forming in the vessel. Some precipitation was noted upon addition of acidified ether. The aliquots were then reduced in volume to $100 \mathrm{~mL}$, cooled, and $3 \mathrm{~mL}$ of an uncalibrated solution of ethereal 
diazomethane added. \{Diazomethane is produced by stirring an ethereal slurry of N-methyl-Nnitrosourea over a 40-percent $\mathrm{KOH}$ solution (Fieser and Fieser 1967)\}. The esterification is essentially complete immediately; the colored diazomethane is used to visually confirm the presence of excess diazomethane. To ensure complete conversion, the sample was left for one hour in the presence of excess diazomethane before analysis.

Prior GC/MS analysis has tentatively identified other materials related to bis(2-ethylhexyl) phosphate in Tank C-106 samples. The mass spectral signature ions (both EI and CI modes) for this group of organic analytes makes identification of these moieties relatively straightforward. We have evidence of the following molecules being present in samples containing D2EHP: butyl bis(2ethylhexyl) phosphate, tris(2-ethylhexyl) phosphate, and butyl (2-ethylhexyl) phosphate.

Gas chromatography analysis was done using an HP 5890 ${ }^{\mathrm{TM}} \mathrm{GC}$ (FID) equipped with a lowpolarity, thin phase capillary column (HP-5, $30 \mathrm{~m} \times 0.32 \mathrm{~mm} \times 0.25 \mathrm{~mm}$ ). The temperature was ramped from $50^{\circ}$ to $260^{\circ}$ at $8 \% \mathrm{~min}$, and held at $260^{\circ}$ for 5 minutes, affording an adequate separation of the analytes previously observed in Tank C-103 floating layer materials.

Inspection of the chromatogram reveals the presence of butyl bis(2-ethylhexyl) phosphate (retention time $24.3 \mathrm{~min}$ ) and tris(2-ethylhexyl) phosphate (retention time $27.13 \mathrm{~min}$ ) only. There does not appear to be an appreciable amount of D2EHP (retention time $22.2 \mathrm{~min}$ ) in this sample. The ratios of these two materials, relative to each other, is similar to that observed in the Tank C-106 analysis. The remainder of the chromatogram resembles the results previously reported by Pool and Bean (1994). Unfortunately, standard materials are not available for butyl bis(2-ethylhexyl) phosphate (BuD2EHP) or tris(2-ethylhexyl) phosphate (T2EHP) at this time; the response observed for the analyte used for C-106 analysis (D2EHP) was used to calculate these minor components.

The resulting quantitation for these materials (per gram of sample) in the archived C-103 sample is as follows:

$\begin{array}{lccc}\text { Component } & \text { mg/g_Amount } & \text { mg Carbon/g Amount } \\ \text { BuD2EHP } & 0.003 & \cdot & 0.0017 \\ \text { T2EHP } & 0.0005 & & 0.0003\end{array}$

These materials comprise trace components in the mix of TBP and normal paraffinic hydrocarbons found in the $\mathrm{C}-103$ matrix. By comparison, the TBP component has a FID response 50 times as large. In essence, the combination of these two components cannot represent more than 1 percent of the total carbon present in the sample.

It is significant to note the presence of BuD2EHP and T2EHP in these samples in the apparent absence of D2EHP. The presence of butylated species is highly indicative of transesterification from TBP or capture of butanol in the sample matrix over the life of the sample. These materials do not appear to be artifacts of sample preparation or analysis. An additional derivatization is warranted to determine if there is some reason for incomplete or inadequate derivatization of this sample.

In summary, the D2EHP was the major organic component in the sludge oil from Tank C106. The results from this analysis and others helped determine that the sluicing of the contents of Tank C-106, in accord with proper controls, will pose no unacceptable risk to workers, public safety, 
or the environment. In addition, it is expected that the sluicing operation will successfully resolve the High-Heat Safety Issue for Tank C-106 (Babad et al. 1996).

\section{Phosphate Ester Identification}

As a result of the identification of various phosphate esters in samples from C-106, simple mass spectrometric fragmentation patterns have been observed which can be used for the tentative identification for each phosphate species. Chemical ionization (CI) mass spectrometry can be used to determine the molecular weight; electron impact (EI) can be used to determine the length of the carbon chains.

In the EI mode, alkylated phosphate esters tend to lose alkyl groups. Basically this means that the alkyl groups are sufficiently long to donate two hydrogens to the phosphate interior structure during the fragmentation process. As an example, tri-alkylated phosphate esters will afford $\mathrm{m} / \mathrm{z} 99$ as the base ion.

$$
\left[\begin{array}{c}
\stackrel{\mathrm{OH}}{\mathrm{HO}-\underset{\mathrm{P}}{1} \mathrm{OH}} \\
\mathrm{OH}
\end{array}\right]^{\oplus} \quad \begin{aligned}
& - \\
&
\end{aligned}
$$

Once the fragmentation mechanisms are understood, the EI mass spectral interpretation for alkyl phosphates and alkyl phosphonates is fairly simple. Unfortunately, the phosphonium ions, such as $\mathrm{m} / \mathrm{z}$ 99, are the predominant ions present in EI spectra. Careful inspection of the minor ions, coupled with chemical ionization are very beneficial in interpreting the mass spectra of these compound classes. In addition, we are establishing a mass spectral library of phosphate ester-type compounds.

The major component observed in the analyses of C-106 samples was bis(2-ethylhexyl) phosphate. Multiple minor components were observed which appear to have originated from combination of D2EHP with butanol present in the waste possibly from alkaline hydrolysis of TBP. Materials present in the $\mathrm{C}-106$ waste are difficult to rationalize as arising from D2EHP. These include butylmethyl (2-ethylhexyl) phosphate and butyl bis(2-ethylhexyl) phosphate. The latter component represents a significant fraction of the organophosphorus compound. An explanation for the presence of these materials is the apparent transesterification of bis(2-ethylhexyl) phosphate with TBP also present in the matrix. It is surprising to observe the apparent exchange of alkyl groups among alkylated phosphates in the highly alkaline tank wastes.

\section{Analyses of Waste Simulants}

Simulant waste samples were analyzed for organics and inorganics to determine the extent of organics degradation and to identify degradation products under the Organic Analytical Support Task to support the Waste Aging Studies Task (Don.Camaioni, Task Leader). The majority of the methods used to determine organic components have been described previously (Wahl et al. 1995). However, adjustments and improvements have been made as different simulant waste mixtures have been submitted and the need to identify degradation products has progressed; sample analyses were not routine. Many samples have been analyzed and degradation products identified throughout FY 1996. The relative degradation rates of organics observed in simulants and the resulting degradation products have been used to relate to actual waste. 


\section{Functional Group Screening Method}

Promising results were obtained using Fourier transform (FT)-IR and Raman spectroscopy for the organic-functional group determination in liquid and solid simulant waste samples. Further development is required before implementing these techniques as a screening tool to determine organic functional groups rapidly for energy estimation (Wahl et al. 1996).

For quantitating $\mathrm{COO}^{-}$content in simulant waste-sample solutions, FT-IR spectroscopy produced promising results. Calibration curves from integration over the $\mathrm{COO}^{-}$stretching frequencies for six different organic components were very similar. To determine $\mathrm{C}-\mathrm{H}$ content, linear calibration curves were obtained by integrating over the $\mathrm{C}-\mathrm{H}$ stretching frequencies for each of seven organic analytes tested. The extinction coefficients were not identical. Formate analysis produced the main discrepancy in determining $\mathrm{C}-\mathrm{H}$ content. Using FT-IR spectroscopy of solid simulants produced mixed results in determining $\mathrm{C}-\mathrm{H}$ and $\mathrm{COO}^{-}$content. Qualitative determination of these functional groups could be made in these solutions; however, high organic concentrations and samples with low moisture content presented difficulties. As a screening tool for distinguishing high and low organic functional group content, FT-IR spectroscopy might still be a viable technique.

Fourier transform Raman spectroscopy was successful for the semi-quantitation of EDTA, citrate, acetate, and oxalate in solutions that varied between $0.5 \%$ to $4 \%$ by mass organic in basic solution. Surface-enhanced Raman was also evaluated as a method for increasing sensitivity for analysis. Fourier transform Raman spectroscopy provided a good correlation of the C-H functional group and organic content independent of the type of organic and water content of the solid simulants. The results improved with decreasing water content of the sample due to the noncontact nature of the sampling.

The preliminary results suggest that FT-IR and Raman spectroscopy would be useful as screening tools for determining $\mathrm{C}-\mathrm{H}$ and $\mathrm{COO}^{-}$organic content in tank waste samples analyzed in a hot-cell environment. Both of these techniques are not truly meant to be quantitative in nature and would be primarily used for identifying tank wastes of potential concern that might require additional organic speciation.

\section{Draft Test Plan}

From the tank fill data $\left\{\right.$ Agnew $\left.^{(1)}\right\}$, the amounts and types of organics that were added to the tanks can be closely approximated, but due to thermal and radiolytic degradation of the wastes (Camaioni et al. 1995), the nature of the organic carbon in the tanks will be significantly different. To provide a more reasonable value for the reactive nature of the organics-containing wastes in the tanks, the organics must be identified. For several years, the nature of the organics in the tanks has been studied under the Flammable Gas Program (Campbell et al. 1995a) and the current work proposed in the test plan will build on this knowledge to provide a better understanding of the organic species in the tanks. A test plan was written for the speciation of organics in actual tank wastes to support the verification of solubility and aging assumptions by staff of PNNL and WHC. The test plan details the efforts to determine the organic species in Hanford tanks that are currently on or could be potentially placed onto the Organic Tanks Watch List. The test plan is in the final stages of review, and a copy is included in Appendix A.

(a) SF Agnew to Dr. H Babad, August 31, 1995. E-mail message on updated estimate for SY-101 fill history. 


\section{Degradation of Organics}

We have estimated the extent that organics have degraded in flammable gas tanks by comparing the fill history with the composition of the organics as determined by speciation. As an example, we have compared the fill history of SY-101 with the results obtained by organic analyses. For oxalic acid, the fill history estimates the concentration to be approximately $0.0008 \mathrm{mg} / \mathrm{g}$ of samples $\left\{\right.$ Agnew $^{(a)}$ \}, but the results from actual analysis indicate a concentration of approximately 15 $\mathrm{mg} / \mathrm{g}$. Another example is citric acid with an initial concentration of $3.5 \mathrm{mg} / \mathrm{g}$ from fill history compared to $0.8 \mathrm{mg} / \mathrm{g}$ from speciation. Citric acid appears to be less reactive than either HEDTA or EDTA; these results have been confirmed by Camaioni et al. (1996) and the results of analysis of the heated SY-103 samples (Bryan 1996). The results may provide a means to determine the extent of degradation. As an example, detecting the ratio of citric acid to oxalate may provide insight into the extent of degradation. Additional tank samples must be analyzed.

\section{Alternative Techniques}

Derivatization GC/MS for analyzing chelators and chelator fragments is time consuming, produces artifacts, and is costly. As a result, several techniques have been evaluated, including matrix-assisted laser desorption/ionization time-of-flight (MALDI-TOF) and LC with copper complexation and ultraviolet (UV) detection. Both of these methodologies allow the sample to be analyzed directly, without prior derivatization. Even though not directly funded by the Organic Tanks Safety Program, the development of these techniques may have implications for the program. Positive ion MALDI-TOF spectra of EDTA, HEDTA, NTA, and IDA have been obtained. Negative ion spectra of phosphate, sulfate, nitrate, and nitrate have also been obtained. Preliminary results from analysis of simulated wastes using ion-pair chromatography indicate separation of IDA, EDTA, symmetrical ethylenediaminediacetic acid (S-EDDA) and unsymmetrical ethylenediaminediacetic acid (U-EDDA), HEDTA, and ethylenediaminetriacetic acid (ED3A). In addition, analyzing real tank wastes has shown that the concentration of EDTA as determined by derivatization GC/MS may be underestimated. Further studies are underway.

\section{Manuscripts}

Several manuscripts have been submitted for publication as a result of work on the Tank Safety Programs. One publication regarding LC/MS for the qualitative analysis of low-molecular weight acids has been accepted in the Journal of Radioanalytical and Nuclear Chemistry. Two other manuscripts entitled "Determination of Chelators and Chelator Fragments in Samples from Tank 241-SY-101 Using Derivatization Gas Chromatography" and "Cation Exchange for the Reduction of Radioactivity in the Analysis of Tank Wastes" have been submitted for publication. A MALDITOF paper describing the analysis of low-molecular weight organics is in preparation. Another manuscript regarding the analysis of DBP and MBP has also been submitted for peer review and is included in Appendix B. 


\subsection{Discussion of Methods}

\subsection{Tank Waste Analysis}

\subsubsection{Analysis of Samples from Tank 241-C-204}

Two auger samples were taken from C-204 in May 1995. Both samples were taken from . riser 7. Unfortunately, for both auger samples, a rag was caught in the auger. Visible rag material was segregated in the hot cell. One of the chemists reported seeing rag fibers in a sample from the tank, which suggested that the sample might be contaminated with rag material. However, by visual examination, the sample was largely tank waste solids (yellow and brown solids observed during extrusion).

Westinghouse Hanford Company performed DSC on samples from C-204. Results indicated exotherms well above the criterion of $481 \mathrm{~J} / \mathrm{g}$. Final values could not be obtained in many instances as the DSC scans did not return to baseline. An estimate of the average value is $1200 \mathrm{~J} / \mathrm{g}$.

Two samples were also submitted for TOC analyses by hot persulfate oxidation (direct analysis) at WHC. The average of the sample and duplicate results was $128,000 \mu \mathrm{g} \mathrm{C} / \mathrm{mL}$. This is almost $13 \mathrm{wt} \%$ TOC, uncorrected for moisture (moisture content was approximately $55 \% \mathrm{H}_{2} \mathrm{O}$ derived from thermogravimetric analysis results). The total inorganic carbon (TIC) results obtained at WHC averaged $10,500 \mu \mathrm{g} \mathrm{C} / \mathrm{mL}$ obtained at WHC.

Samples were submitted to the Advanced Organic Analytical Methods Group at PNNL for organic analysis. The samples from C-204 were analyzed in the 329 laboratory for chelators, chelator fragments, low-molecular weight organic acids, and organically soluble carbon. The results indicated the majority of the organic carbon consisted of TBP.

Approximately $15 \mathrm{~g}$ of total tank sample was taken in the 325 West hot cell. Two duplicate samples, approximately 1.8-g samples each, were made basic with $6 \mathrm{~N} \mathrm{NaOH}$ and eluted through ion exchange beds (AG-5OW-X8, Biorad, $\mathrm{Na}^{+}$form) to reduce radioactivity (Campbell et al. 1994b). The samples were then surveyed for dose rate and released from the hot-cell facility.

Two 1-g samples of the original tank sample were stirred with water to dissolve salts and then extracted with measured volumes of methylene chloride. These samples were released from the hotcell facility after being surveyed for dose rate. The bench sheets from the hot-cell technician reveal that a "thin floating layer" was observed in at least one sample after dissolution with water.

Aliquots of the aqueous extracts were taken to dryness $(2 \mathrm{~mL}$ of the total aqueous extract; representing approximately $100 \mathrm{mg}$ of the original tank matrix) for analysis of organic acids. These samples were treated with $\mathrm{BF}_{3} /$ methanol complex $(2 \mathrm{~mL})$ for $1 \mathrm{~h}$ at $100^{\circ} \mathrm{C}$ to derivatize potential chelator components such as EDTA, NTA, and HEDTA.

Samples of the aqueous extract were deemed low enough in radioactivity to allow benchtop ion chromatographic separation to analyze for formate, acetate, and oxalate components. Samples $(20 \mu \mathrm{L})$ were introduced into the IC system and eluted from an AS-11 (Dionex) column using a ramped sodium hydroxide eluent $(0.5 \mathrm{mM}$ to $38 \mathrm{mM} \mathrm{NaOH})$. An additional separation using 25 $\mathrm{mM}$ of $\mathrm{NaOH}$ and an AS-4A (Dionex) system was employed to quantitate DBP. 
The methylene chloride extracts were dried with a bed of sodium sulfate to remove residual aqueous radioactive components, taken to a minimum volume $(300 \mu \mathrm{L})$ using a gentle stream of dry nitrogen and reconstituted to a known volume $(5 \mathrm{~mL})$ with methylene chloride. Dilutions of this known volume were used to analyze for extractable organic components (e.g., TBP).

For quantitation results, TBP (99+\% Aldrich Chemical Co; lot \# 06828CX) and butyl phosphate (technical grade, Pfaltz and Bauer; lot \# 040927) were used. The TBP was assumed to be adequate for a comparison standard, based on analytical results from the manufacturer. Butyl phosphate, technical grade, has been found to contain about 50\% MBP and 50\% DBP, based upon its reaction with diazomethane and subsequent $G C$ analysis. Additionally, we have examined butyl phosphate by IC to ascertain the approximate distribution of butyl phosphates in the liquid. Since these materials are in dynamic equilibrium, any quantitation for these two components should be considered to be approximate.

Weights of materials were determined in the laboratory using a calibrated Mettler AC 100 balance (sensitivity $=0.1 \mathrm{mg}$ ). Dilution volumes were done using Eppendorf $1 \mathrm{~mL}$ and $0.1 \mathrm{~mL}$ adjustable pipettes that were previously calibrated using the weighed volumes of water delivered from the pipettes. Class A volumetrics were used for bulk dilutions.

Mass spectrometric data were obtained on low-resolution GC/MS systems (Hewlett-Packard 5988 and 5987) that were tuned with perfluorotributylamine (PFTBA) before use. Standards of TBP were run concurrently with the samples to determine relative response. Duplicate samples were run with each analysis. Additional GC/MS data were obtained using a Hewlett-Packard (HP) 5970 mass selective detector (MSD) system, tuned to PFTBA before use. Quantitative data were not obtained from the HP 5970 instrument.

Aqueous extract samples were treated with an unquantified excess of ethereal diazomethane (formed from base treatment of N-methyl-N-nitrosourea) to estimate DBP by GC/MS analysis.

Ion chromatographic responses were obtained using a Dionex conductivity detector system and acetic acid-glacial (Mallinckrodt, lot 8817) and formic acid 95 to 97\% (Aldrich, Lot \# $04324 \mathrm{EV}$ ) as primary standards.

The TOC/TIC analyses performed in the 325 laboratory were checked versus glucose (Kodak lot \#B1F) and calcium carbonate (lot \#N261) as check standards. The TOC/TIC measurements were done in duplicate and with spiked check samples.

The aqueous extracts obtained from C-204 did not reveal any quantifiable amount of the typical chelator components associated with tank wastes (EDTA, NTA, HEDTA, or citric acid). The IC analysis revealed small (less than $100 \mu \mathrm{g} / \mathrm{g}$ sample) amounts of acetate, formate, and oxalate in the matrix material. Trace amounts of butyric acid, toluene, and benzoic acid were confirmed to be in the matrix from analyzing the $\mathrm{BF}_{3} /$ methanol complex derivatized samples. None of these were quantified at this time.

Gas chromatographic/mass spectrometric analysis of the methylene chloride extracts revealed TBP to be the major carbon species. Figure 3.1 is a total ion chromatogram (GC/MS analysis) of the C-204 sample and mass spectrum of TBP. The value for TBP obtained from GC/MS analysis of the methylene chloride extracts averages $0.18 \mathrm{~g}$ of carbon/g of wet weight sample (at time of sampling in the hot cell). This corresponds to $0.33 \mathrm{~g}$ of $\mathrm{TBP} / \mathrm{g}$ of sample as delivered to the hot cell. This 

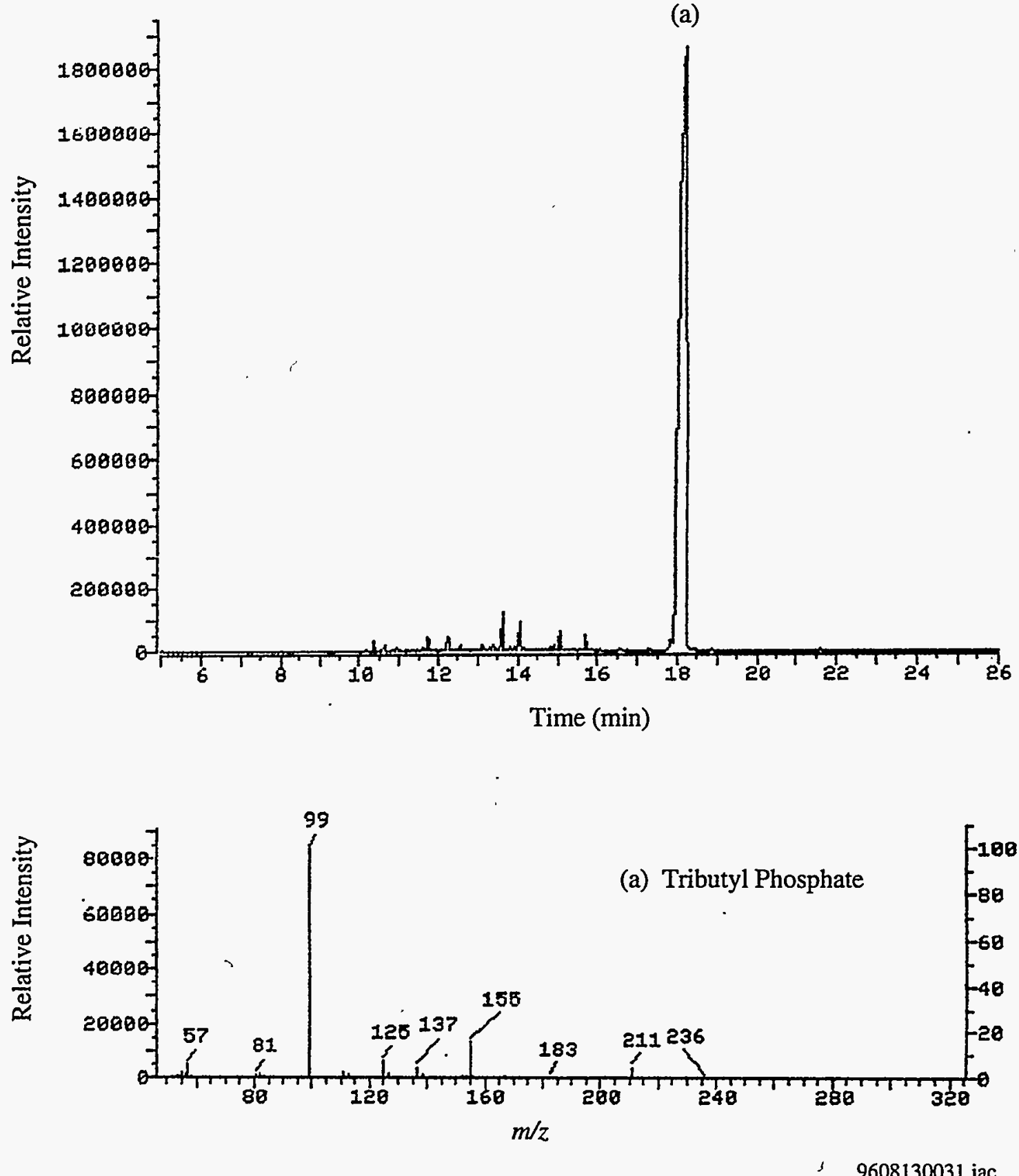

Figure 3.1. Total Ion Chromatogram (GC/MS-EI Mode) of Diazomethane Derivatized Tank Sample C-204 and the Mass Spectrum of the Only Major Component Tributyl Phosphate

unexpected result was verified by an additional duplicate GC/MS analysis. The observation of a visible floating layer in the hot-cell workup is supported by the high value obtained for TBP. For very concentrated samples of the TBP extracts obtained from C-204, trace amounts of normal paraffin hydrocarbons (NPHs) were also observed in the GC/MS analysis. These were present in such minor amounts (compared to TBP) that quantification was not attempted. 
The TOC analysis of the waste matrix by hot persulfate oxidation revealed about $60,000 \mu \mathrm{g}$ oxidizable carbon/g of sample in the material (preliminary result). This is in line with the observations of D. Baldwin (1994) related to other TOC data obtained with TBP. Baldwin interprets his results to indicate that the hot persulfate oxidation does not give complete or quantitative results with TBP.

In summary, the major organic species in the samples of C-204 matrix delivered to PNNL was TBP. Fully $0.18 \mathrm{~g}$ of carbon/g of wet weight sample was accounted for as TBP. This corresponds to $0.33 \mathrm{~g}$ of TBP/g of wet weight sample as delivered to the hot cell. Relatively small amounts of DBP appeared in the water soluble materials, representing about $2000 \mu \mathrm{g}$ of carbon/g of original tank sample. Quite surprisingly, no MBP was found in the extracts presented for analysis. The potential for incomplete assay of DBP and MBP in the aqueous phase exists; studies must be undertaken to determine the solubility limit of DBP and MBP in aqueous base to be certain that these materials are not left behind in the necessary ion-exchange step used to reduce the radioactivity of the final matrix material. Acetate and formate appear to be in the tank waste in very minor amounts (analysis by IC).

\subsubsection{Analysis of Tank C-106 Centrifuged Oil Samples}

Samples from C-106 (7SA and 13-3) were prepared in the 325 west hot cell by diluting with methylene chloride, drying the liquid with sodium sulfate, and filtering out solids using a pasteur pipette plugged with clean cotton.

These samples were dried to constant weight in the 329 labs (Mettler PB303 balance -sensitivity $\pm 1 \mathrm{mg}$ ) and were found to be as follows: sample $7 \mathrm{SA}=15 \mathrm{mg}$ and sample 13-3 = $22 \mathrm{mg}$. The samples were taken to known volume and aliquoted for analysis $(7 \mathrm{SA}=3.75 \mathrm{mg}$ aliquot, $13-3=5.5 \mathrm{mg}$ aliquot).

Each sample aliquot was dissolved in $2 \mathrm{~mL}$ methylene chloride and treated with an additional $2 \mathrm{~mL}$ diethyl ether that had been previously saturated with hydrochloric acid. The treatment appears to quantitatively transform the sodium D2EHP in the sample into the free acid form; as evidenced by copious amounts of white precipitate $(\mathrm{NaCl})$ forming in the vessel. The aliquots were then reduced in volume to $100 \mathrm{~mL}$ and cooled, and $3 \mathrm{~mL}$ of an uncalibrated solution of ethereal diazomethane was added. \{Diazomethane is produced by stirring an ethereal slurry of $\mathrm{N}$-methyl-N-nitrosourea over a $40 \% \mathrm{KOH}$ solution (Fieser and Fieser 1967)\}. The esterification is essentially complete immediately; the colored diazomethane is used to visually confirm the presence of excess diazomethane. The samples were left for 1 hour in the presence of excess diazomethane before analysis to ensure complete conversion.

Figure 3.2 is a total ion chromatogram \{GC/MS, electron impact (EI) mode \} of a derivatized Tank C-106 centrifuged oil sample, and Figure 3.3 is a total ion chromatogram [GC/MS, chemical ionization (CI) mode \} of the same sample. Prior GC/MS analysis has tentatively identified other materials related to D2EHP in these samples. The mass spectral signature ions (both EI and CI modes) for this group of organic analytes makes identification of these moieties relatively straightforward. We have evidence that the following molecules are also in the sample: BuD2EHP, T2EHP and Bu2EHP. The presence of butylated species is highly indicative of trans-esterification from TBP or capture of butanol in the sample matrix over the life of the sample. These materials do not appear to be artifacts of sample preparation or analysis.

Analysis by GC of the major phosphoric ester components versus two independently prepared standards of methyl D2EHP (prepared in the same fashion as detailed above) using sodium 
(b)
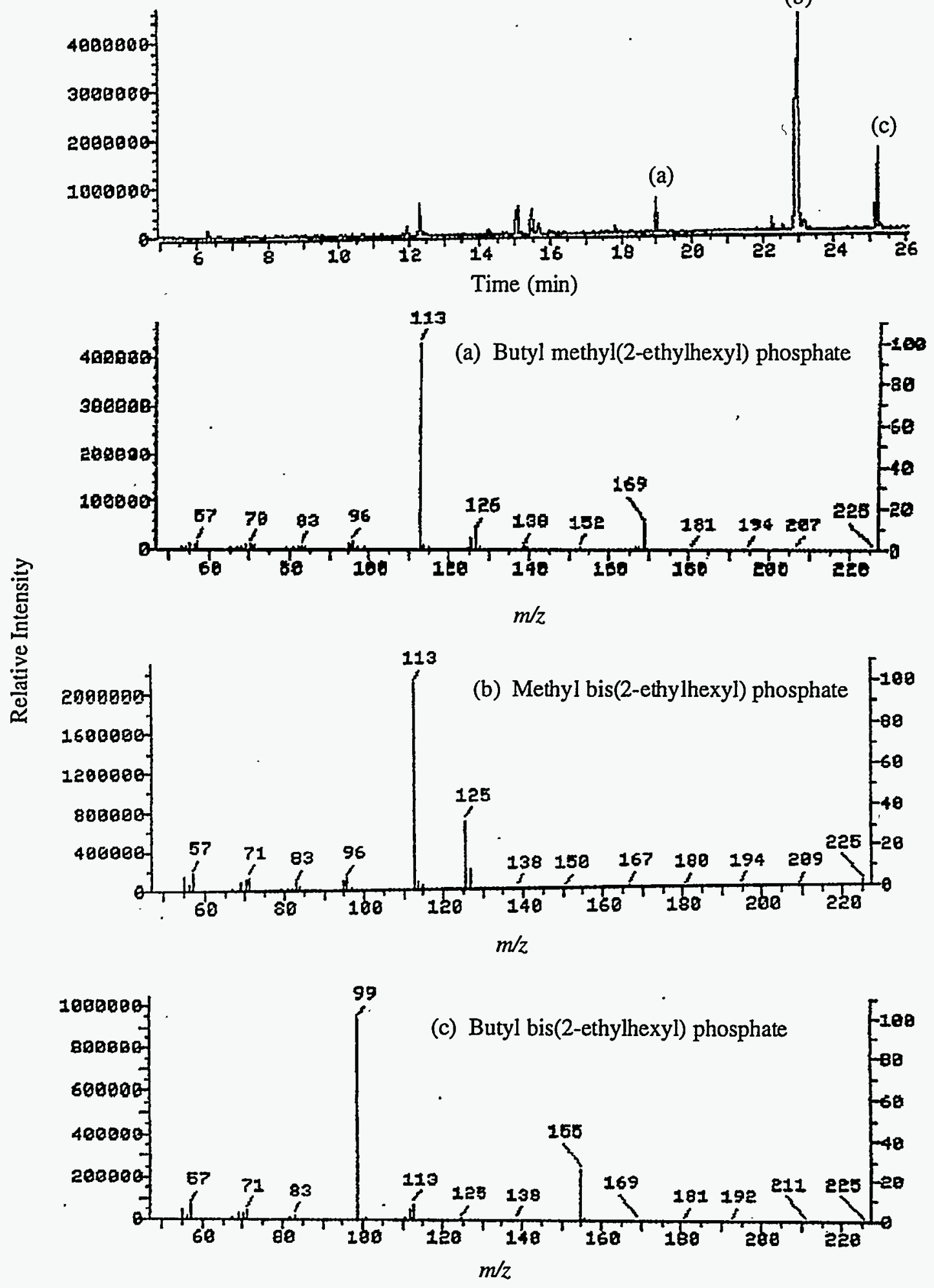

9608130030.jac

Figure 3.2. Total Ion Chromatogram (GC/MS-EI Mode) of Diazomethane Derivatized Tank C-106 Centrifuged Oil Sample and the Associated Mass Spectra of the Major Components 

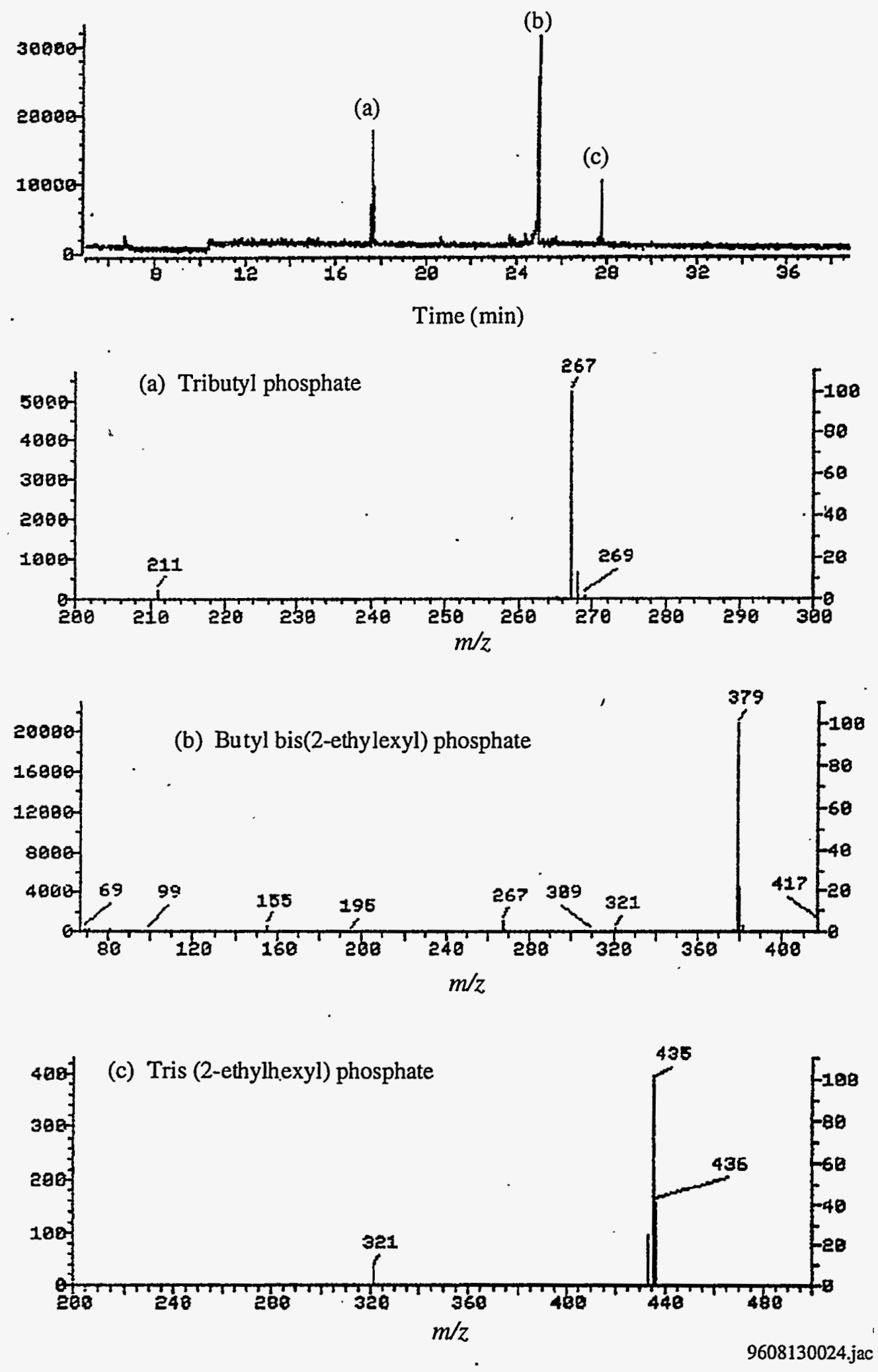

Figure 3.3. Total Ion Chromatogram (GC/MS-CI Mode) of Diazomethane Derivatized Tank C-106 Centrifuged Oil Sample and the Associated CI Mass Spectra of the Major Components 
D2EHP (Chem Service, West Chester, Pennsylvania) was done using an HP 5890 GC flame ionization detection (FID) equipped with a low polarity, thin phase capillary column (HP-5, 30m x $0.32 \mathrm{~mm} \mathrm{x}$ $0.25 \mathrm{~mm}$ ). A single dilution of TBP (Aldrich, Milwaukee, Wisconsin) was also prepared. Quantitation of the major components ( $>5 \%$ of the total peak area) are detailed below.

In terms of gram amount, the organic quantitation represents $82 \%$ and $70 \%$ of the total observed mass of the two samples. The numbers are representative of the sodium salt forms in the sample and standard before acidification or methylation. Unfortunately, standard materials are not available for BuD2EHP, T2EHP, or Bu2EHP at this time; the response observed for the major component (D2EHP) was used to calculate these minor components. Both samples contain small quantities of hydrocarbon materials that were not individually quantitated. The sum total of these materials may constitute a maximum of $5 \%$ of the total mass of material in the sample.

Carbon analysis is somewhat more suspect in these analyses. Carbon furnace oxidation (PNL ALO 381) of the samples (corrected for inorganic carbon using the acidification step of persulfate oxidation - PNL ALO 380 ) gave values of $61.7 \%$ and $55.7 \%$ carbon for sample 7SA (duplicate analysis). Sample 13-3 was done in quadruplicate, yielding values of $27.7 \%, 33.4 \%, 31.3 \%$, and $34.4 \%$ carbon. Furnace oxidation afforded values of $68.7 \%$ and $62.8 \%$ carbon from D2EHP acid form; this material should exhibit a theoretical maximum TOC of $59.6 \%$ carbon (the values are $15 \%$ and $5 \%$ high respectively).

Using the TOC furnace analysis as a benchmark, we have accounted for $78 \%$ of the carbon in sample 7SA by GC; for sample 13-3, GC analysis accounts for $123 \%$ of the total seen by TOC. If sample 13-3 were not entirely dried when TOC analysis was performed, this might account for some of the discrepancy.

An aliquot of a Tank C-106 sample was weighed and carbon tetrachloride was added. The mixture was slurried and anhydrous sodium sulfate was added to remove the water. The carbon tetrachloride extract was analyzed by Fourier transform infrared (FT-IR) spectroscopy. The FT-IR was equipped with a zinc selenide attenuated total reflectance solution sample cell that had a transparent optical window in the mid-IR region of interest. Carbon tetrachloride was used as the reference spectrum to subtract the infrared absorbance of the solvent from the sample spectrum. All spectra were collected at 4 reciprocal centimeter regions.

Comparison of the Tank C-106 sample and the reference bis(2-ethylhexyl)phosphate salt materials showed a close match between the two spectra, indicating that the infrared active ingredients in both the tank sample and the reference material were basically the same compounds. The peak locations of each major band in both spectra (reference and sample) match within the resolution of the sample spectrum. In summary, the major infrared active compound in the Tank C-106 sample was bis(2-ethylhexyl)phosphate.

\section{Mass Spectrometry of Phosphate Esters}

The mass spectrometry of the alkyl phosphate esters follow simple fragmentation patterns which can be used for tentative identification for each species. The molecular weight of each alkylated phosphate must be determined by chemical ionization mass spectrometry; additional information can be readily obtained from the EI mass spectrum in order to ascertain the length of carbon chains attached to the phosphate parent. 
The alkylated phosphate esters prefer to lose alkyl groups in EI mode by the McLafferty and "McLafferty + 1" type rearrangements (McLafferty and Turecek 1993). Fundamentally, this means that alkyl groups that are sufficiently "long" (at least $\mathrm{C}_{3} \mathrm{H}_{7}$ ) will be able to donate two hydrogens to the phosphate interior structure during the EI fragmentation process:<smiles>CCCC(C)COP(=O)(O)OCCC(C)C(C)C</smiles>

This mode is preferred in the formation of the base ion (most abundant ion in the EI spectrum). Trialkylated phosphate esters, in which the alkyl chains are at least three carbons long, will afford $\mathrm{m} / \mathrm{z} 99$ as the base ion.

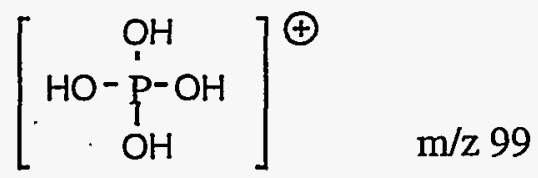

For alkylated phosphates in which the side chains are methyl, the transfer of hydrogens to the phosphate is not possible. In these materials the base ion observed for EI mass spectrometry is made up of the phosphate core plus the residual methyls present on the original molecule:

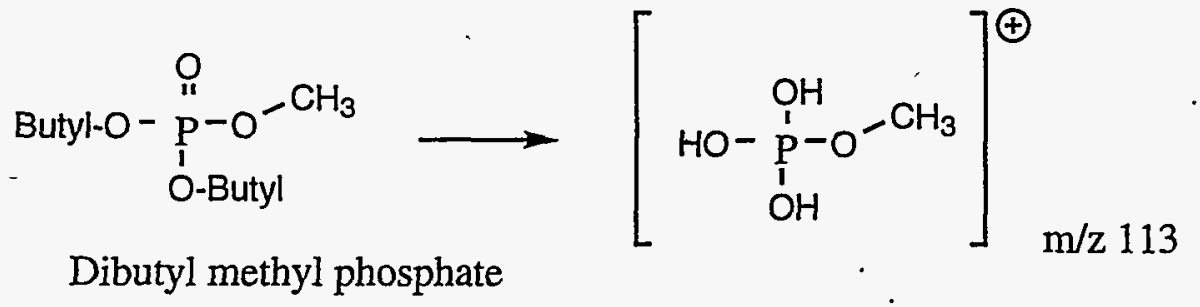<smiles>CCCOP(=O)(OC)OC</smiles><smiles>[C+]CP(O)(O)(O)OC</smiles>

Butyl dimethyl phosphate

For our work we have utilized diazomethane to methylate the acidic functionality of butylated phosphates for analysis by gas chromatography. The EI mass spectrum obtained for these materials is easily rationalized by the above structures.

When alkyl groups are directly attached to the phosphate grouping as a phosphonate, there is little propensity for this alkyl group to donate hydrogens by the McLafferty mechanisms: 


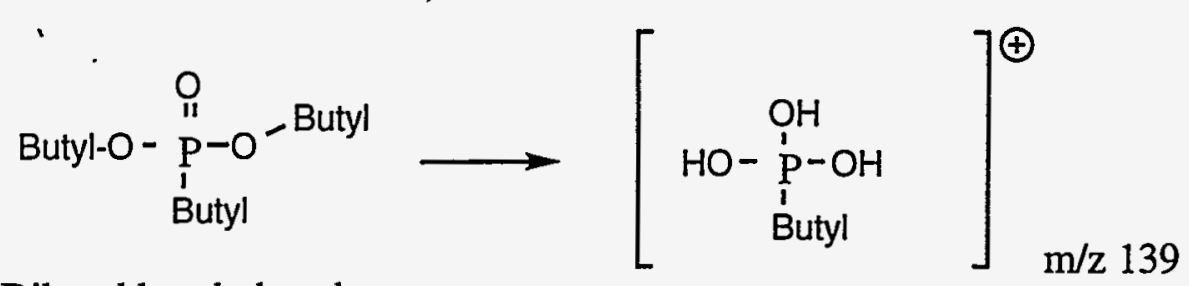

Dibutyl butyl phosphonate

We have previously identified dibutyl butyl phosphonate (DBBP) as a component of the C-103 floating layer. Dibutylbutyl phosphate was used as an experimental extractant in some Hanford processes. Additionally, we have evidence that as alkyl substituents become bulkier and more branched, these are preferentially fragmented from the molecule as compared to shorter chains such as butyl.

Once these mechanisms are understood, the EI mass spectral appearance for alkyl phosphates and alkyl phosphonates is quite straightforward. Unfortunately, the phosphonium ions depicted above are the overriding preference in the EI mode; parent ions are usually absent, and other fragment ions are generally much less abundant than the base ion. Careful inspection of these minor ions, coupled with chemical ionization data (to determine the molecular weight of the analyte) are very beneficial in interpreting the mass spectrometry of these compound classes. The response obtained for phosphate/phosphonate materials in CI mode is very favorable, due to the ease of formation of the corresponding phosphonium ion.

Tributyl phosphate contributes an $\mathrm{M}+1 \mathrm{CI}$ ion of $\mathrm{m} / \mathrm{z} 267$; the EI spectrum is dominated by $\mathrm{m} / \mathrm{z}$ 99, minor ions occur at $\mathrm{m} / \mathrm{z} 211$ (loss of 55 mass units by "McLafferty +1 " rearrangements from one butyl group) and at $\mathrm{m} / \mathrm{z} 155$ (loss of an additional 56 mass units by McLafferty rearrangement from one butyl group). Minor hydrocarbon signature ions are observed up to mass $\mathrm{m} / \mathrm{z} 57$, indicating butyl groupings on the molecule. This is shown schematically in Figure 3.4.

With respect to molecules relevant to $\mathrm{C}-106$ analysis, the primary constituent observed was methyl bis(2-ethylhexyl) phosphate. This material results from the conversion of D2EHP to its methyl ester from treatment with diazomethane. This treatment is necessary to render the D2EHP amenable to gas chromatographic analysis. We found the molecular weight of this analyte to be 336 from the observed $\mathrm{m} / \mathrm{z} 337$ ion from $\mathrm{Cl}$ mass spectrometry. The principle (base) ion for this analyte is $\mathrm{m} / \mathrm{z} 113$, establishing the attachment of a methyl grouping to the phosphate. Minor ions at 71 and 83 indicate that the other alkyl chains are longer than butyl. The other ions of importance include $\mathrm{m} / \mathrm{z} 125$ (loss of one ethylhexyl group by McLafferty rearrangement and loss of $\mathrm{C}_{7} \mathrm{H}_{15}$ from another alkyl substituent. This is a minor pathway for EI fragmentation indicative mostly of the long alkyl substituents), and $\mathrm{m} / \mathrm{z} 225$ (loss of one $\mathrm{C}_{8} \mathrm{H}_{15}$ alkyl unit through "McLafferty +1 " rearrangements). These ions strongly indicate the presence of "octyl" groupings about the phosphate grouping. In the underivatized material a free phosphoric acid grouping existed prior to treatment with diazomethane. All of these data firmly support the probable presence of D2EHP, which was used in Sr recovery processes in B plant.

In addition, there exists a significant component in C-106 extractant samples with the following characteristics: $\mathrm{CI}$ at ion $\mathrm{m} / \mathrm{z} 379$ (imputed mass of compound is therefore 378 ), and $\mathrm{EI}$ signature ions similar to TBP: $\mathrm{m} / \mathrm{z} 99,155,211$. A minor ion at $\mathrm{m} / \mathrm{z} 225$ implies the presence of an octyl loss through the "McLafferty +1 " mechanism. Minor alkyl ions at $\mathrm{m} / \mathrm{z} 57$ and 71 indicate butyl and/or longer alkyl chains. The best explanation for this component is the trans-esterification 

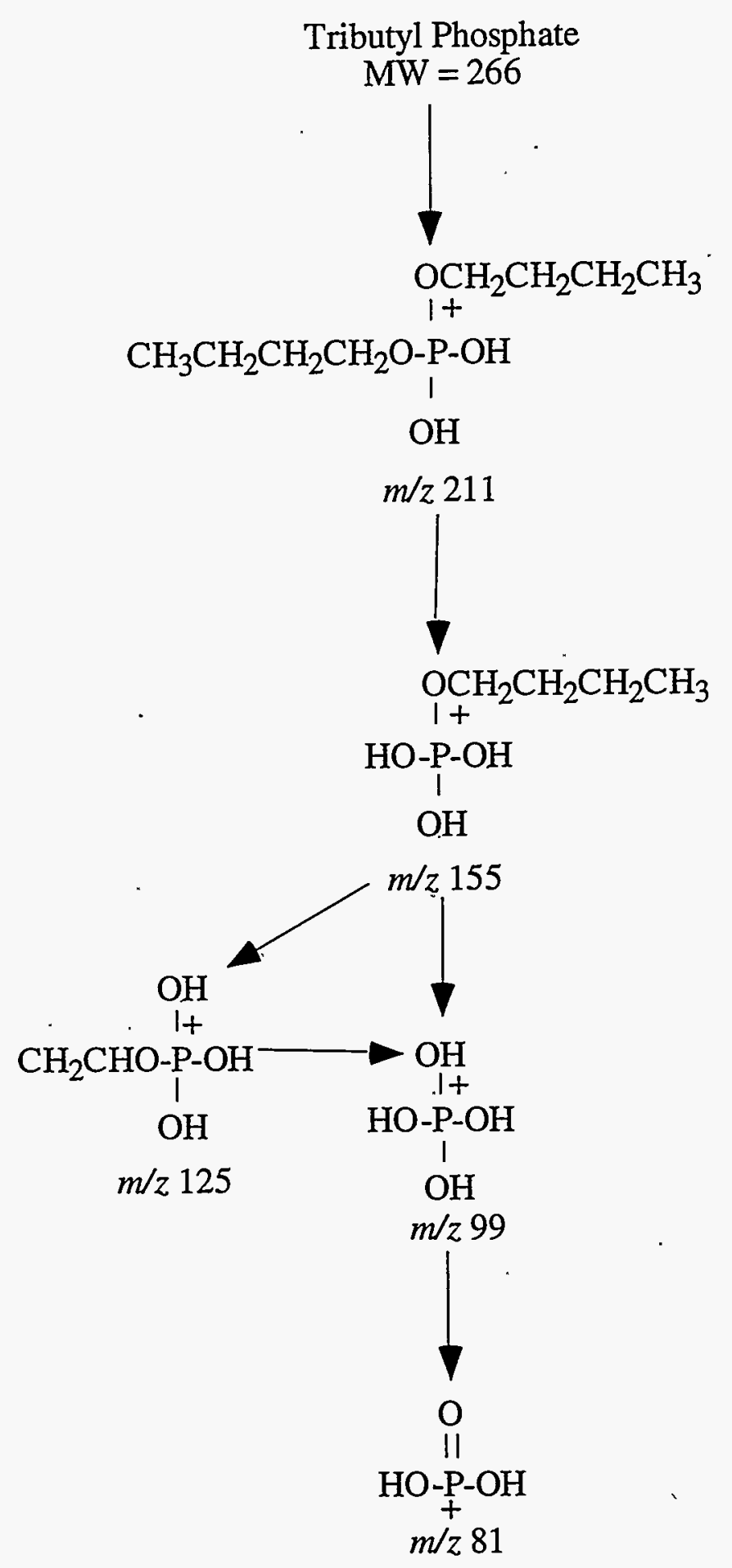

Figure 3.4 Mass Spectral Fragmentation Pattern for Tributyl Phosphate

of bis(2-ethylhexyl) phosphate with butanol or the butyl groupings of TBP to produce butyl bis(2ethylhexyl) phosphate in situ. This identification is inferred from inspection of the mass spectra; confirmation will have to be done using a generated standard. 
A minor component of the C-106 extractant afforded EI ions at $\mathrm{m} / \mathrm{z} 127$ (base) and 139 . The base peak indicates two methyls were added (by diazomethane derivatization), and that similar fragmentation is proceeding to that observed in methyl bis(2-ethylhexyl) phosphate. The logical identity (corroborated by an observed $\mathrm{CI}$ ion at $\mathrm{m} / \mathrm{z} 239$ ) is interpreted as dimethyl (2-ethylhexyl) phosphate. Another minor component, affording a base ion of $\mathrm{m} / \mathrm{z} 99$ and smaller fragment ions corresponding to the alkyl series ( $\mathrm{m} / \mathrm{z} 57,71,85,113)$ which elutes far later than the other components, is most likely the tris(2-ethylhexyl) phosphate which is an apparent by-product of the manufacture of bis(2-ethylhexyl) phosphate (full alkylation of the substrate). In an instance such as this one, the lack of $\mathrm{m} / \mathrm{z} 155$ discounts the presence of butyl groups on the molecule. From other examples seen above, the loss of very long alkyl chains is facile in comparison with butyl or especially methyl groups.

There are several other phosphate ester decomposition and trans-esterification components which can be tentatively identified in the C-106 samples using the simple inspection method. An apparently trans-esterified butyl methyl 2-ethylhexyl phosphate is present in these samples. The base ion of $\mathrm{m} / \mathrm{z} 113$ indicates a methyl phosphate (again methylated by our analysis technique). The most prevalent secondary ion is $\mathrm{m} / \mathrm{z} 169$ which is 56 mass units more than the base ion, this strongly indicates a butyl grouping. Chemical ionization mass spectrometry confirmed the molecular weight of this component to be 280 .

The last mass spectrometric identification done for this study involves the fully methylated compound trimethyl phosphate. This compound with all alkyls as methyls is stable enough to show a parent ion at $\mathrm{m} / \mathrm{z} 140$. The base ion, $\mathrm{m} / \mathrm{z} 110$, apparently arises from loss of formaldehyde from the parent.

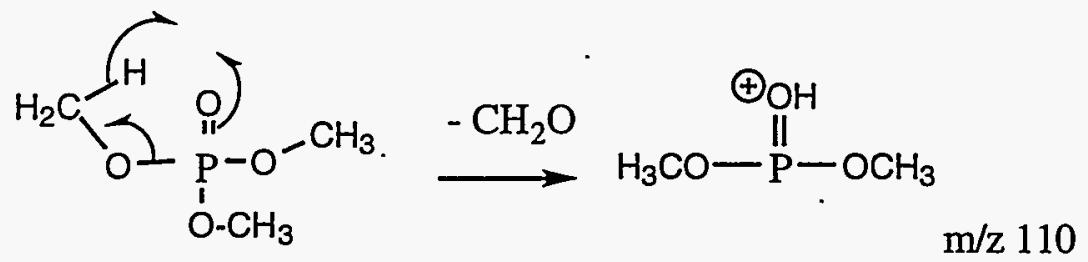

This mode is not as energetically favorable as the loss of longer substituents via the McLafferty routes and is not observed in higher alkyl phosphate homologues as an important fragmentation route.

\section{Transesterification of Phosphate Esters Within Hanford Tank Wastes}

Organophosphorus compounds such as D2EHP and its sodium salts have been utilized in past Hanford work such as the B plant strontium recovery campaigns. Due to its use, and the combination of other organic wastes in tanks such as C-106 and C-103, the presence of apparent transesterification products is evident when such wastes are fully analyzed.

The major component observed in selected sub-samples originating from C-106 (sample 7SA and 13-3) was shown to be D2EHP (Babad et al. 1996). Multiple minor compoñents were observed, which, upon further MS analysis, appear to have originated from fortuitous combination of D2EHP with butanol present in the waste (from alkaline hydrolysis of TBP) or possibly from direct exchange from TBP. 
Direct analysis of D2EHP is not possible by GC or GC/MS because the free OH group (phosphoric acid residue) on the molecule lacks volatility. The principle methodology that appears to proceed in high yield involves the direct esterification of the D2EHP using a diazoalkane (Knapp 1979). Acidification of samples from $\mathrm{C}-106$ (using ethyl ether wetted with $\mathrm{HCl}$ ) followed by excess diazomethane affords the analyte methyl bis(2-ethylhexyl) phosphate. Also noted as a minor component was the doubly methylated dimethyl (2-ethylhexyl) phosphate. All samples of D2EHP we have analyzed contain trace amounts of tris(2-ethylhexyl) phosphate, and this component has been identified in C-106 waste as a late eluting peak in the GC profile by CI MS (mass $435=\mathrm{M}+1$ ).

Materials are present in C-106 waste (and its analytical derivatives) that are more difficult to rationalize as arising directly from the D2EHP originally used in the Sr recovery process. These include butyl methyl (2-ethylhexyl) phosphate and butyl bis(2-ethylhexyl) phosphate. The latter component represents a significant fraction of the organophosphorus component found in C-106 extracts \{up to $15 \%$ of the integrated peak size of methyl bis(2-ethylhexyl) phosphate\}. The only rational explanation for the presence of these materials is the apparent transesterification of bis(2ethylhexyl) phosphate with TBP also present in the matrix. The identification of butyl bis(2ethylhexyl) phosphate in C-106 extracts has led us to re-examine some of our results from the C-103 organic layer samples examined earlier (Pool and Bean 1994). Butyl butyl bis(2-ethylhexyl) phosphate has been identified as a component in the $\mathrm{C}-103$ organic layer, but as a minor component ( $<1 \%$ of the total organic content of the sample). This is illustrated in Figure 3.5, a total ion chromatogram (GC/MS) of derivatized C-103 sample.

The MS of the phosphate esters allows easy tentative identification for each species. Butyl bis(2-ethylhexyl) phosphate affords ions typical of long-chain phosphates $(\mathrm{m} / \mathrm{z}$ 99, 155) and a CI ion of mass $379(\mathrm{M}+1)$. Butyl methyl (2-ethylhexyl) phosphate affords ions typical of phosphate esters encumbered with a short alkyl chain (major ion is $\mathrm{m} / \mathrm{z} 113$ ), and a $\mathrm{CI}$ ion of $\mathrm{m} / \mathrm{z} 279(\mathrm{M}+1)$. Once the mechanistics of electron impact fragmentation of alkyl phosphates are understood, the identification of probable alkyl phosphates is greatly simplified. The signature ions cited above for EI MS are very useful in partially solving structural information for whole series of alkyl phosphates.

We can find no precedent for the transesterification of alkyl phosphate esters in the highly alkaline environment represented by the Hanford tank wastes. The hydrolysis of alkyl phosphates in this media is well known (Burger 1959). The free phosphoric acid residue in the hydrolyzed species is very acidic and cannot be effectively esterified using combinations of mineral acids and alcohols or with Lewis acids (such as $\mathrm{BF}_{3}$ ) and alcohols. The phosphoric acid group is not noted for participation as a nucleophile in nucleophilic displacement reactions and is considered a good candidate for displacement from any attached alkyl chains (Streitwieser and Heathcock 1976). Thus, it is somewhat surprising to observe the apparent exchange of alkyl groups among alkylated phosphates in the highly alkaline tank wastes.

\subsection{Analyses of Simulant Wastes for Waste Aging Studies}

Simulant waste samples were analyzed for organics and inorganics under the Organic Analytical Support Task to support waste-aging studies. The majority of the methods used for the organic component determinations have been described previously (Wahl et al. 1995). Some minor adjustments and improvements of these methods have been made as different simulant mixtures with different matrix behavior are submitted for analysis. Briefly, the methods used for the majority of the samples analyzed are summarized in Table 3.1. 


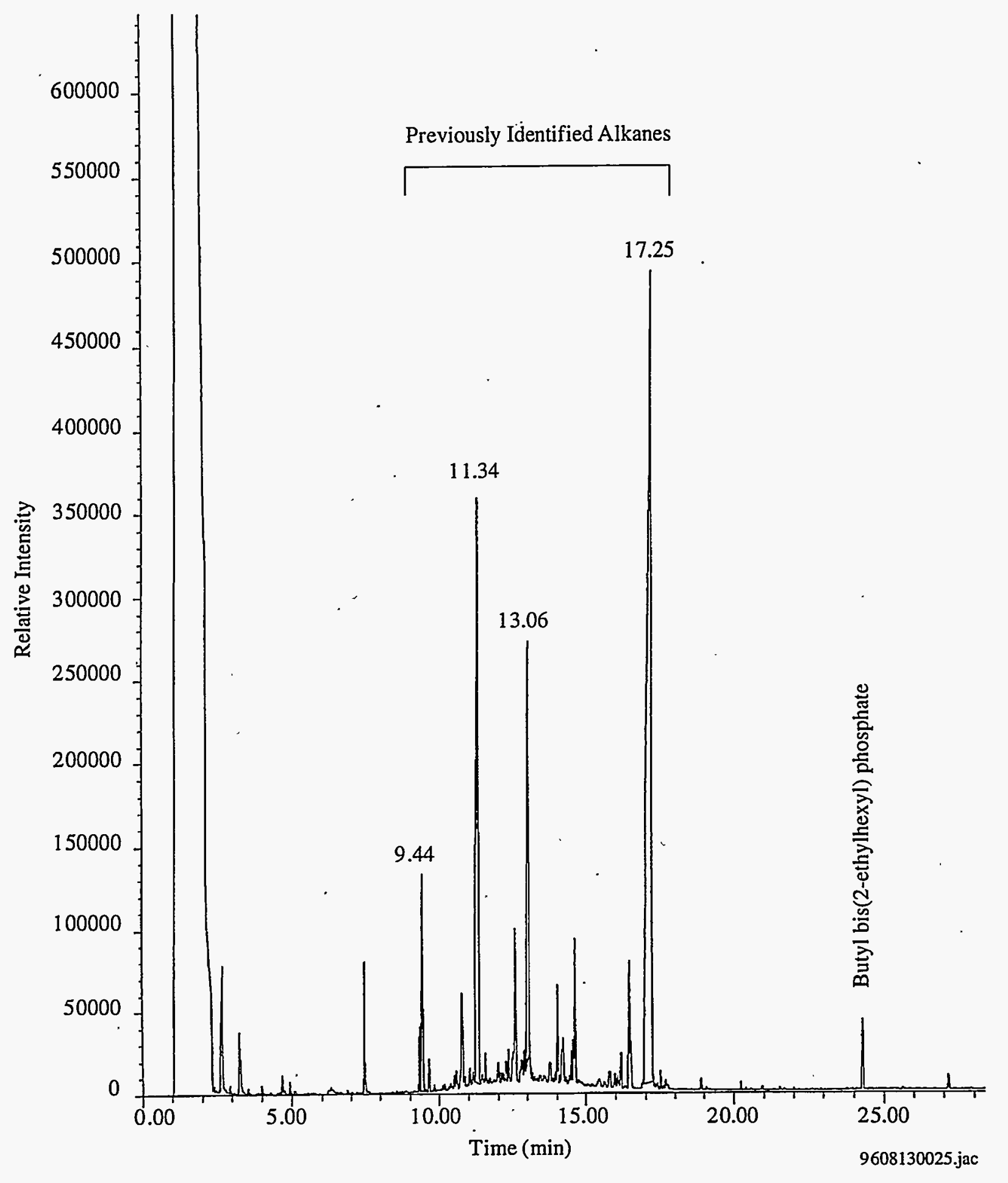

Figure 3.5. Reanalysis of Tank C-103 Sample by GC/MS. The component eluting at 24.3 minutes is now identified as butyl bis(2-ethylhexyl) phosphate. 
Table 3.1. Analytical Methods Used for Support of Aging

Analytes
Chelators
Low molecular weight organic
acids
Chelator fragments and larger
non-volatile organics
Nitrate, nitrite
Total inorganic carbon
Total organic carbon

Method of Analysis

Ion-pair chromatography

IC with conductivity detection

Derivatization GC/MS with

$\mathrm{BF}_{3} / \mathrm{MeOH}$

IC

Carbon analyzer

Hot persulfate wet oxidation $\underline{\text { Reference }}$

Wahl et al. 1995

Wahl et al. 1995

Campbell et al. 1994

Procedure PNL-ALO-212, Rev 1

Procedure PNL-ALO-382.1, Rev. 0

Baldwin et al. 1994

Fur different types of simulant mixtures were submitted for various organic and inorganic analyses. The first priority was to quantitatively determine the effect of the aging processes (heat and/or irradiation) on the concentration of the initial starting organics. The next priority was to identify any degradation products from these organic species and quantitate these products as much as possible. To estimate material balance, some of the samples were analyzed for TIC and for nitrite and nitrates. The results were provided to the Waste Aging Studies Task (Don Camaioni, Task Leader) for data analysis and incorporation into the report for that task (Camaioni et al. 1996)

One series of samples contained only citrate and EDTA as starting organics in an inorganic matrix containing sodium hydroxide and the sodium salts of phosphate, nitrate, nitrite, carbonate, and sulfate with varying amounts of water. The starting organic components were analyzed by IC for citrate and ion-pair liquid chromatography for EDTA. Degradation products were also identified with these two analysis methods.

Another series of samples analyzed contained only one organic component, either butanol or butyric acid, in a simple inorganic matrix containing sodium hydroxide, sodium nitrate, and aluminum nitrate. Monitoring the disappearance of these starting components following gamma irradiation was performed by GC/MS. Degradation products, which were primarily small organic acids, were determined by IC with conductivity detection. The sample preparation and analysis procedure is as follows:

\section{Butyric Acid and Butanol Analysis by GC/MS}

1. $\quad 0.2 \mathrm{~mL}$ sample is delivered to screw top test tube.

2. $50 \mu \mathrm{L}$ surrogate is added $(4 \mathrm{mg} / \mathrm{mL}$ valeric acid).

3. $1 \mathrm{~mL} 2 \mathrm{~N}$ phosphoric acid is added to neutralize hydroxide.

4. $\quad 500 \mu \mathrm{L}$ saturated $\mathrm{NaCl}$ is added to further salt out the organic species.

5. $2 \mathrm{~mL}$ ethyl acetate is added to extract organics.

6. Organic layer is transferred to $10 \mathrm{~mL}$ volumetric flask. Extraction is repeated twice.

7. $\quad 10-\mathrm{mL}$ flask is filled to volume with ethyl acetate.

8. Organic extract is analyzed by GC/MS.

The final major sample series analyzed was the SYM-PAS-95-1a simulant used for tube propagation studies by Fauske and Assoc. Inc. in addition to the aging studies (Carlson 1996). These samples contained trisodium HEDTA, tetrasodium EDTA, trisodium citrate, and glycolate as the 
starting organic components in a complex inorganic matrix containing a wide variety of metals. The analysis scheme for these samples is outlined in Figure 3.6.

One problem faced with the IC analysis of the degradation products with the original procedure (Wahl et al. 1995) was the co-elution of potential degradation products, such as butyrate and formate, acetate and glycolate, and oxalate and fumarate. To avoid these overlapping peaks, a different column and separation scheme were used with encouraging results. The original chromatogram of organic acid standards obtained by IC on the AS-11 (Dionex) column is shown in Figure 3.7 with several co-eluting organic species whereas the same standard mixture run on the AS-6 (Dionex) column without co-eluting species is shown in Figure 3.8. The retention times of the standards with the two different columns are provided in Table 3.2.

\subsection{Organic Functional Group Screening Development}

A subtask of this project was to investigate techniques such as FT Raman and IR spectroscopy as screening tools for determining specific organic functional groups that relate to energetics content of tank waste simulants. The findings of this work were detailed in a separate report titled "Use of Organic Functional Group Concentrations as a Means of Screening for Energetics" (Wahl et al. 1996). The theoretical basis for relating specific organic functional groups such as $\mathrm{C}-\mathrm{H}$ and $\mathrm{COO}^{-}$to sample reaction enthalpy was described. Simultaneous to development of the spectroscopy techniques for functional group determination, studies with conventional energetics determinations (e.g., DSC) were employed to determine experimentally if functional groups could relate to energetics and the spectroscopic results could be tied to more traditional methods.

Preliminary results from the FT-IR and Raman spectroscopy studies suggested that spectroscopic determination of functional groups would be a good indicator of enthalpy content as a preliminary screening technique. For example, FT-IR analysis of liquid simulant samples showed that $\mathrm{COO}^{-}$content could be quantitated within $20 \%$ relative error for different organics and $\mathrm{C}-\mathrm{H}$ content within $30 \%$ relative error. Since the goal of this analytical method is to provide a screening tool to determine relative enthalpy content of tank waste samples in a hot cell and not complete quantitation, these preliminary results are well within the range of a useful screening tool. Additional work on testing mixtures of organics and testing actual tank waste samples that have been speciated for comparison should be completed for final testing of this method. A summary of the key findings of these two spectroscopic techniques is provided.

\section{FT-Raman Spectroscopy}

- A non-linear but predictable trend of $\mathrm{C}-\mathrm{H}$ response over the range of 2 to 8 moles $\mathrm{C}-\mathrm{H}$ bond $/ \mathrm{kg}$ sample was produced. Little variation due to water content of the solid samples was observed.

- A linear $\mathrm{C}-\mathrm{H}$ response for liquid samples down to a level of $0.5 \% \mathrm{w} / \mathrm{w}$ was obtained. However, organic compounds responded somewhat differently.

- Initially, FT-Raman spectroscopy may need more development than FT-IR for liquid samples and hot-cell applications, but it is more amenable in the long term for solid samples and intank analysis with fiber optic probes. 


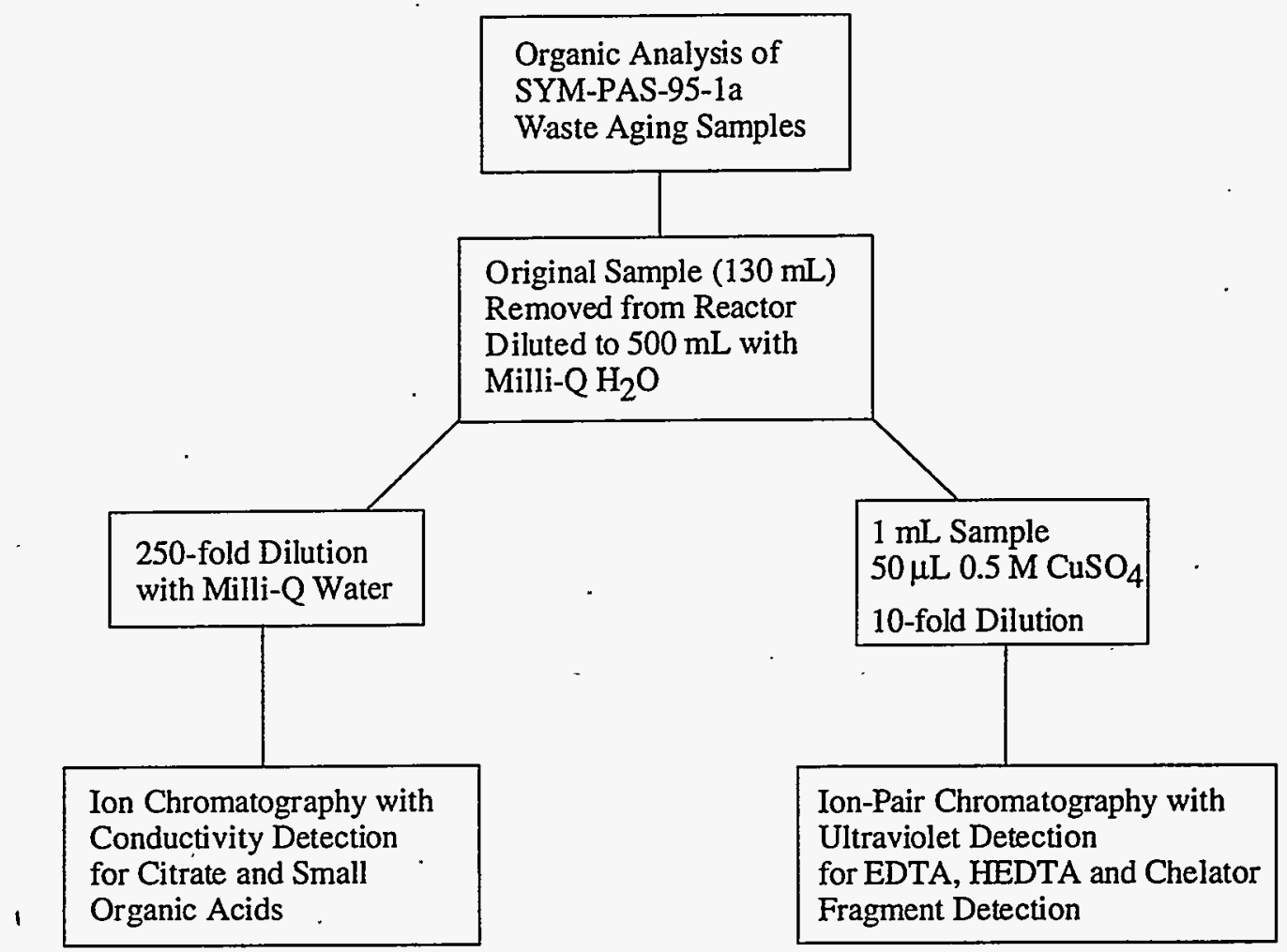

Figure 3.6 Schematic of Organic Analysis Scheme of SIM-PAS-95-1a Waste Aging Samples

Table 3.2. Retention Times of Organic Acid Standards with Two Different Ion Chromatography Columns and Separation Schemes

Standard

Acetic

Glycolic

Propionic

Formic

Butyric

Glyoxylic

Succinic

Maleic

Oxalic

Fumaric

Citric

\section{AS11 Retention Time (min)}

2.6

2.6

2.8

3.4

3.4

5.7

9.8

10.4

11.0

11.0

14.9
AS6 Retention Time (min)

15.4

9.7

25

10.5

58

6.9

16.5

5.6

5.1

20

7.2 


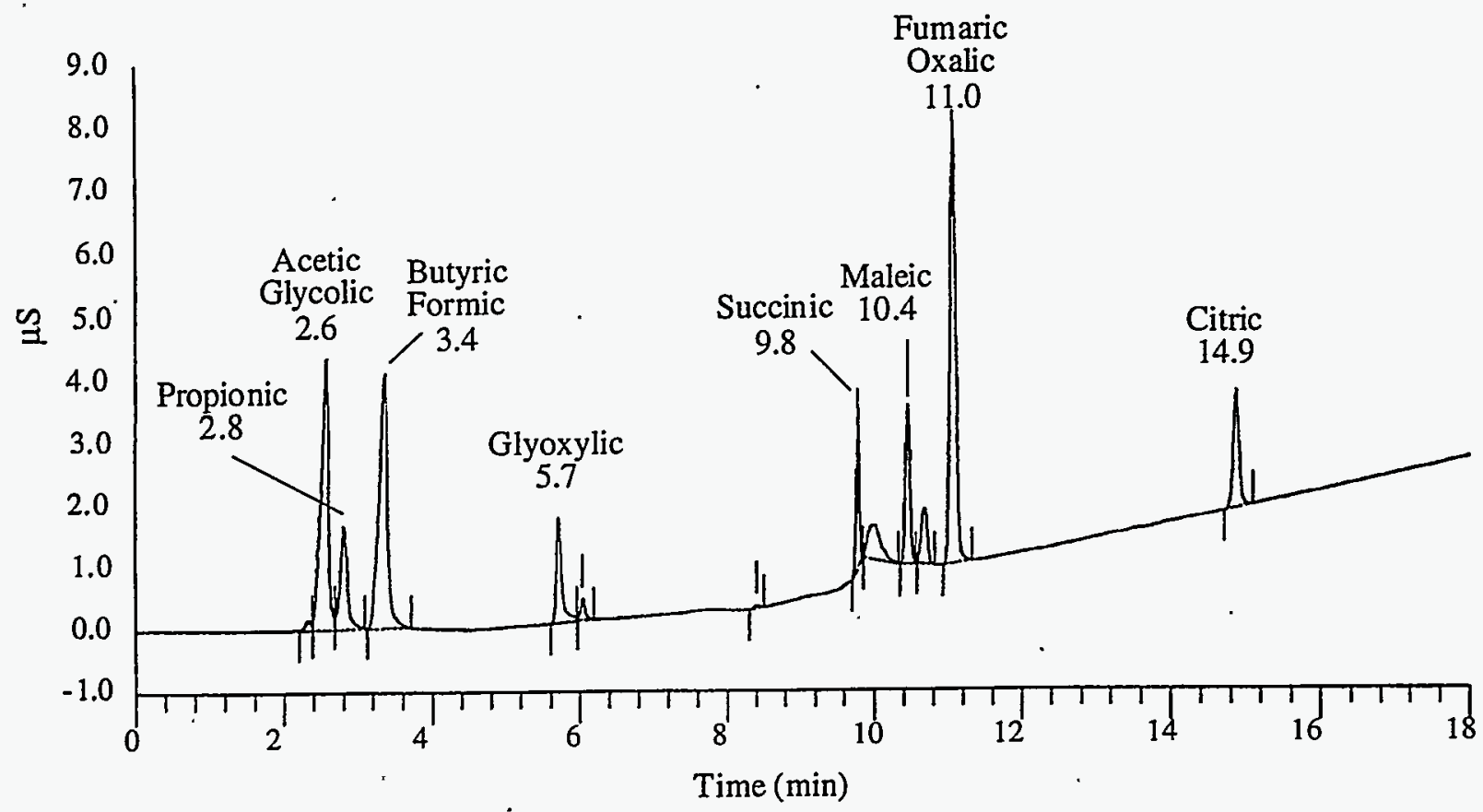

Figure 3.7. Ion Chromatogram of Organic Acid Standards with AS-11 Column (Dionex). Several organic acids of interest co-elute under the separation conditions employed.

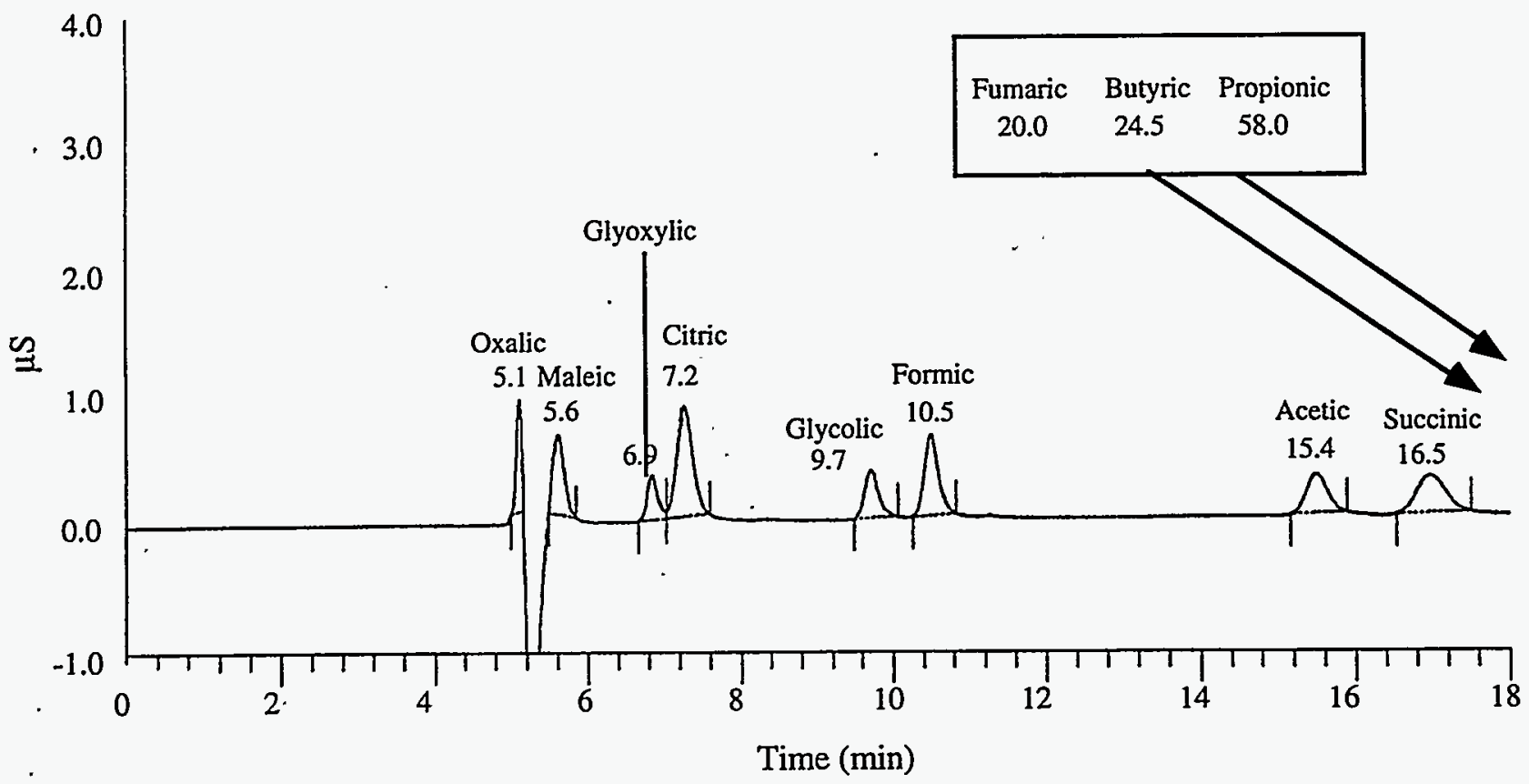

Figure 3.8. Ion Chromatogram of Organic Acid Standards with AS-6 Column (Dionex) 


\section{FT-IR Spectroscopy}

- Solution response for mole carboxylate $/ \mathrm{kg}$ solution was linear for all organics tested. The maximum $\mathrm{COO}^{-}$error was $20 \%$.

- Solution response for $\mathrm{C}-\mathrm{H}$ was linear for all organics tested. The quantitation of $\mathrm{C}-\mathrm{H}$ was broken into three distinct wavelength regions in the spectrum. Quantitation errors using these three regions resulted in a maximum error of $27 \%$.

- Solid response for carboxylate and $\mathrm{C}-\mathrm{H}$ was non-linear, but quantifiable. Quantitation errors are possible for TOC levels greater than $4 \% \mathrm{COO}^{-}$because almost all of the light is absorbed by the sample.

- Moisture content did not affect quantitation of $\mathrm{COO}^{-}$or $\mathrm{C}-\mathrm{H}$ of solids unless the samples contained less than $10 \%$ total water because the sample contacted the crystal poorly. This can likely be resolved by adding a slight amount of liquid to the sample to ensure good contact during analysis.

- Quantitation of $\mathrm{COO}^{-}$and $\mathrm{C}-\mathrm{H}$ is excellent for solution work; however, solution work requires sample preparation. Quantitation of $\mathrm{COO}^{-}$and $\mathrm{C}-\mathrm{H}$ for solids works well; however, solids analysis may require minimal treatment of the sample if the moisture level is too low (i.e., adding small quantity of water to facilitate crystal contact).

- Industry is using remote analysis systems; however, sensitivity and other problems may be encountered with deployment to remote tank analysis.

- For solids analysis, attenuated total reflectance may not be the best method. It was chosen because it can be used in the hot-cell working environment easily.

The complementary nature of IR and Raman spectroscopy was apparent for the solid and liquid simulant waste samples studied. It may be possible to correct for the changes in tank matrix that would otherwise interfere with results. For Raman, the Rayleigh line (elastically scattered radiation) could, in theory, be used to partially correct for the matrix effects. Similarly for FT-IR, the $2200 \mathrm{~cm}^{-1}$ region of the spectrum, where no distinct features are present, could be used to correct for scattering due to the tank matrix. "Additional work on testing mixtures of organics and testing actual

( tank waste samples that have been speciated for comparison should be completed for final testing of this method.

\subsection{Draft Test Plan}

The draft test plan for the analysis of organics in actual tank waste samples is included in Appendix A. It is in the final stages of review.

\subsection{Alternative Methods Being Developed .}

Some difficulty and uncertainty still exists in using derivatization GC for chelator analysis. While this is currently the best method available for analyzing these components in the complex tank waste samples, the derivatization procedure is time-consuming and often difficult because of the consistency of the actual tank waste matrix. Although not explicitly in the FY 1996 scope of work 
and not funded directly through the Tanks Safety Program, techniques have been evaluated for analyzing chelators and chelator fragments directly using liquid chromatography with copper complexation and UV detection and MALDI-TOF MS. Both techniques show considerable promise for analyzing chelators and organic acids directly. If successful with actual wastes, these techniques could save an appreciable amount of money currently invested in analyzing for organics.

\subsubsection{Matrix-Assisted Laser Desorption/Ionization Time-of-Flight MS}

The MALDI-TOF MS technique is used to obtain molecular-weight information of nonvolatile, thermally labile compounds. The MALDI technique desorbs and ionizes these thermally labile compounds followed by TOF MS analysis to determine molecular weights of the analyte ions based on their mass-to-charge $(\mathrm{m} / \mathrm{z})$ ratios. The samples analyzed by MALDI are mixed uniformly with a matrix substance and applied to a metal slide in microliter amounts. The matrix and analyte solutions are allowed to dry and form uniform crystals. The sample slide is inserted in the vacuum system of the MS, and a laser beam is directed at the sample spot to volatilize the sample. A brief pulse ( $3 \mathrm{~ns}$ ) of nitrogen laser light (wavelength $=337 \mathrm{~nm}$ ) is directed onto a small target area (about $100 \mu \mathrm{m}$ in diameter) of the sample/matrix deposited on the sample slide. The matrix rapidly absorbs heat energy from irradiation, inducing vaporization and ionization of itself and the analyte. Common matrices are sinapinic acid (3,5-dimethoxy-4-hydroxycinnamic acid) and gentisic acid (2,5-dihydroxybenzoic acid). When the laser light contacts the matrix and sample, there is localized and rapid (nanoseconds) heating of the matrix and sample. Under rapid heating conditions, organic compounds favor vaporization reactions over decomposition reactions (Buehler et al. 1974). Matrixassisted laser desorption/ionization has been shown to be a very useful MS ionization technique for biomolecules (Hillenkamp et al. 1991), polymers (Bahr et al. 1992), and other organic molecules (Ligard and Duncan 1995).

The MALDI technique has many potential advantages for analyzing tank waste. It is a very rapid analysis technique (minutes) and thus would be an ideal rapid screening tool for determining non-volatile organics in tank waste if high salt content does not interfere with the analyses. In addition, this technique works best at relatively low analyte concentrations (micromolar), and samples can therefore be diluted to reduce radioactivity levels before sample handling. This technique would be very simple to implement for radioactive sample analysis. A small drop of sample is deposited on a stainless steel probe, the solvent is dried, and then the probe is inserted onto a probe tip holder for insertion into the vacuum system by remote operation (computer controlled). This is shown schematically in Figure 3.9. If sample contamination levels are too high, the benchtop instrument design would be compatible with glovebox or fume hood operations.

Preliminary examples of the capability of MALDI for a variety of organic compounds are shown in Figures 3.10, 3.11, 3.12, and 3.13: The MALDI technique characteristically provides molecular-weight information for both small and large molecules. While matrix ions are always observed, the $(\mathrm{M}+\mathrm{H})^{+}$or $(\mathrm{M}+\mathrm{Na})^{+}$ions dominate the analyte signal in the positive ion mode, and the $(\mathrm{M}-\mathrm{H})^{-}$ion dominates in the negative ion mode, where $\mathrm{M}$ is the intact analyte molecule. Figure 3.10 shows the $(\mathrm{M}+\mathrm{H})^{+}$ion of HEDTA (molecular weight $=278$ ) at $\mathrm{m} / \mathrm{z} 279$. The matrix ions at $\mathrm{m} / \mathrm{z} 138$ and 155 are from the gentisic acid matrix. The spectrum of EDTA is shown in Figure 3.11. The $(\mathrm{M}+\mathrm{H})^{+}$ion is at $\mathrm{m} / \mathrm{z} 294,(\mathrm{M}+\mathrm{H}+\mathrm{Na})^{+}$ion at $\mathrm{m} / \mathrm{z} 316$, and the di-, tri-, and tetra Na adducts. The positive ion spectrum of NTA is shown in Figure 3.12. The $(\mathrm{M}+\mathrm{Na})^{+}$ion is at $\mathrm{m} / \mathrm{z} 215$ and the di-Na ion at $\mathrm{m} / \mathrm{z} 237$. The ions at $\mathrm{m} / \mathrm{z} 137,155$, and 177 are from the matrix gentisic acid. The negative ion spectrum of citric acid is illustrated in Figure 3.13 with the expected $(\mathrm{M}-\mathrm{H})^{-}$ion at $\mathrm{m} / \mathrm{z} 191$. Table 3.3 lists the ions observed for the analytes in the positive and negative ion mode. Further 
Deposit $1 \mu \mathrm{L}$ Sample and

Matrix Solution
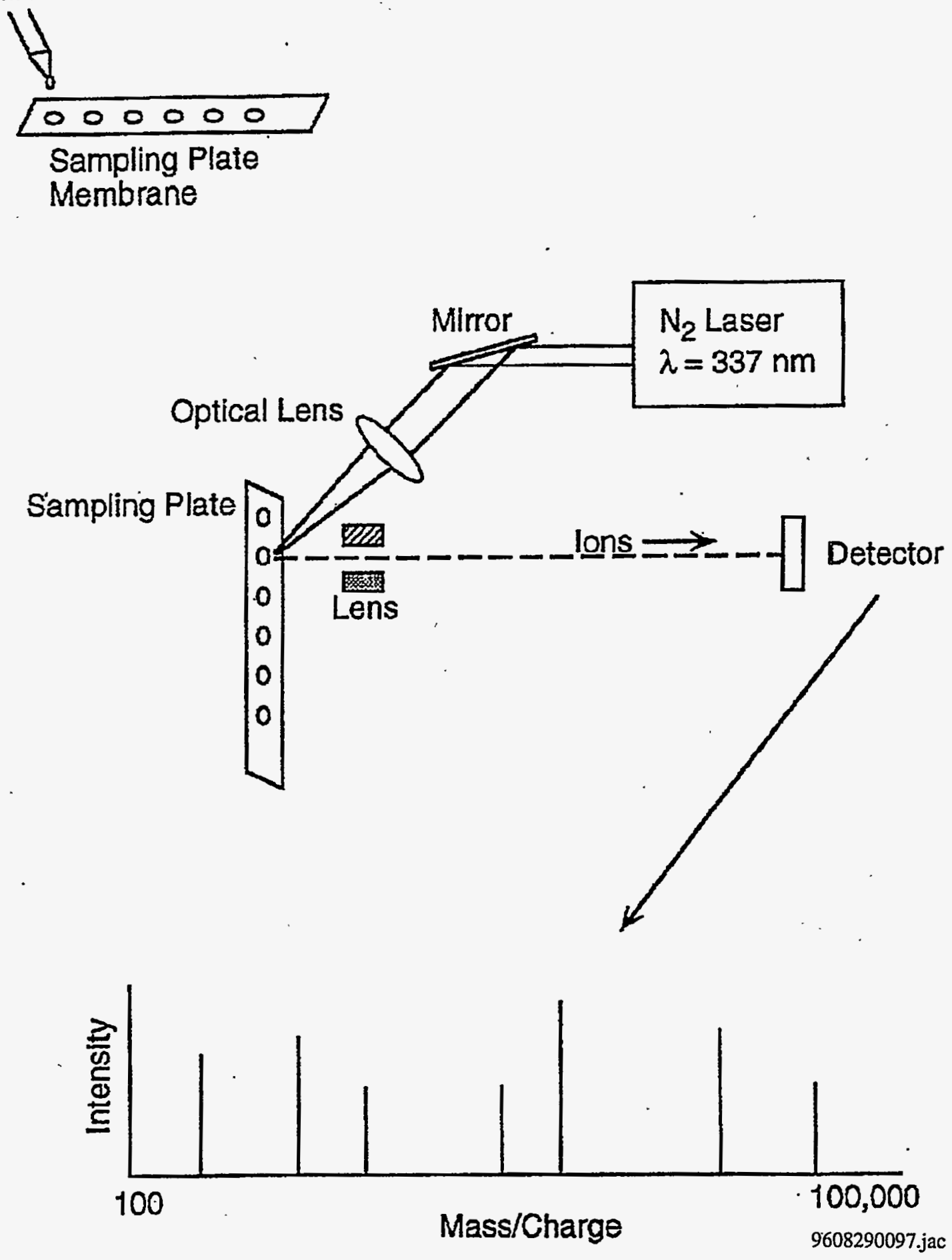

Figure 3.9. Schematic Illustrating MALDI Operation 


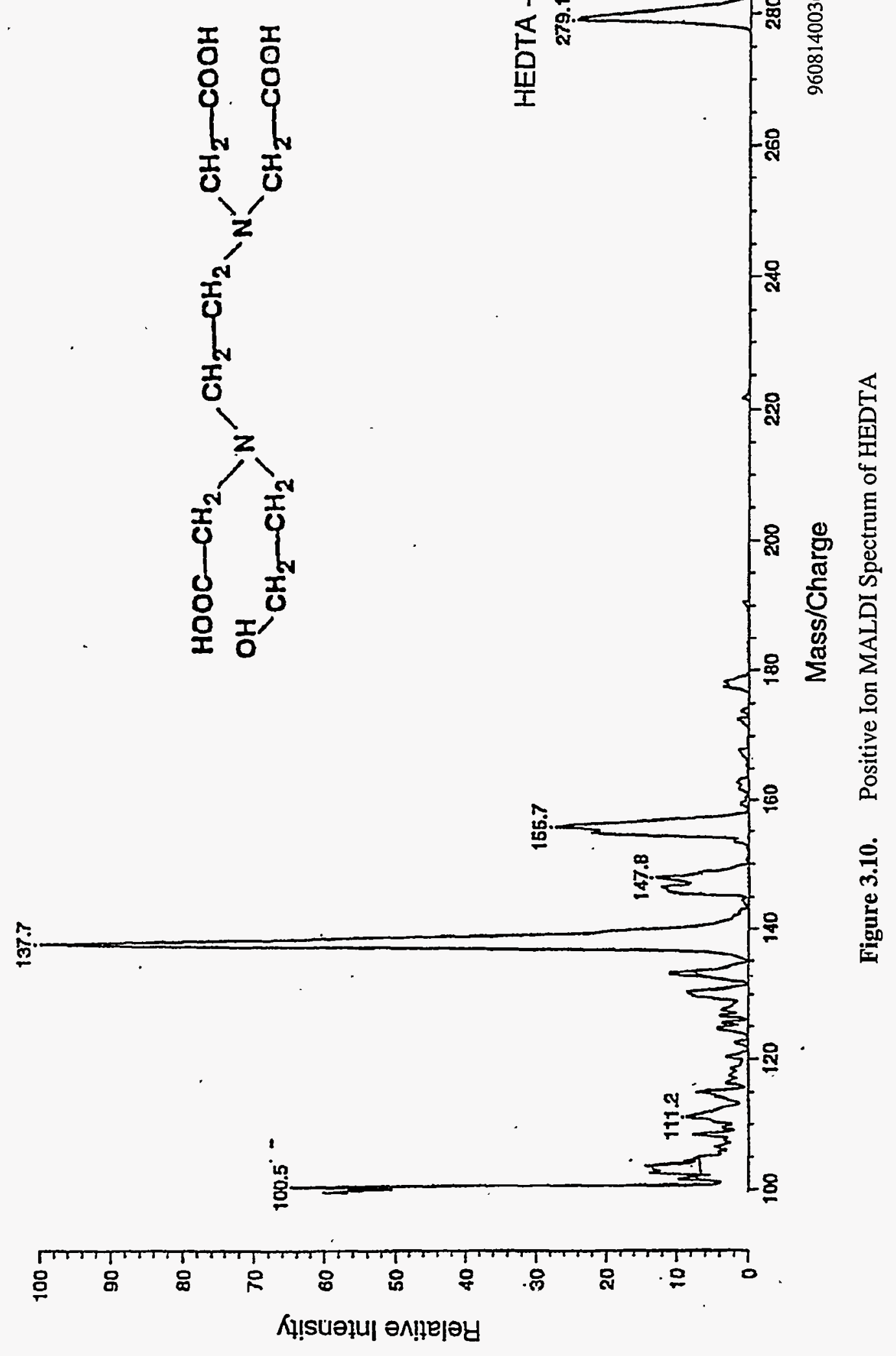




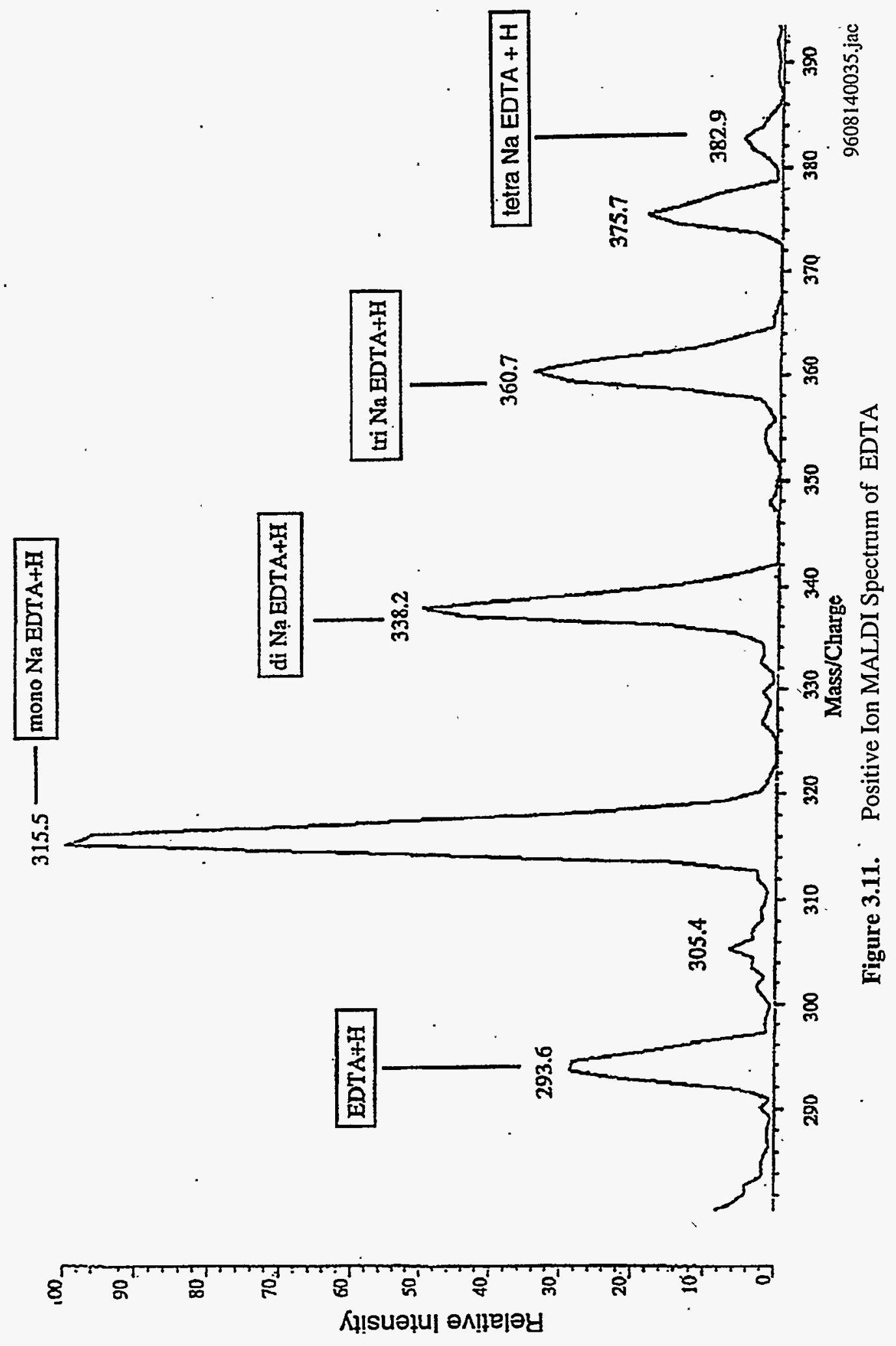




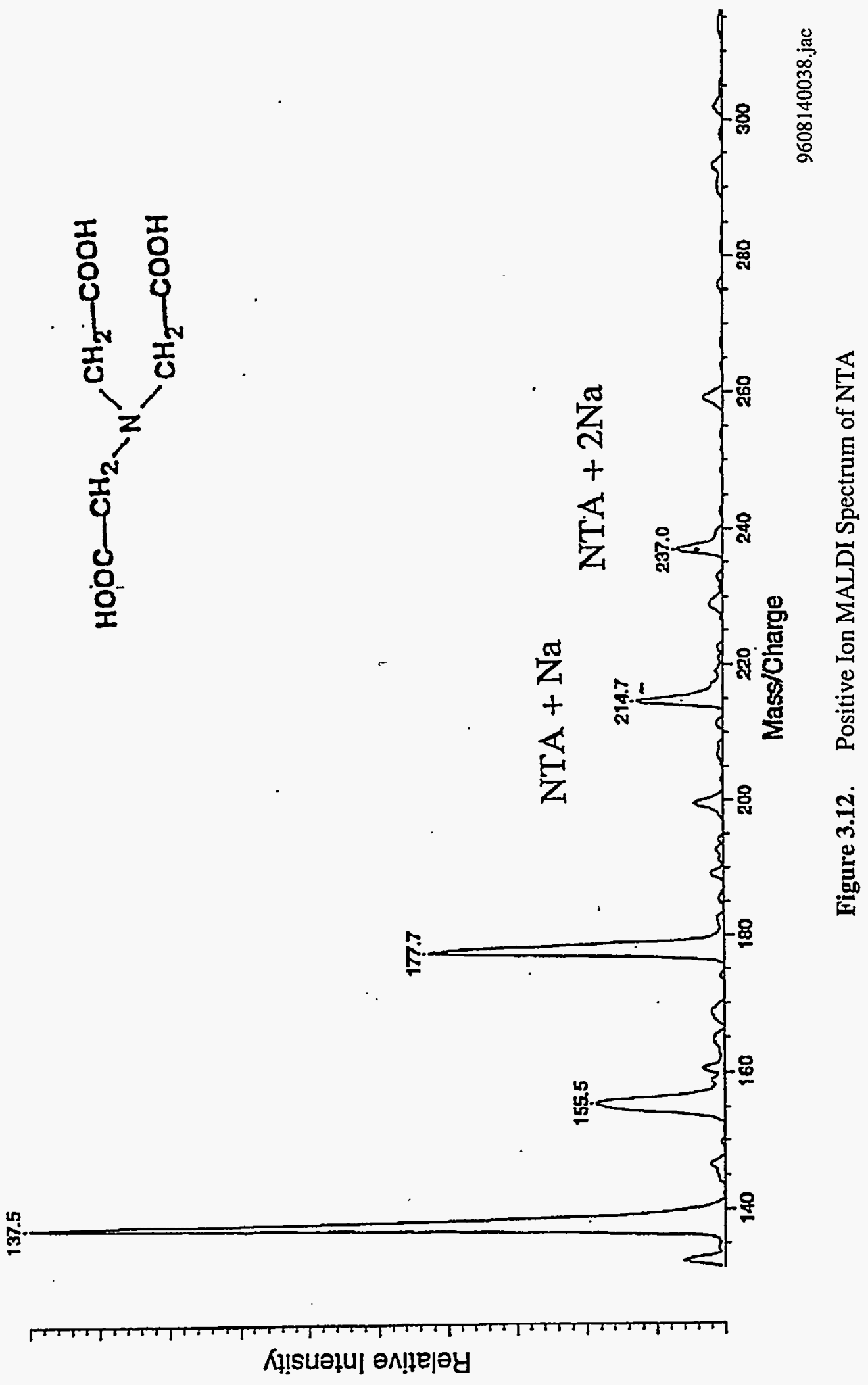




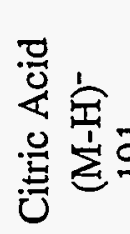
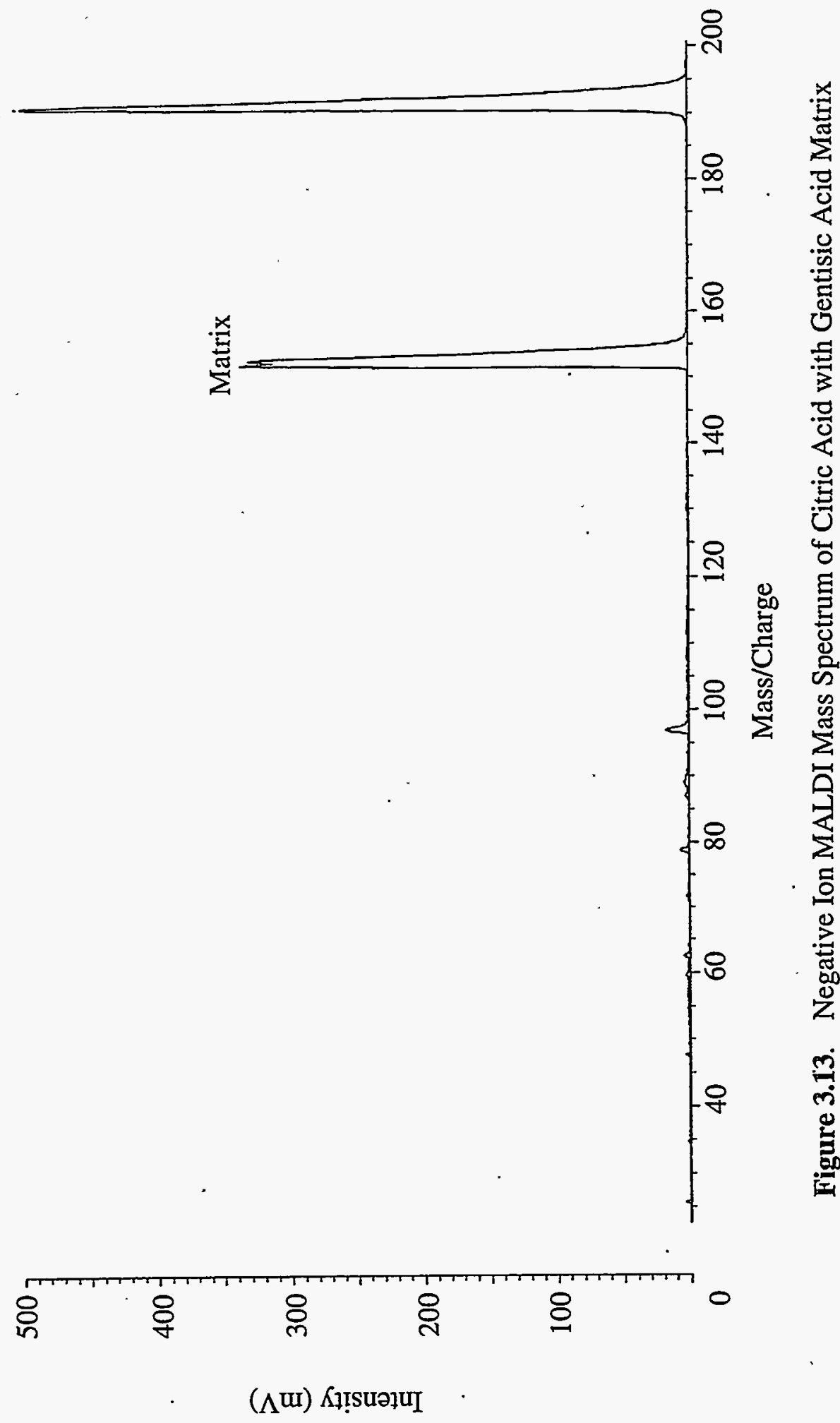
studies are being conducted to determine the effects from other sample components, such as salts and sample $\mathrm{pH}$, on these analyses. No positive ions were observed for sodium nitrate, sodium nitrite, oxalic acid, fumaric acid, maleic acid, succinic acid, ammonium sulfate, and citric acid. There were no negative ions for IDA, HEDTA, EDDA, NTA, and EDTA.

Table 3.3. Ions Observed for the Analytes by MALDI-TOF MS in the Positive or Negative Ion Mode.

Analyte

Sodium Nitrate

Sodium Nitrite

Oxalic Acid

Fumaric Acid

Maleic Acid

Succinic Acid

Ammonium Sulfate

Citric Acid

IDA

HEDTA

EDDA

NTA

EDTA
Molecular Weight

85

69

90

116

116

118

132

192

134

278

191

292

\section{Ions Observed $(\mathrm{m} / \mathrm{z})$}

$(-)$

\subsubsection{Ion-Pair Chromatography for Chelators and Chelator Fragments}

An ion-pair chromatographic technique with copper complexation has successfully separated the chelators and their fragments. This method previously determined EDTA and HEDTA at pH 6.5. However, work with simulants subjected to $\gamma$-radiation showed other peaks, some of which co-elute at this $\mathrm{pH}$. We studied mobile phase $\mathrm{pH}$ values and found that all peaks in a standard mixture were efficiently separated by adjusting the $\mathrm{pH}$ to 5.5. The retention times of the standards were then used to successfully identify the chelator fragments in $\gamma$-aged simulants supplied by William Samuels (PNNL).

The instrumentation included a Hewlett Packard Series 1050 isocratic high-performance liquid chromatography (HPLC) pump, a Unicam 4225 UV detector, and a Hewlett-Packard (HP) 3396 Series II integrator for collecting data. The analytical column was a Brownlee RP18, $25 \mathrm{~cm} \mathrm{x}$ $4.6 \mathrm{~mm}$, spheri-5 monofunctional $5 \mu \mathrm{C} 18$ with equivalent guard column. The mobile phase consisted of $0.002 \mathrm{M}$ dodecyltrimethylammonium bromide as the ion-pairing agent and $0.05 \mathrm{M}$ potassium dihydrogen phosphate to buffer the system. The $\mathrm{pH}$ was brought up to 5.5 using $6 \mathrm{~N}$ $\mathrm{NaOH}$. Samples were prepared by weighing $50 \mathrm{mg}$ in a $25-\mathrm{mL}$ solution and pipetting $1 \mathrm{~mL}$ of the latter into a $10-\mathrm{mL}$ volumetric. Fifty $\mu \mathrm{L}$ of $0.5 \mathrm{M} \mathrm{CuSO}_{4}$ was added to complex with the analytes, thus making them visible to the detector. The solution was then diluted to the mark, and $20 \mu \mathrm{L}$ was injected into the HPLC for ion-pair chromatographic analysis. Simulants were filtered before analysis if necessary. 
Figure 3.14 is an ion-pair chromatogram of the chelator standards. The peak identification was determined from retention times of standards injected individually or spiked into simulant mixtures. The order of elution at a flow rate of $1.5 \mathrm{~mL} / \mathrm{min}$ under these buffer conditions was ED3A with HEDTA, S-EDDA, IDA, U-EDDA, NTA, and EDTA. Complete separation of all the chelator fragments is being pursued by careful control of the mobile phase $\mathrm{pH}$. To confirm these preliminary peak identifications, efforts to couple this separation to mass spectrometry are also being pursued.

Figure 3.15 is a chromatogram of a simulated waste. All of these fragments were identified in simulant samples exposed to $150 \mathrm{Mrads}, 100 \mathrm{Mrads}, 50 \mathrm{Mrads}$, and $30 \mathrm{Mrads}$. The S-EDDA, which does not derivatize with $\mathrm{BF}_{3} /$ methanol, IDA, and to some extent, U- EDDA; have proved difficult to detect by methods used to date. This procedure offers the advantage of determining all of the common chelators directly in the waste sample without the need for prior derivatization. Studies are ongoing to determine detection limits and the feasibility of quantitating the fragments.

Figure 3.16 is an ion-pair chromatogram of a convective-layer sample from Tank SY-103. The major components tentatively identified include S-EDDA, U-EDDA, EDTA, IDA, and HEDTA. Figure 3.17 is an ion-pair chromatogram of a heated convective-layer sample.

\subsubsection{Ion-Pair Chromatography of Dibutyl Phosphate}

One method being developed to detect DBP in simulant waste mixtures is ion-pair chromatography with refractive index detection (Muller et al. 1985). The ion-pairing agent used is tetrahexylammonium bromide. The ion-pair chromatography of a standard solution containing MBP and DBP is shown in Figure 3.18. A good separation of DBP and MBP is obtained in less than $15 \mathrm{~min}$. The assay has been shown to be linear for standard samples over the working range of DBP in the simulant waste samples (Figure 3.19). Similar linearity was obtained for MBP response in standard solutions (data not shown). Preliminary results obtained with inorganic simulant waste samples spiked with DBP and MBP were very encouraging (Figure 3.20). The DBP could be detected easily and was well separated from peaks due to other waste components. The MBP was frequently lost due to chromatographic interference from co-eluting species, undoubtedly caused by large quantities of nitrates and other salts in the waste matrix. During early attempts to analyze DBP in simulant waste matrices, the retention time for DBP would decrease, perhaps indicating that column sites were being increasingly occupied by other waste species. A DBP peak and a small MBP peak were detected in simulated waste containing inorganic and organic components. Muller et al. (1985) suggested acidifying $(\mathrm{pH} \sim 2.5)$ the aqueous-phase solution before analysis. Our initial efforts suggest that acidification results in loss of DBP and MBP. This seems reasonable since an acidic medium would favor MBP to remain as $\mathrm{H} 2 \mathrm{MBP}$ and $\mathrm{DBP}$ to occur as $\mathrm{HDBP}$, thus making ion pairing with tetrahexylammonium bromide to give neutral species less effective. Therefore, for the remainder of this study, the samples have remained basic.

As a way of removing the waste-sample matrix and improving the baseline stability, work was undertaken to try the preconcentration column procedure described by Muller et al. (1985). The Muller procedure uses a preconcentration column to eliminate uranium, plutonium, fission products, nitric, phosphoric and hydrofluoric acids, butanol, hydrazine, etc. before the analysis of DBP and TBP. A weaker mobile phase was used to flush out the impurities while retaining DBP and TBP in the pre-column. Then a stronger eluting solvent was used to wash the DBP and TBP onto the analytical column. A similar procedure was followed in these studies for DBP and MBP analysis. The preconcentration column was flushed with $1.00 \mathrm{~mL}$ of preconcentration mobile phase $(35 \%$ methanol, $65 \%$ water, and $2 \times 10^{-3} \mathrm{M}$ tetrahexylammonium bromide) between each injection. 


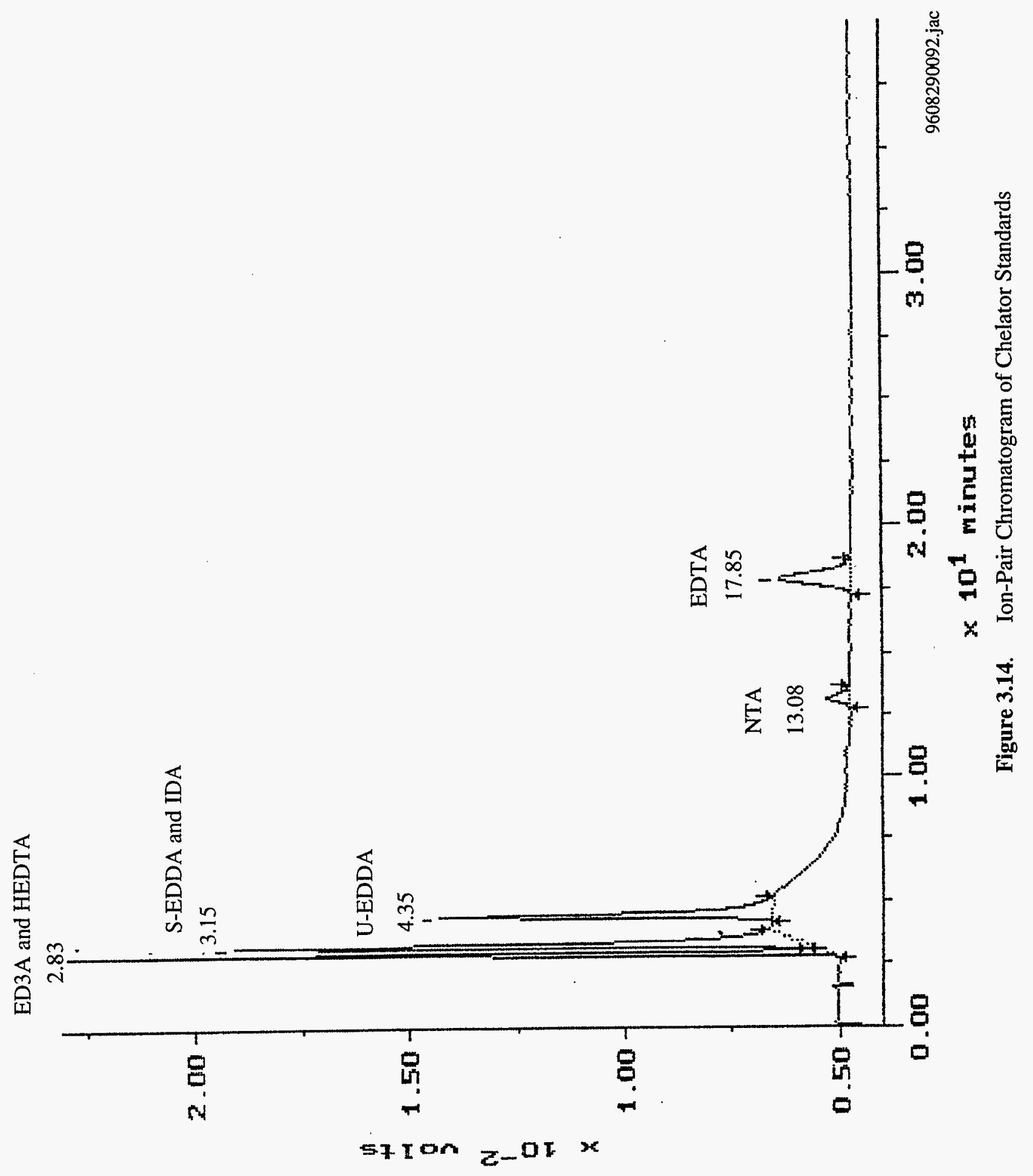




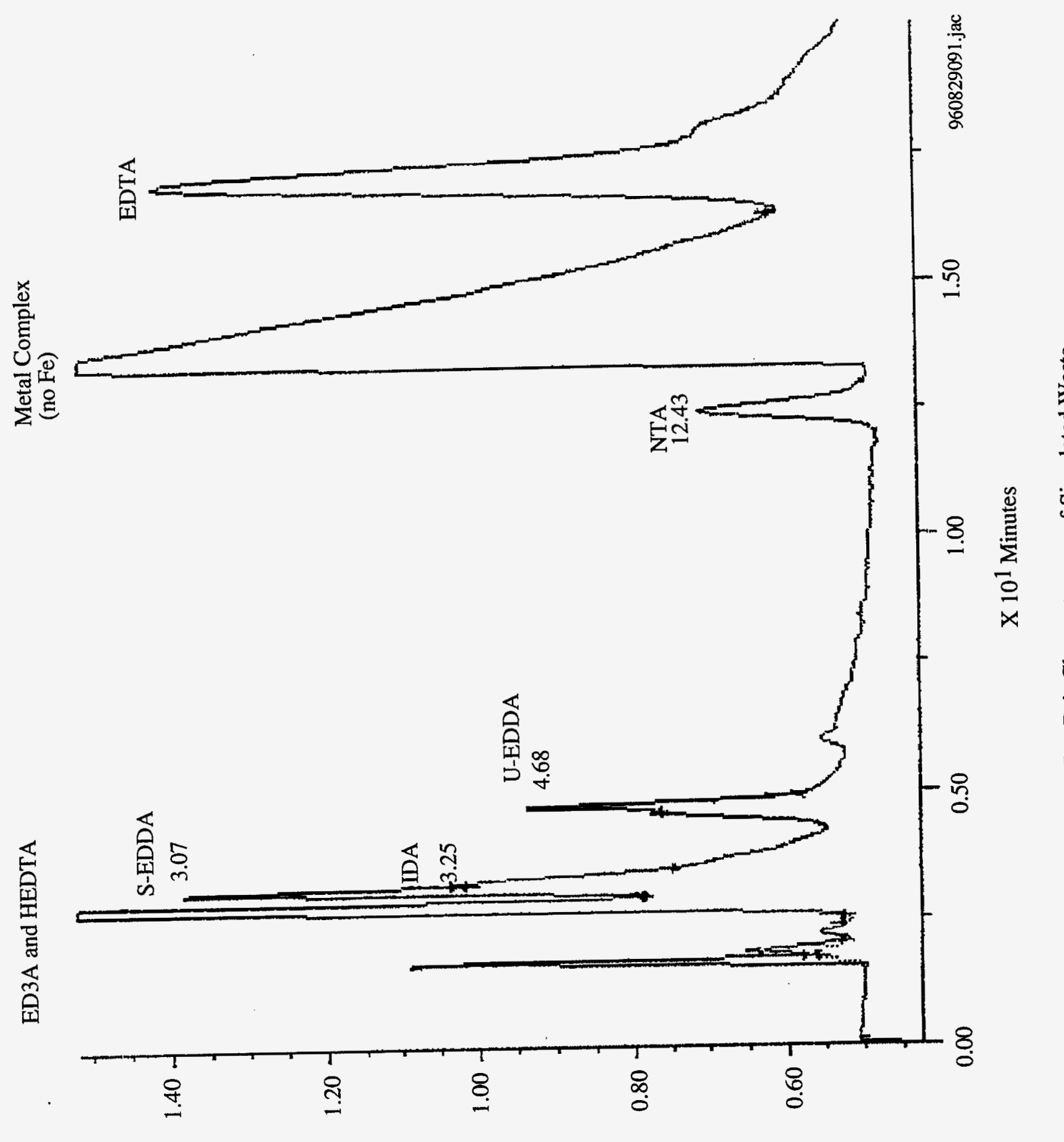

s)[o $\Lambda$ z-OI X 


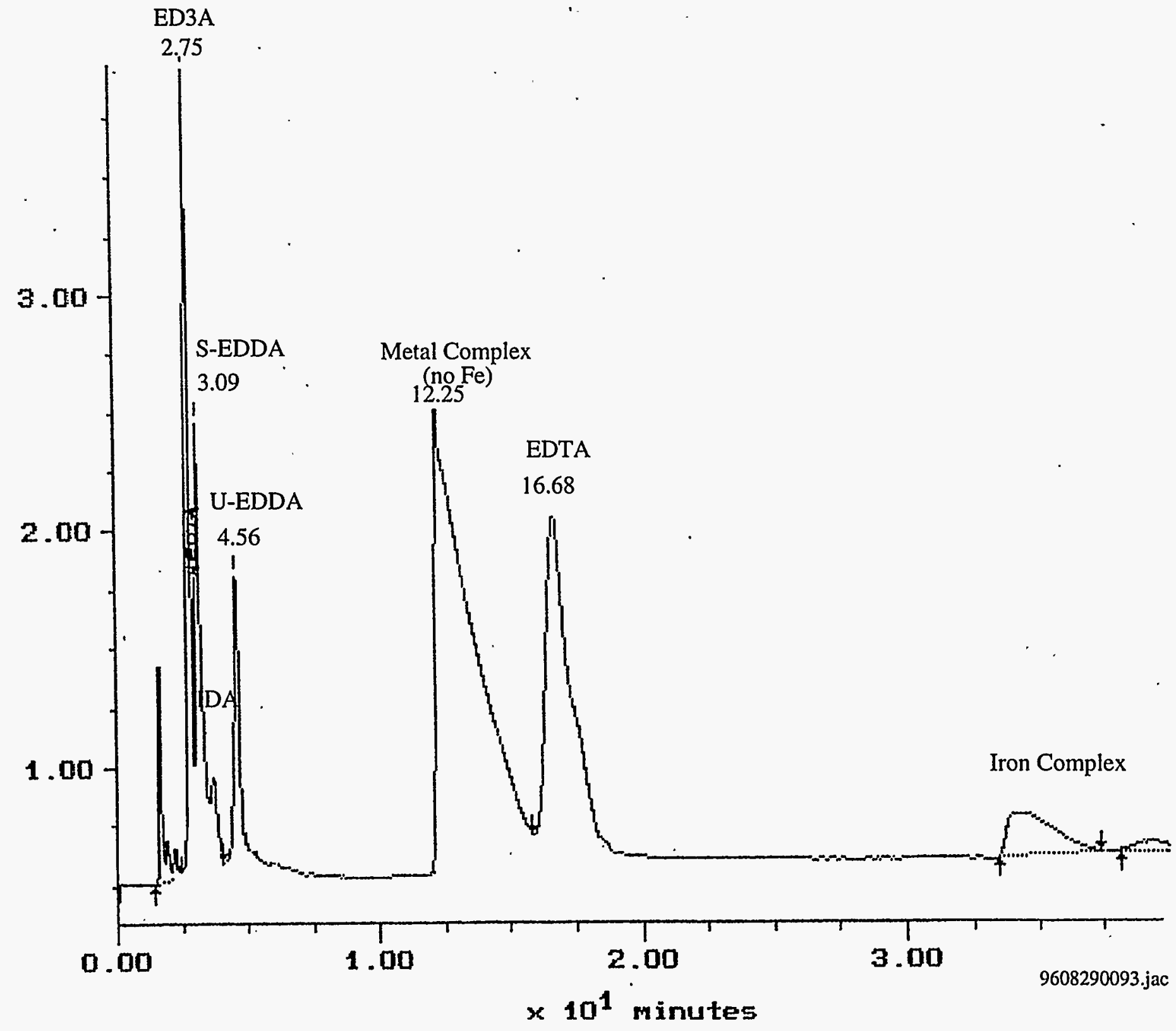

Figure 3.16. Ion-Pair Chromatogram of SY-103 Sample 


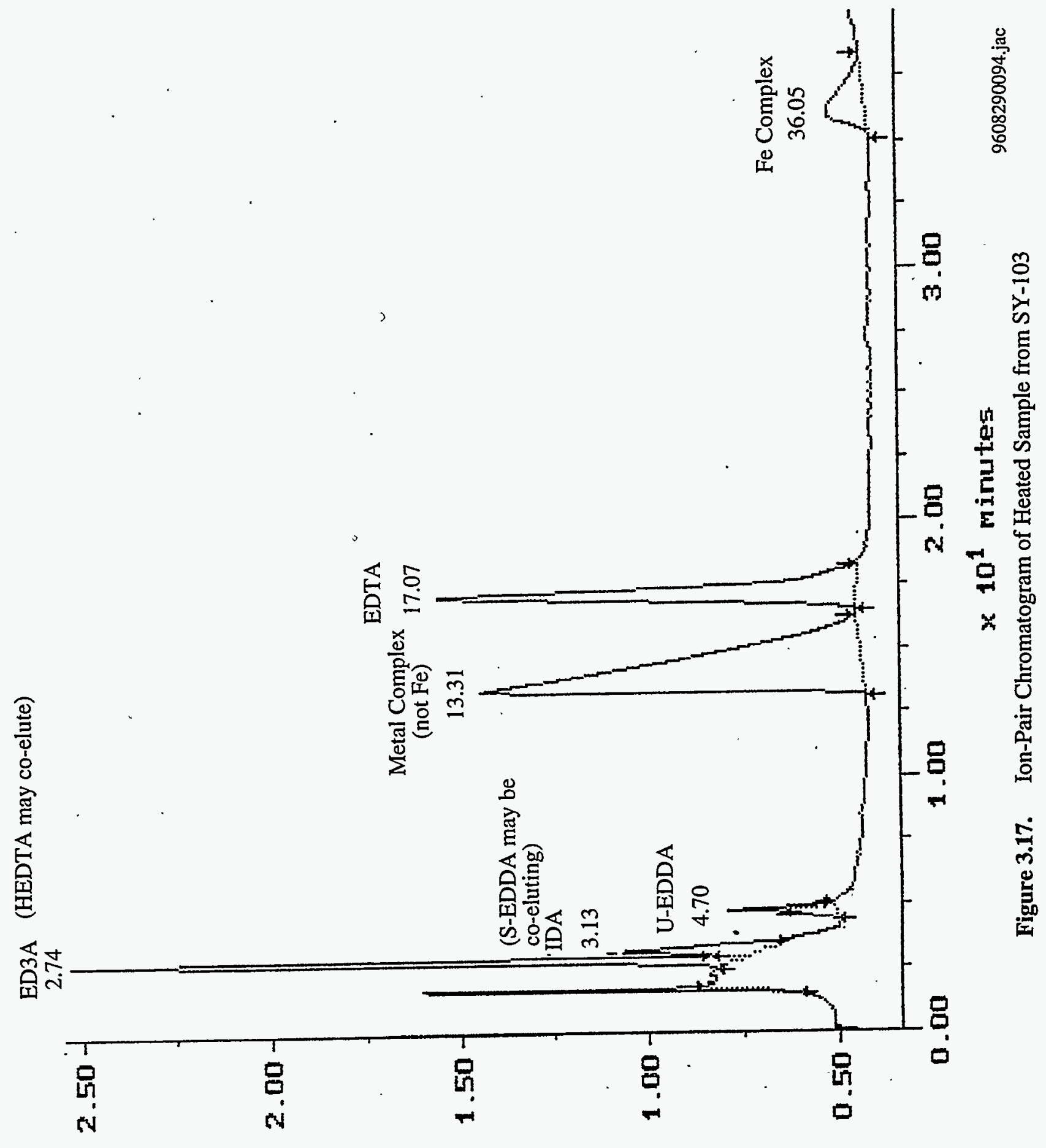




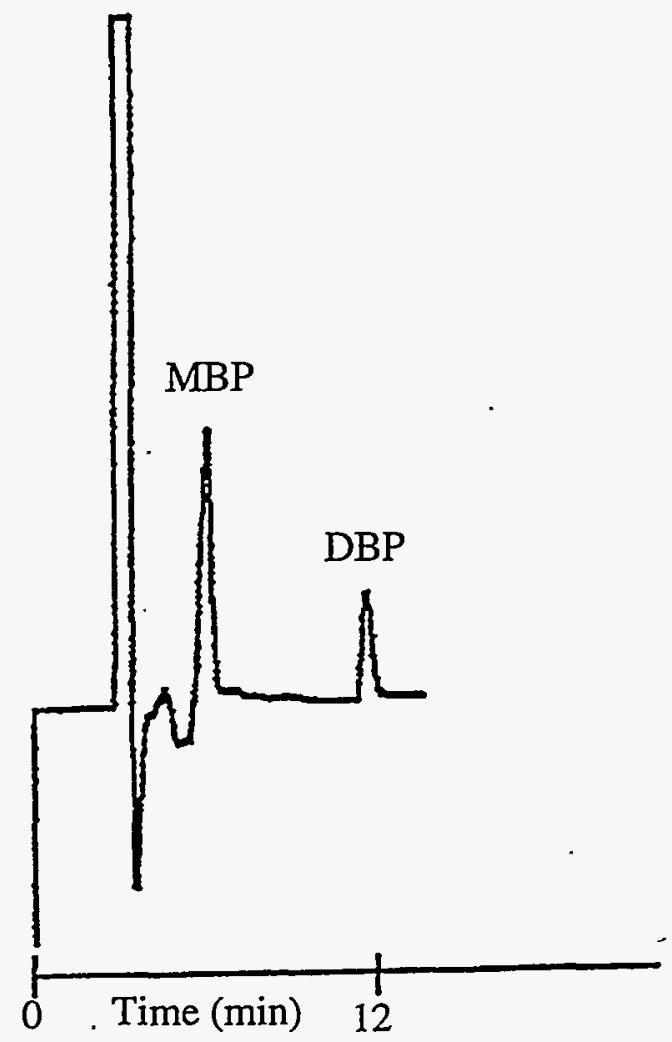

Figure 3.18. Ion-Pair Chromatography of MBP and DBP Standards with Refractive Index Detection

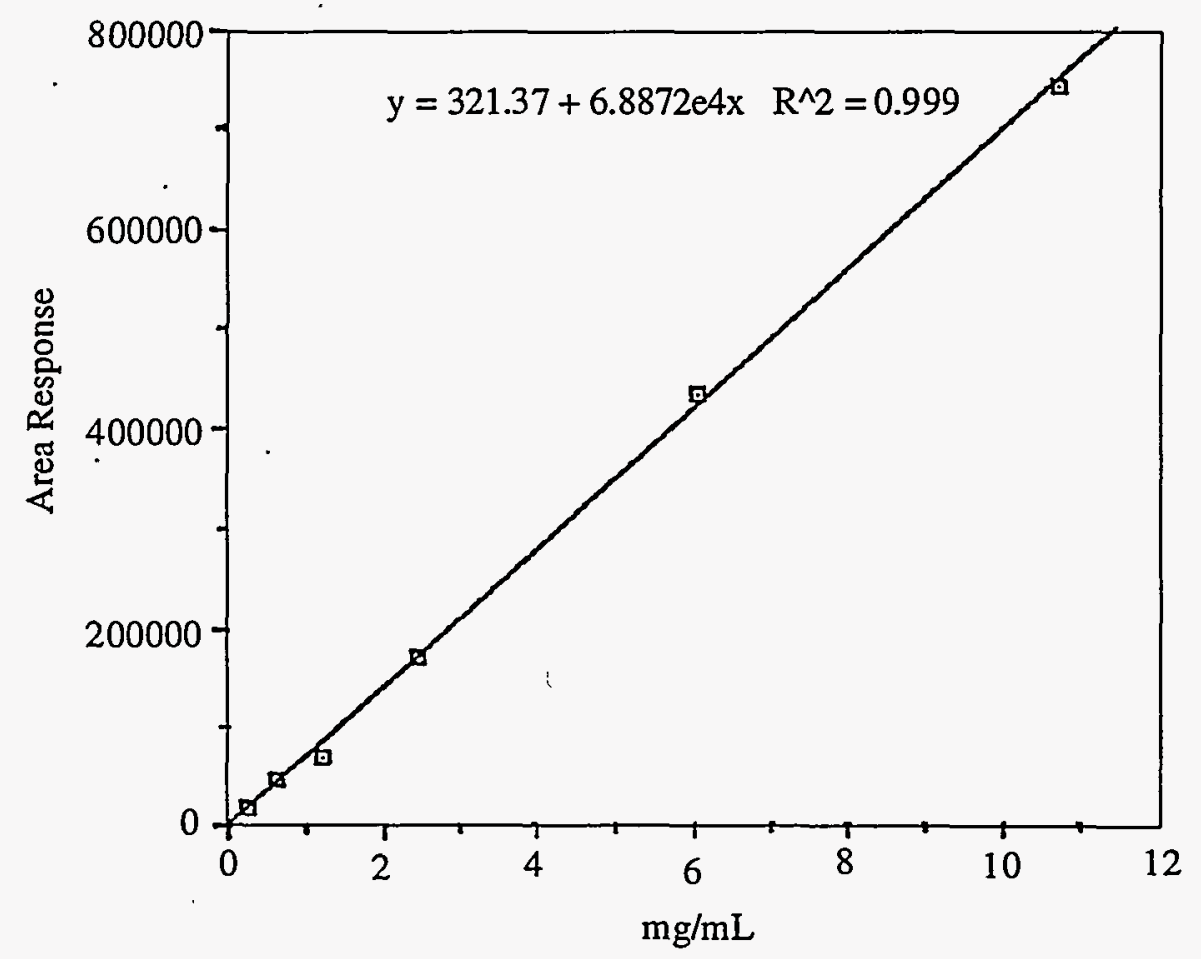

Figure 3.19. Calibration Curve for Dibutyl Phosphate in Standard Solutions 


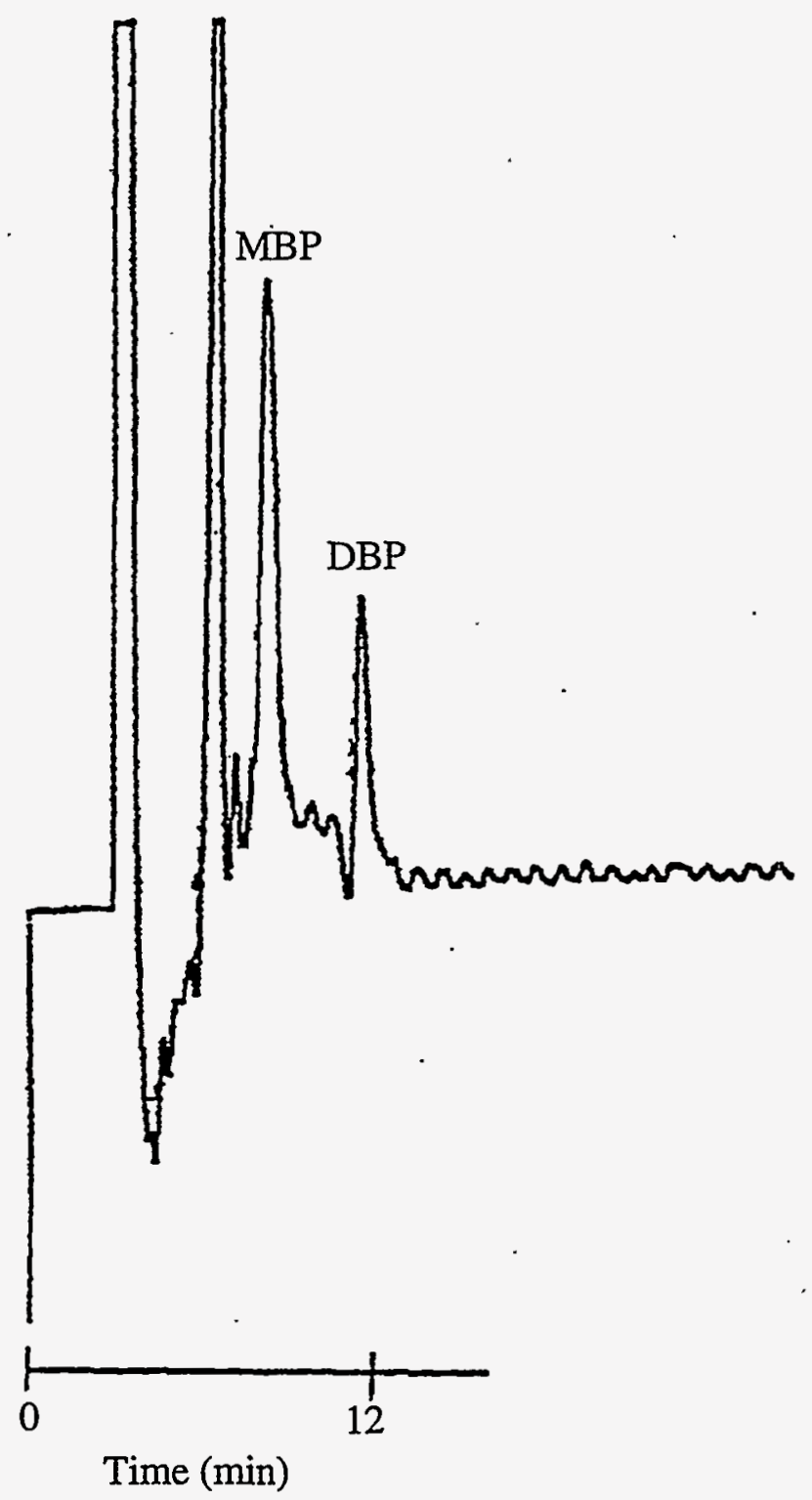

Figure 3.20. Ion-Pair Chromatography of Inorganic Simulant Spiked with $\mathrm{DBP}$ and $\mathrm{MBP}$

Simulant waste sample ( $20 \mu \mathrm{L}$ ) was injected onto this preconcentration column. Then the other waste components were flushed through the preconcentration column and into waste with $1.00 \mathrm{~mL}$ of preconcentration mobile phase. Finally, the analytes were flushed off the preconcentration column and onto the analytical column by means of the stronger eluting mobile phase consisting of the $73 \%$ methanol, $27 \%$ water, and $4.0 \times 10^{-3} \mathrm{M}$ tetrahexylammonium bromide. Adding this preconcentration clean-up step resulted in a much cleaner, more reproducible chromatogram for the simulant waste samples. Figure 3.21 shows the ion-pair chromatography with this preconcentration step for simulant waste spiked with MBP and DBP. The 94C-SIM-101-SY simulant prepared by W. Samuels for the waste aging studies was used (Camaioni et al. 1994). Figure 3.22 is a chromatogram of a waste simulant containing MBP, DBP, and TBP. The main interference with the baseline near the elution of MBP was no longer a problem. In addition, the retention times of MBP and DBP. stabilized 


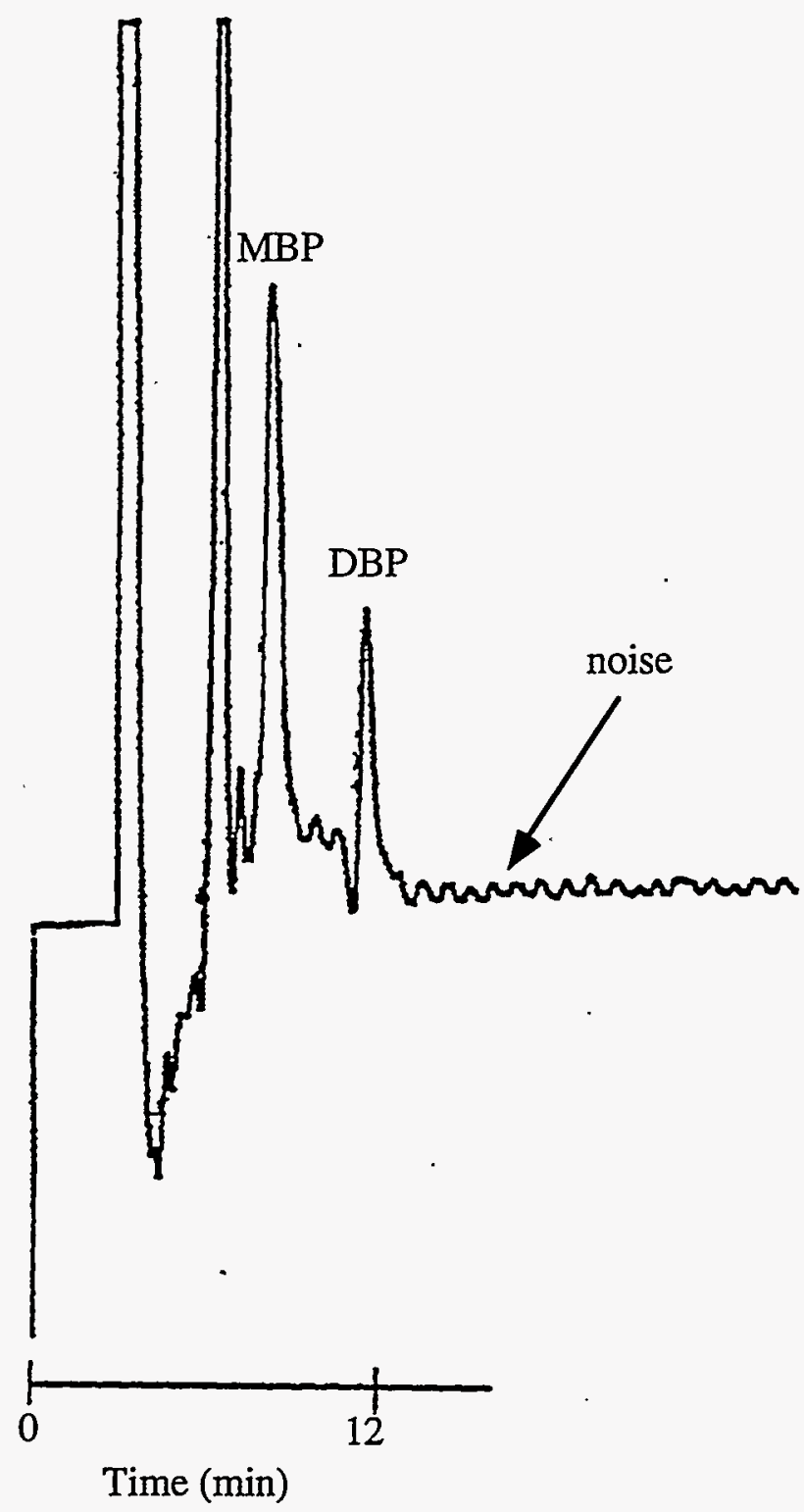

Figure 3.21. Ion-Pair Chromatography with Preconcentration Clean-up of a Simulant Waste Sample Spiked with $\mathrm{DBP}$ and $\mathrm{MBP}$

for replicate simulant waste analysis runs at approximately $8 \mathrm{~min}$ for MBP and $11 \mathrm{~min}$ for DBP. Recovery studies are in progress to determine the quantitation capabilities of this technique.

Ion-pair chromatographic analysis of the aqueous extracts of Tank C-204 revealed the presence of DBP. This is illustrated in Figure 3.23. Quantification was done using a $25-\mathrm{mM} \mathrm{NaOH}$ eluent and an AS-4A (Dionex) column. The DBP concentration was found to be approximately $2500 \mu \mathrm{g}$ of carbon/g of sample by this method. Two samples of the aqueous matrix were acidified with hydrochloric acid, taken to dryness, and treated with an ethereal solution of diazomethane (above) to allow GC quantification of DBP as dibutylmethyl phosphate. The result obtained from this analysis gave a value of DBP of $2000 \mu \mathrm{g}$ of carbon/g of sample as received. It is interesting to 


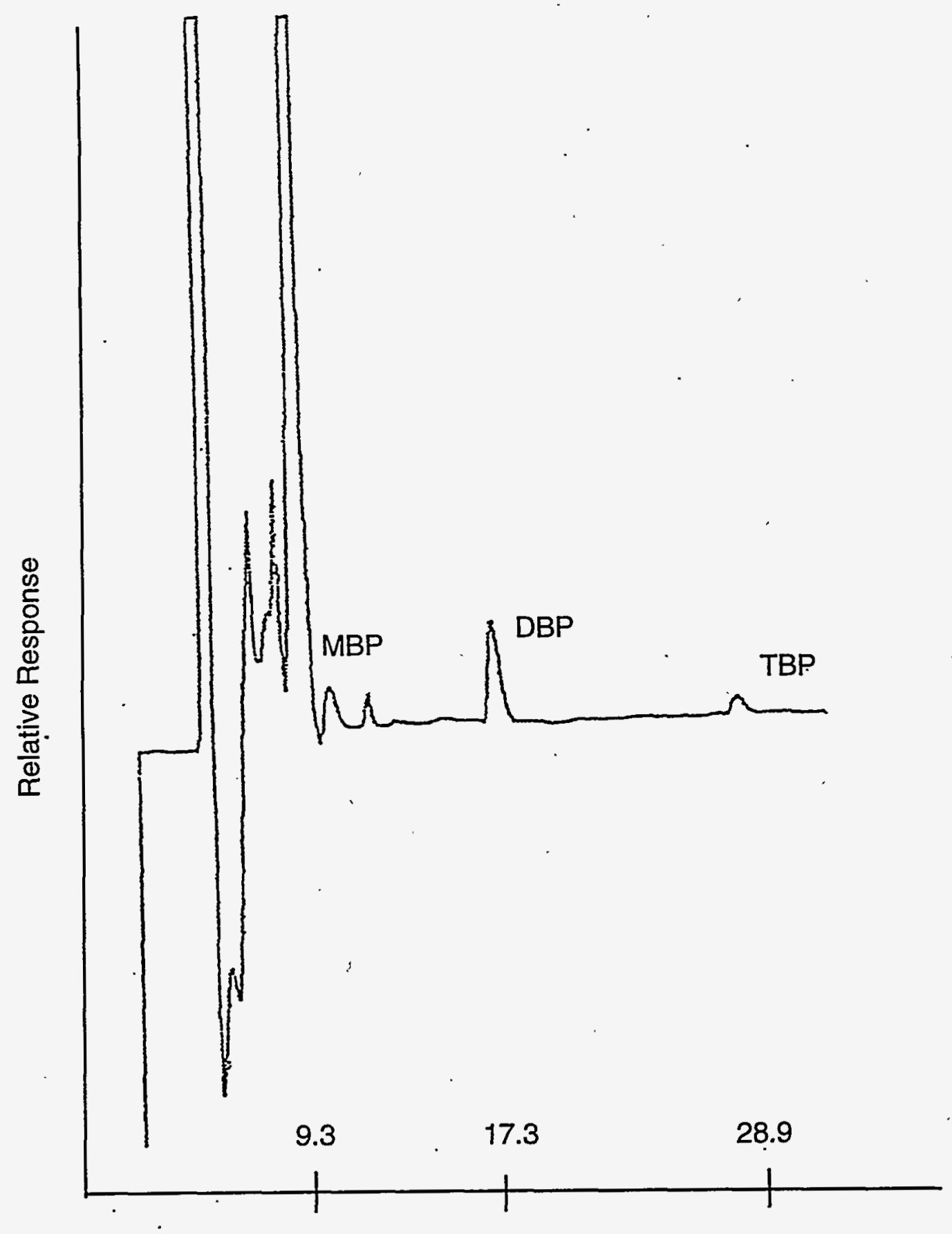

\section{Retention Time (min)}

Figure 3.22. Ion-Pair Chromatogram of a Waste Simulant Containing MBP, DBP, and TBP

note that in neither the IC data nor the diazomethane derivatization/GC analyses was MBP observed. The IC data suggest that the level of inorganic phosphate is in similar concentration to that observed for DBP; the intermediate degradation product (MBP) being absent. 


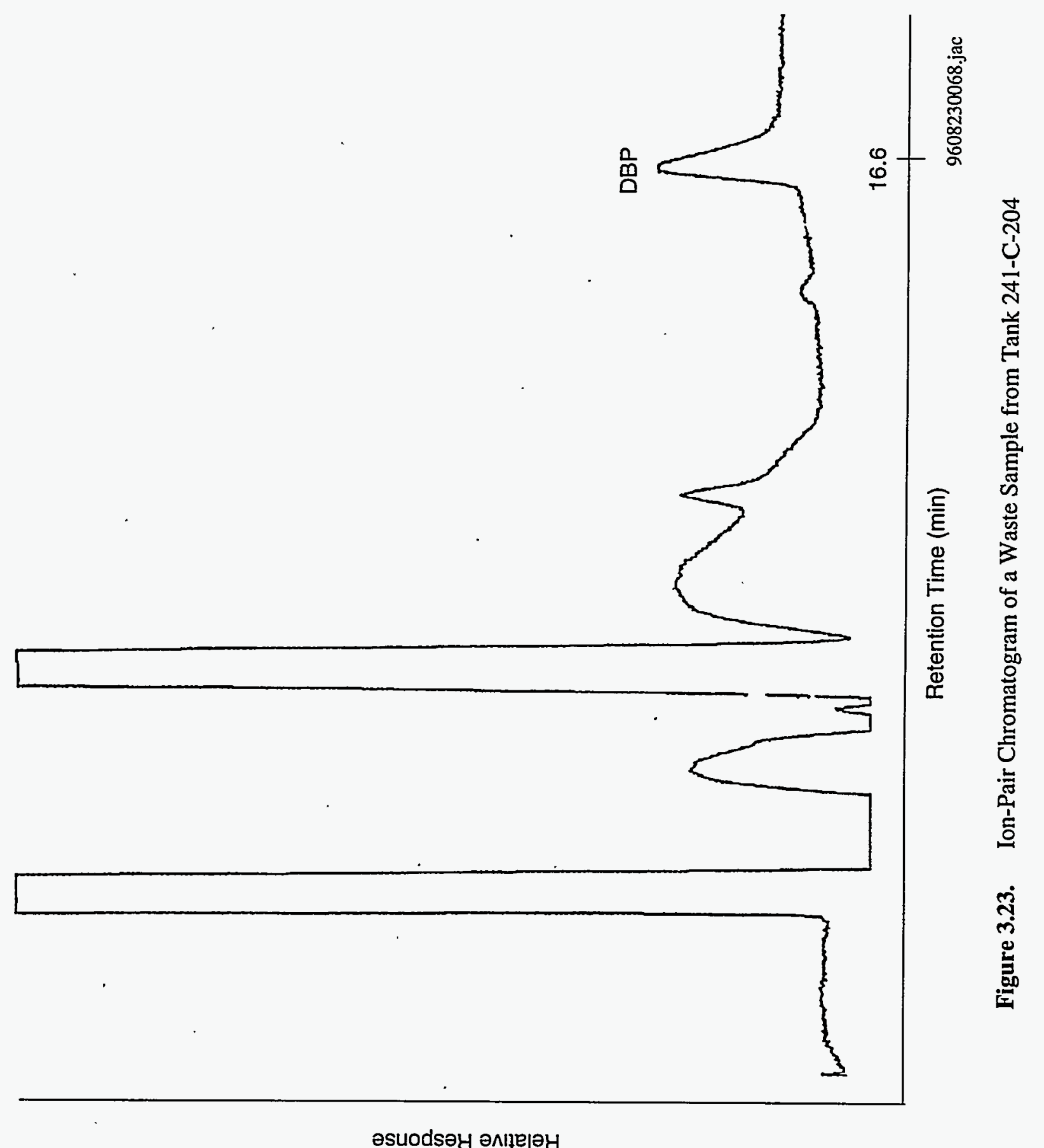




\subsection{Degradation of Organics in Flammable Gas Tanks}

Although not explicitly in the FY 1996 scope of work, it was deemed appropriate to discuss the preliminary results of estimating degradation for chelators and chelator fragments. We are estimating the extent that organics have degraded in Flammable Gas Tanks by comparing the fill history with the composition as determined by organic speciation. As an example, we have obtained the fill history of SY-101 and compared this with the results obtained from organic analysis. For oxalic acid, the fill history estimates the concentration to be approximately $0.008 \mathrm{mg} / \mathrm{g}$ of sample (Agnew 1996), but the results from actual analysis indicate a concentration of approximately $15 \mathrm{mg} / \mathrm{g}$. Another example is citric acid with an initial concentration of $3.5 \mathrm{mg} / \mathrm{g}$ from fill history compared to $0.8 \mathrm{mg} / \mathrm{g}$ from speciation. For EDTA, the initial concentration was estimated to be $12 \mathrm{mg} / \mathrm{g}$, and the measured concentration was determined to be $4.2 \mathrm{mg} / \mathrm{g}$. These results are consistent with degradation studies of waste simulants where EDTA and citric acid degrade to smaller organic compounds, whereas oxalic acid is a degradation product (Camaioni et al. 1994).

We have made several assumptions: 1) the fill history is reasonably accurate, 2) the analysis of small samples really represents the tank composition, and 3) the tank waste is relatively homogeneous. With these caveats, the preliminary results may be used to estimate the degree of degradation of the organics to this point. The fill histories of other tanks will be compared with actual analysis of tank samples to make additional statements regarding the degradation of organics. The results of comparing fill history and actual analysis may provide information concerning when a tank may be deemed safe and also simplify speciation. In other words, if degradation of the organics can be linked to the determination of several components, the number of analyses will be greatly reduced. 


\subsection{Future Work}

The objective of the Actual Waste Organic Analysis Task is to apply organic analytical methods to Organics Tanks Safety Program waste samples to identify and/or quantify the amount of specific organic species. As analytical problems, such as different waste types, interferences, etc., arise, methods will be modified to produce needed results. Initial efforts will focus on complete development of the ion-pair LC method for quantitative determination of chelator fragments to avoid costly and problematic derivatization GC/MS currently employed. In addition, efforts to interface this LC method to MS to verify the component identification and retention times will be pursued.

Present plans for funding during FY 1997 include combining the Actual Waste Organic Analysis Task (Flammable Gas Task) with the Advanced Waste Analysis (Organic Tanks Safety Program) under the auspices of the Organic Tanks Safety Program. Analytical capabilities will be used to support other PNNL Flammable Gas Tasks, such as Gas Generation Studies (Sam Bryan, Task Leader) and Gas Bubble Retention Studies (Phil Gauglitz, Task Leader) as needed. In addition, analytical support will be provided for the Waste Aging Studies (Don Camaioni, Task Leader). 


\subsection{References}

Babad, H, BA Crawford, RD Schreiber, JA Campbell, GM Mong, SA Bryan. 1996. Chemical and Chemically-Related Considerations Associated with Sluicing Tank C-106 Waste to Tank AY-103. WHC-SD-WM-Ti-756, p 4-11 and p 4-12, Westinghouse Hanford Company, Richland, Washington.

Bahr, U, A Deppe, M Karas, F Hillenkamp, and U Giessman. 1992. "Mass Spectrometry of Synthetic Polymers by UV-Matrix Assisted Laser Desorption/Ionization," Anal. Chem. 64:2866.

Baldwin, DL, RW Stromatt, and WI Winters. 1994. Comparative Study of Total Organic Carbon (TOC) Methods for High-Level Mixed Waste. PNL-SA-23718, Pacific Northwest National Laboratory, Richland, Washington.

Bryan, SA, CM King, LR Pederson, SV Forbes, and RL Sell. 1996. Gas Generation from Tank 241SY-103 Waste. PNNL-10978, Pacific Northwest National Laboratory, Richland, Washington.

Buehler, RJ, E Flanigan, LJ Greene, and L Friedman. 1974. "Proton Transfer Mass Spectrometry of Peptides. A Rapid Heating Technique for Underivatized Peptides Containing Arginine.” J. Am. Chem. Soc., 96:3990-3999.

Burger, LL. 1959. The Chemistry of Tributyl Phosphate. HW-40910, Hanford Atomic Products Operation, Richland, Washington.

Camaioni, DM and WD Samuels; contributors: BD Lenihan, SA Clauss, KL Wahl, and JA Campbell. 1994. Waste Tank Organic Safety Program, Waste Aging Studies, PNL-SA-10616, Pacific Northwest National Laboratory, Richland, Washington.

Camaioni, DM, WD Samuels, SA Clauss, BD Lenihan, KL Wahl, JA Campbell, and WJ Shaw. 1995. Organic Tanks Safety Program, FY95 Waste Aging Studies, PNL-10794, Pacific Northwest Laboratory, Richland, Washington.

Camaioni, DM, WD Samuels, JC Linehan, SA Clauss, AK Sharma, KL Wahl, and JA Campbell. 1996. Organic Tanks Safety Program: FY96 Waste Aging Studies. PNNL-11312. Pacific Northwest National Laboratory, Richland, Washington.

Campbell, JA, SA Clauss, KE Grant, FV Hoopes, BD Lerner, RB Lucke, GM Mong, JK Rau, and RT Steele. 1994a. Flammable Gas Safety Program Analytical Methods Development: FY 1993 Progress Report. PNL-9062, Pacific Northwest Laboratory, Richland, Washington.

Campbell, JA, SA Clauss, KE Grant, FV Hoopes, BD Lerner, RB Lucke, GM Mong, JK Rau, KL Wahl, and RT Steele. 1994b. Flammable Gas Safety Program. Analytical Methods Development: FY 19094 Progress Report. PNL-10127, Pacific Northwest Labǫratory, Richland, Washington.

Campbell, JA, SA Clauss, KE Grant, FV Hoopes, BD Lerner, RB Lucke, GM Mong, JK Rau, RT Steele, and KL Wahl. 1994c. Organic Tanks Safety Program. Analytical Methods Development: FY 1994 Progress Report. PNL-10128. Pacific Northwest Laboratory, Richland, Washington. 
Campbell, JA, SA Clauss, KE Grant, V Hoopes, BD Lèrner, GM Mong, J Rau, R Steele, and KL Wahl. 1995a. Flammable Gas Safety Program Analytical Methods Development: FY 1995 Progress Report. PNL-10776. Pacific Northwest Laboratory, Richland, Washington.

Campbell, JA, RM Bean, KL Wahl, GM Mong, KE Bell, KB Wehner, AD Rick, RJ Ray, DB Bechtold, BR Wels, RW Schroeder, JW Ball, BD Valenzuela, JM Frye, SL Fitzgerald, PP Bachelor, B Griffin, RK Fuller, AB Benally, and SM Parong. 1995b. Analysis of Samples from Hanford Waste Tanks 241-C102, 241-BY-108, and 241-C-103. PNL-10531. Pacific Northwest Laboratory, Richland, Washington.

Carlson, CD. 1996. Test Plan for Fauske and Associates to Perform Tube Propagation Experiments with Simulated Hanford Tank Wastes. PNNL-10970. Pacific Northwest National Laboratory, Richland, Washington.

Feiser, LF and M Feiser. 1967. "Reagents for Organic Synthesis. John Wiley and Sons, Inc., Vol. 1, p. 192.

Gerber, MA. 1994. Waste Tank Organic Safety Project: Organic Concentration Mechanisms Task. FY 1994 Progress Report. PNL-10064, Pacific Northwest Laboratory, Richland, Washington.

Hillenkamp, F, M Karas, RC Beavis, and BT Chait. 1991. "Matrix-Assisted Laser

Desorption/Ionization Mass Spectrometry of Biopolymers." Anal. Chem. 63:1193A.

Knapp, Daniel R. 1979. Handbook of Analytical Derivatization Reactions, Wiley,- Interscience, p. 387

Ligard, R and MW Duncan. 1995. "Utility of Matrix-Assisted Laser Desorption/Ionization Time-ofFlight Mass Spectrometry for the Analysis of Low Molecular Weight Compounds," Anal. Chem., 9:128.

McLafferty, FW and F Turecek. 1993. Interpretation of Mass Spectra, 4th ed. University Science Books, section 4.10, pp. 81-83.

Muller, JO, J Cojean, and A Deloge. 1985. "Determination du Phosphate de Dibutyle et du Phosphate de Tributyle a l'État de Traces dans Solutions de Retraitement des Combustibles Nucleaires par Chromatographic en Phase Liquide." Analysis, 13:160-165.

Pool, KH ; RM Bean. 1994. Waste Tank Organic Safety Project, Analysis of Liquid Samples from Hanford Waste Tank 241-C-103, PNL-9403, Pacific Northwest Laboratory, Richland, Washington, p. 6-10.

Schreiber, RD. 1996. Tank 241-C-106 Grab Sampling and Analysis Plan, WHC-SD-WM-TSAP080, Rev. 1, Westinghouse Hanford Company, Richland, Washington.

Streitwieser, A; CH Heathcock: 1976. Introduction to Organic Chemistry, McMillan Publishing Co., New York, NY, p. 503-505.

Wahl, KL, JA Campbell, SA Clauss, BD Lerner, AK Sharma, AJ Saenz, IE Burgeson, RL Sell, KE Grant, GM Mong, CE Petersen, SA Bryan, and RD Scheele. 1995. Advanced Organic Analysis and 
Analytical Methods Development: FY 1995 Progress Report. PNL-10777, Pacific Northwest Laboratory, Richland, Washington.

Wahl, KL, JA Campbell, IE Burgeson, SA Bryan, DM Camaioni, RT Hallen, BD Lerner, and RD Scheele. 1996. Use of Organic. Functional Group Concentrations as a Means of Screening for Energetics. PNNL-10883. Pacific Northwest National Laboratory, Richland, Washington. 
Appendix A

ORGANIC TANKS SAFETY PROGRAM

TEST PLAN FOR THE SPECIATION OF ORGANICS IN ACTUAL TANK WASTES TO SUPPORT VERIFICATION OF SOLUBILITY AND AGING ASSUMPTIONS 
ORGANIC TANKS SAFETY PROGRAM

TEST PLAN FOR THE SPECIATION OF ORGANICS

IN ACTUAL TANK WASTES TO SUPPORT VERIFICATION

OF SOLUBIIITY AND AGING ASSUMPTIONS

C. D. Carlson

J. A. Campbell

Pacific Northwest National Laboratory

H. Babad

Westinghouse Hanford Company

April 1, 1996

Prepared For

the U. S. Department of Energy

under Contract DE-AC06-76RLO 1830

Pacific Northwest National Laboratory

Richland, Washington 99352 


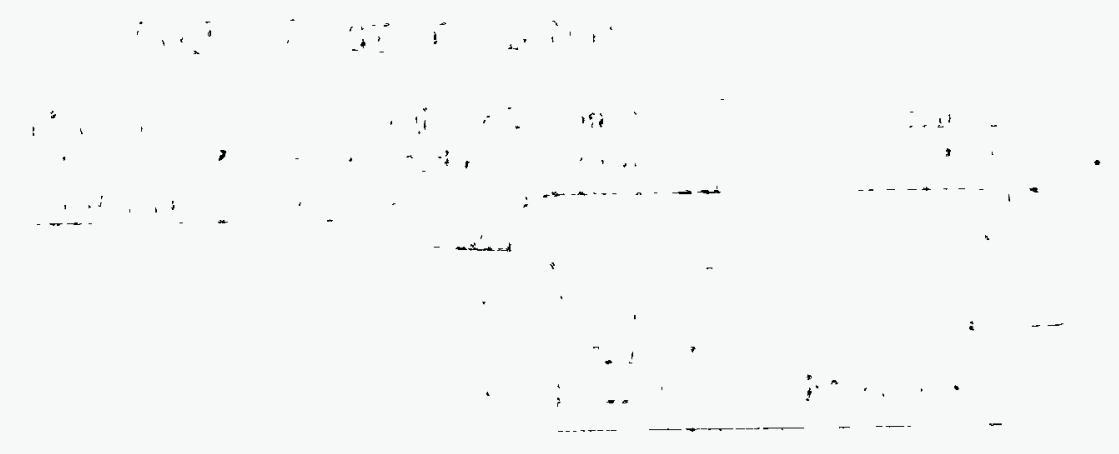

A. 3 


\subsection{INTRODUCTION}

This test plan will detail the efforts to determine the organic species present Hanford Tank which are currently on or could potentially be placed onto the Organic Tanks Watchlist. Since the report on the deflagration of a waste tank in Krishtym, USSR (Fisher 1990), the presence of organics in nitrate bearing wastes became a significant safety issue at the Hanford Site. Using information from the Krishtym deflagration, a set of 26 experiments using various combinations of sodium acetate with sodium nitrate/sodium nitrite and diluents were performed to determine the reactivity of these mixtures. Sodium acetate was used as the organic species because it provided the highest energy content per unit of organic carbon of the organic complexant thought to be present in the tanks, providing a margin of safety. From these results, the safety criteria was determined to be $10 \%$ by weight organics as sodium acetate on a dry weight basis (3\% TOC on a dry weight basis)(Babad and Turner 1993).

The nature and quantity of organic compounds in high-level waste has an impact on a variety of TWRS programs. Such waste may contain complexants added during strontium removal in BPlant in the 1960's; solvents and their degradation products from Uranium metal recovery (dates) Purex and Redox process fuel reprocessing and/or small quantities of a variety of surface active agents used for corrosion protection (hot water and stream boiler plants) and equipment and facility decontamination. Organic complexants are associated with both the generation of flammable gasses in the waste and the potential for initiated nitrate-nitrite-organic fuel propagation reactions in the waste. Complexants also interfere with the separation of wastes, during pretreatment, into HLW and LLW fractions required for disposal. The presence of organic solvents, extractants and their water insoluble degradation products are associated with the "solvent fire" safety issues and will effect the solids-liquid separation operations associated with waste pretreatment. At present, little is known about the concentration or effects of surfactants on either interim safe storage of the waste or retrieval and pretreatment. The effects of organics on either interim safe storage or disposal are highly species and concentration specific, necessitating a flexible cost effective program of organic speciation. Such a program has been developed by PNNL scientists in collaboration with WHC chemists.

In order to provide a more reasonable value for the reactive nature of the organics containing wastes present in the tanks, the identity of those organics must first be determined. From the tank fill data (Agnew et al, 1995), the amounts and types of organics which were added to the tanks can be estimated determine to a close approximation, but due to thermal and radiolytic degradation of the wastes (Camaioni et al. 1995) the nature of the organic carbon currently present in the tanks will be significantly different. The determination of the nature of the organics present in the tanks has been studied under the Flammable Gas Program for several years (Campbell et al. 1995) and the current work will build on this knowledge to provide a better understanding of the organic species present in the tanks.

Organic speciation is a complex analytical process that aims at identifying the specific organic chemicals in a variety of diverse and heterogeneous waste mixture and where possible quantifying the concentrations of the major species in that waste. Speciation requires initial decontamination of the waste to allow chemists to perform complex analyses of the mixtures in low and non-radiation facilities. Identification and quantitation of the organic waste constituents can then be carried out by a variety of methods that are described below. 


\subsection{METHODOLOGY}

Table 1. General Available Methodology

\begin{tabular}{|c|c|c|c|}
\hline Analytical Technique & Analytes & Constituent Type & $\begin{array}{c}\text { Method Focus and } \\
\text { Quantification }\end{array}$ \\
\hline $\begin{array}{l}\text { Derivatization Gas } \\
\text { Chromatography/Mass } \\
\text { Spectrometry } \\
.\end{array}$ & $\begin{array}{l}\text { Chelators } \\
\text { Chelator Fragments }\end{array}$ & $\begin{array}{l}\text { Complexants } \\
\text { Aging Products } \\
\text { [EDTA, NTA, IDA, } \\
\text { ED3A, HEDTA, } \\
\text { succinic, citric acids } \\
\text { and their salts] }\end{array}$ & $\begin{array}{l}\text { oly-functional } \\
\text { Carboxylic Acids } \\
\text { (Species identification } \\
\text { and (Qualitative) } \\
\text { analysis) }\end{array}$ \\
\hline $\begin{array}{l}\text { Derivatization Gas } \\
\text { Chromatography with } \\
\text { Flame Ionization } \\
\text { Detection }\end{array}$ & $\begin{array}{l}\text { Chelators } \\
\text { Chelator Fragments }\end{array}$ & $\begin{array}{l}\text { Complexants } \\
\text { Aging Products } \\
\text { [EDTA, NTA, IDA, } \\
\text { ED3A, HEDTA } \\
\text { succinic, citric acids } \\
\text { and their salts] }\end{array}$ & $\begin{array}{l}\text { Poly functional } \\
\text { Carboxylic Acids } \\
\text { (Quantitative) Analysis) }\end{array}$ \\
\hline $\begin{array}{l}\text { Liquid } \\
\text { Chromatography and/ } \\
\text { or } \\
\text { Ion Chromatography }\end{array}$ & $\begin{array}{l}\text { Chelators } \\
\text { Chelator Fragments }\end{array}$ & $\begin{array}{l}\text { Low Molecular Weight } \\
\text { Acids }\end{array}$ & $\begin{array}{l}\text { Oxalate, formate, } \\
\text { acetate, glycolate } \\
\text { (Quantitative) Analysis) }\end{array}$ \\
\hline $\begin{array}{l}\text { High Resolution Mass } \\
\text { Spectrometry }\end{array}$ & $\begin{array}{l}\text { Solvents } \\
\text { Extractants } \\
\text { Chelators } \\
\text { Chelator Fragments }\end{array}$ & $\begin{array}{l}\text { All Organic Species } \\
\text { Capable of being } \\
\text { volatilized }\end{array}$ & $\begin{array}{l}\text { Qualitative } \\
\text { Identification } \\
\text { of unknowns }\end{array}$ \\
\hline $\begin{array}{l}\text { Spectroscopy } \\
\text {-Infrared } \\
\text {-Raman } \\
\text {-UV-Visible }\end{array}$ & $\begin{array}{l}\text { Solvents } \\
\text { Extractants } \\
\text { Chelators } \\
\text { Chelator Fragments }\end{array}$ & $\begin{array}{l}\text { Functional Groups in } \\
\text { all organic species }\end{array}$ & $\begin{array}{l}\text { Quantitative or } \\
\text { Qualitative analysis } \\
\text { depending on standard } \\
\text { availability }\end{array}$ \\
\hline $\begin{array}{l}\text { Nuclear Magnetic } \\
\text { Resonance } \\
\text {-Proton } \\
\text {-Phosphorous-31 } \\
\text {-Carbon-13 }\end{array}$ & $\begin{array}{l}\text { Solvents } \\
\text { Extractants } \\
\text { Chelators } \\
\text { Chelator Fragments }\end{array}$ & $\begin{array}{l}\text { Functional groups and } \\
\text { structural environments } \\
\text { in all organic species }\end{array}$ & $\begin{array}{l}\text { Quantitative or } \\
\text { Qualitative analysis } \\
\text { depending on standard } \\
\text { availability }\end{array}$ \\
\hline
\end{tabular}


Table 2. Species Specific Methodology

\begin{tabular}{|c|c|c|c|}
\hline Specific Analyte & Analytical Technique & $\begin{array}{c}\text { Degree of } \\
\text { Quantification [Note 1] }\end{array}$ & Method Complexity \\
\hline EDTA & $\begin{array}{l}\text { Derivatization GC/MS } \\
\text { Derivatization GC }\end{array}$ & $\begin{array}{l}\text { Species Identification } \\
\text { Quantitation }\end{array}$ & $\begin{array}{l}\text { sample must be dried } \\
\text { prior to derivatization, } \\
\text { low sample size to } \\
\text { reagent ratio, complex }\end{array}$ \\
\hline HEDTA & $\begin{array}{l}\text { Derivatization GC/MS } \\
\text { Derivatization GC }\end{array}$ & $\begin{array}{l}\text { Species Identification } \\
\text { Quantitation }\end{array}$ & $\begin{array}{l}\text { sample must be dried } \\
\text { prior to derivatization, } \\
\text { low sample size to } \\
\text { reagent ratio, complex }\end{array}$ \\
\hline NTA & $\begin{array}{l}\text { Derivatization GC/MS } \\
\text { Derivatization GC }\end{array}$ & $\begin{array}{l}\text { Species Identification } \\
\text { Quantitation }\end{array}$ & $\begin{array}{l}\text { sample must be dried } \\
\text { prior to derivatization, } \\
\text { low sample size to } \\
\text { reagent ratio, complex }\end{array}$ \\
\hline IDA & $\begin{array}{l}\text { Derivatization GC/MS } \\
\text { Derivatization GC }\end{array}$ & $\begin{array}{l}\text { Species Identification } \\
\text { Quantitation }\end{array}$ & $\begin{array}{l}\text { sample must be dried } \\
\text { prior to derivatization, } \\
\text { low sample size to } \\
\text { reagent ratio, complex }\end{array}$ \\
\hline ED3A & $\begin{array}{l}\text { Derivatization GC/MS } \\
\text { Derivatization GC }\end{array}$ & $\begin{array}{l}\text { Species Identification } \\
\text { Quantitation }\end{array}$ & $\begin{array}{l}\text { sample must be dried } \\
\text { prior to derivatization, } \\
\text { low sample size to } \\
\text { reagent ratio, complex }\end{array}$ \\
\hline Succinic Acid & $\begin{array}{l}\text { Derivatization GC/MS } \\
\text { Derivatization GC }\end{array}$ & $\begin{array}{l}\text { Species Identification } \\
\text { Quantitation }\end{array}$ & $\begin{array}{l}\text { sample must be dried } \\
\text { prior to derivatization, } \\
\text { low sample size to } \\
\text { reagent ratio, complex }\end{array}$ \\
\hline Citric Acid & $\begin{array}{l}\text { Derivatization GC/MS } \\
\text { Derivatization GC }\end{array}$ & $\begin{array}{l}\text { Species Identification } \\
\text { Quantitation }\end{array}$ & $\begin{array}{l}\text { sample must be dried } \\
\text { prior to derivatization, } \\
\text { low sample size to } \\
\text { reagent ratio, complex }\end{array}$ \\
\hline Oxalate & $\begin{array}{l}\text { Ion Chromatography } \\
\text { or } \\
\text { Liquid } \\
\text { Chromatography }\end{array}$ & Quantitation & $\begin{array}{l}\text { ample analyzed } \\
\text { directly, not as } \\
\text { complex as } \\
\text { derivatization }\end{array}$ \\
\hline Acetate & $\begin{array}{l}\text { Ion Chromatography } \\
\text { or } \\
\text { Liquid } \\
\text { Chromatography }\end{array}$ & Quantitation & $\begin{array}{l}\text { sample analyzed } \\
\text { directly, not as } \\
\text { complex as } \\
\text { derivatization }\end{array}$ \\
\hline
\end{tabular}


Table 2. Species Specific Methodology (cont)

\begin{tabular}{|c|c|c|c|}
\hline Specific Analyte & Analytical Technique & $\begin{array}{c}\text { Degree of } \\
\text { Quantification [Note 1] }\end{array}$ & Method Complexity \\
\hline Glycolate & $\begin{array}{l}\text { Ion Chromatography } \\
\text { or } \\
\text { Liquid } \\
\text { Chromatography }\end{array}$ & Quantitation & $\begin{array}{l}\text { sample analyzed } \\
\text { directly, not as } \\
\text { complex as } \\
\text { derivatization }\end{array}$ \\
\hline $\begin{array}{l}\text { Formate } \\
\text { TPB }\end{array}$ & $\begin{array}{l}\text { Ion Chromatography } \\
\text { or } \\
\text { Liquid } \\
\text { Chromatography } \\
\text { GC/MS }\end{array}$ & Quantitation & $\begin{array}{l}\text { sample analyzed } \\
\text { directly, not as } \\
\text { complex as } \\
\text { derivatization } \\
\text { extract analyzed } \\
\text { directly }\end{array}$ \\
\hline $\mathrm{NPH}$ & GC/MS & & $\begin{array}{l}\text { extract analyzed } \\
\text { directly }\end{array}$ \\
\hline $\begin{array}{l}\text { Aging Products } \\
\text { (Water Insoluble) }\end{array}$ & GC/MS & & $\begin{array}{l}\text { extract analyzed } \\
\text { directly }\end{array}$ \\
\hline & NMR & & $\begin{array}{l}\text { limited by } \\
\text { radioactivity and } \\
\text { concentration }\end{array}$ \\
\hline & IR/Raman & & $\begin{array}{l}\text { Quantitation possible } \\
\text { for known matrix }\end{array}$ \\
\hline & UV-Visible & & $\begin{array}{l}\text { quantitation but non- } \\
\text { selective }\end{array}$ \\
\hline
\end{tabular}

Note 1. Typical limits of detection by GC/MS or GC/FID are 50-100 ppm.

Need to add to table

Di(2ethylhexyl)phosphoric acid, derivatization GC/MS, sample must be made acidic and derivatized 


\subsection{SAMPLE SELECTION}

Since funding and time is limited for the completion of this project, the tank samples to be used will be that remaining from other sampling programs, such as the Characterization Program. This will limit the number of samples which will be available for the speciation. However, from the list of currently available samples, representative tank samples can be collected for most of the safety issues.

A number of issues and characteristics regarding organic species in the tanks drive the Hanford Site Characterization Program. From these isșues and the availability of samples, an initial set of tanks have been identified as potential samples for organic speciation. Table 2.1 shows the samples and the sample availability.

Table 3.1 Samples for Organic Speciation.

\begin{tabular}{|c|c|c|c|}
\hline Tank ID & Safety Issue & Sampling Information & Sample Availability \\
\hline C-103 & $\begin{array}{l}\text { Organic Watch List } \\
\text { Floating Organic Layer }\end{array}$ & 2 push cores & \\
\hline U-107 & $\begin{array}{l}\text { Organic Watch List } \\
\text { High Organic Salt } \\
\text { Content }\end{array}$ & 2 grab samples & $<100 \mathrm{~g}$ \\
\hline BY -110 & Ferrocyanide Tank & 6 rotary cores & \\
\hline AW-101 & Flammable Gas Tank & $\begin{array}{l}2 \text { push cores } \\
3 \text { auger samples }\end{array}$ & $\begin{array}{l}\text { available from } 1996 \\
\text { cores }\end{array}$ \\
\hline$C-106$ & High Heat Tank & 1 push core & unknown \\
\hline$A Z-101$ & Aging Waste Tank & $\begin{array}{l}2 \text { push cores } \\
5 \text { grab samples }\end{array}$ & $\begin{array}{l}\text { only diluted liquid } \\
(1: 10)\end{array}$ \\
\hline B-105 & $\begin{array}{l}\text { Representative Salt } \\
\text { Cake Tank }\end{array}$ & 1 push core & none left \\
\hline C-110 & $\begin{array}{l}\text { Representative } \mathrm{BiPO}_{4} \\
\text { sludge waste }\end{array}$ & 3 push cores & none left \\
\hline S-104 & $\begin{array}{l}\text { Representative REDOX } \\
\text { sludge waste }\end{array}$ & 3 push cores & $170 \mathrm{~g}$ \\
\hline C-104 & $\begin{array}{l}\text { Representative PUREX } \\
\text { sludge waste }\end{array}$ & 1 push core & none left \\
\hline
\end{tabular}

In addition to this list, samples from tanks C-107, C-105, BY-106 and BX-112 are available. These samples have been identified as having potentially large quantities of organic as listed in the Hanford Defined Wastes (Agnew 1996). 


\subsection{SAMPLE PREPARATION AND ANALYSIS}

After receiving samples in the 325-hot cell facility, the sample must be decontaminated to allow analysis to be carried out by PNNL professional staff, in what essentially low or non-radiation zones. Variation of two methods for decontamination are used, depending on the nature of the organic species being investigated. The decontamination procedures involve either leaching of the solid waste samples with water and passing leachate containing the water soluble organics through a cation exchange resin to reduce the levels of radioactivity. Sufficient water is used to assure the dissolution of even low solubility aging products such as sodium oxalate. Values for total organic carbon are obtained at various steps in the procedure to ensure that organic carbon is neither removed or introduced during decontamination. Total organic carbon analysis is done by either by either silver catalyzed persulfate oxidation or the furnace fusion method [or both, depending on the nature of the organic species expected].

Alternatively for samples believed to contain entrained or separable solvents and extractants or their water insoluble reaction products, the sample is extracted with a low boiling solvent (e.g., hexane or methylene chloride) to remove solvent miscible components from the waste samples, and the organic solutions washed with appropriate leachate (e.g., sodium carbonate and ETDA) to remove radionuclides from water insoluble waste such a NPH/TBP or waste organic oils. If needed, the low boiling solvent can be stripped, and the residual organics can be speciated as described below. In addition, the solid and liquid samples will be extracted. A portion of the sample will be extracted with an organic solvent and analyzed using GC/MS to determine any organically-soluble carbon such as TBP and NPH.

An aliquot of the aqueous solution will be removed and evaporated to dryness. After drying, the resulting material will be derivatized (Campbell et al. 1994) and analyzed by GC/MS to identify chelators and chelator fragments. The organic components will be quantified using GC/flame ionization detection (FID).

Another aliquot of the solution will be analyzed by LC of IC with conductivity detection for low molecular weight acids (Campbell et al. 1994, 1995). 


\subsection{DATA}

The data obtained will be the concentration of the organic components in the convective and nonconvective layer samples (depending on availability). In the description of the results, the method used for analysis will be identified along with the quantity of the species present. In addition, any special handling and problems associated with the analysis will be described in full. The list of analytical techniques to be used can be seen in Section 2.0. 


\subsection{TEST PROCEDURE}

1994):

Testing will be conducted at PNNL under the following technical procedures (Campbell et al.

- LC and IC for the analysis of low-molecular-weight acids

- Derivatization GC/MS for the qualitative analysis of chelators and chelator fragments

- GC/FID for quantitative analysis of chelators and chelator fragments

- GC/MS for the analy'sis of organically-soluble carbon 


\subsection{SAFETY}

The following Safe Operating Procedures govern work performed at 325A HLRF and contain applicable hazard assessment and training requirements:

- 325-A-1, 325A HLRF - Use of the 30/5 Ton Crane

- 325-A-4, Transfer Mechanism Operation

- 325-A-8; Waste Removal from "A", "B", and "C" Cells

- 325-A-12, 325A HLRF - Assembling, Using, and Disassembling the Port Adaptor

- 325-A-21, Liquid Waste Disposal

- GEN-325-SPM-1, 325 Building Sample Packaging and Movement

- GEN-325-WM-1, Waste Management Routing; Storage, and Disposal of Hazardous, Low-level Radioactive, or Radioactive Mixed Waste

- GEN-325-GB-1, Use of Glove Box Enclosures for Radiological Operations

- GEN-325-FH-1, Use of Laboratory Fume Hoods for Radiological Operations building:

The following Safe Operating Procedures will govern the work performed in the 329

- AOAM-329-LC1, Analysis of Organics in Potentially Radiologically Contaminated Samples by Liquid Chromatography and Mass Spectrometry

- $\quad$ RAD-329-FH1, Use of Laboratory Fume Hoods for Radiological Operations for 329

- AOAM-329-SP1, Sample Preparation for the Analysis of Extractable Organic Compounds from Radioactive Samples

- AOAM-329-MS2, Routine GC/MS Instrumentation for Analysis of Potentially Radiologically Contaminated Samples 


\subsection{Quality Assurance}

Work performed using this test plan will meet Impact Level II requirements as described in PNL-MA-70. All Data generated in the 325A HLRF will be recorded on test instructions or directly in a laboratory record book. The completed test instructions will be entered into the appropriate laboratory record book at a later time. 


\subsection{CHANGE CONTROL}

Changes affecting the objectives of the testing identified in this test plan shall be reviewed and approved by PNNL Tank Waste Safety Management. The significance of the changes will be determined by the PNNL project manager or his designated alternate. Major changes will be documented by issuing a revision to this test plan. Minor changes will be made by marking issued copies of the current version of this plan. All minor changes shall be signed and dated by the cognizant engineer/scientist (J. A. Campbell). 


\subsection{REFERENCES}

Agnew, S. F.; R. A. Corbin, T. B. Duran, K. A. Jurgensen, T. R. Ortiz, and B. L. Young. 1995. Waste Status and Transaction Record Summary (WSTRS), Rev. 1. WHC-SD-WM-TI-614, 615, 669, 689; Westinghouse Hanford Company, Richland Washington.

Agnew, S. F.; 1996. History of Organic Carbon in Hanford HLW Tanks: HDW Model Rev. 3, LAUR-96-989, Los Alamos National Laboratory, Los Alamos, New Mexico.

Babad, H., and D. A. Turner. 1993. Interim Criteria for Organic Watch List Tanks at the Hanford Site. WHC-EP-0681. Westinghouse Hanford Company, Richland Washington.

Camaioni, D. A.; W. D. Samuels, S. A. Clauss, B. D. Lenihan, K. L. Wahl, J. A. Campbell, and W. J. Shaw. 1995. FY95 Aging Studies. PNL-10794, Pacific Northwest Laboratory, Richland, Washington.

Campbell, J. A.; S. Clauss, K. Grant, V. Hoopes, G. Mong, J. Rau, R. Steele and K. L. Wahl. 1994. Flammable Gas Safety Program; Organic Analysis and Analytical Development: FY 1994 Progress Report. PNL-9062, Pacific Northwest Laboratory, Richland, Washington.

Campbell, J. A.; S. Clauss, K. Grant, V. Hoopes, G. Mong, J. Rau, R. Steele and K. L. Wahl. 1995. Flammable Gas Safety Program; Organic Analysis and Analytical 


\section{Appendix B}

Determination of Monobutyl Phosphate and Dibutyl Phosphate in Mixed Hazardous Wastes by Ion-Pair Chromatography 
Determination of Monobutyl Phosphate and Dibutyl Phosphate in Mixed Hazardous Wastes by Ion-Pair Chromatography

K.E. Grant, G.M. Mong, S.A. Clauss, K.L. Wahl, and J.A. Campbell*

Advanced Organic Analytical Methods Group

Pacific Northwest National Laboratory

Richland, WA 99352

* Address comments to this author 


\title{
Determination of Monobutyl Phosphate and Dibutyl Phosphate in Mixed Hazardous Wastes by Ion-Pair Chromatography
}

\author{
K.E. Grant, G.M. Mong, S.A. Clauss, K.L. Wahl, and J.A. Campbell* \\ Advanced Organic Analytical Methods Group \\ Pacific Northwest National Laboratory \\ Richland, WA 99352
}

\begin{abstract}
Ion-pair chromatography was tested for its applicability in determining monobutyl phosphate (MBP) and dibutyl phosphate (DBP), which are degradation products of tributyl phosphate, in Hanford tank wastes.

In tests with simulant waste mixtures, tetrahexylammonium bromide, an ion-pairing agent, was used to complex with all three phosphate species. Recovery studies indicated that ion-pairing chromatography is quantitative for determining the analytes in spiked samples. Initial results demonstrated that DBP could be detected easily and was fairly well separated from other peaks, but MBP was frequently lost due to large negative peaks. Then a preconcentration column procedure was used to clean up the waste-sample matrix, and the negative peaks disappeared. Results indicated that $80 \%$ of MBP and $90 \%$ of DBP could be recovered.

Most of the radioactivity was removed from actual waste tank samples so that additional sample preparation could be performed safely in a fume hood rather than a hot cell. Dibutyl phosphate was identified in an actual tank waste, but MBP was not found; this result was confirmed by ion chromatography with conductivity detection.
\end{abstract}




\title{
Determination of Monobutyl Phosphate and Dibutyl Phosphate in Mixed Hazardous Wastes by Ion-Pair Chromatography
}

\author{
K.E. Grant, G.M. Mong, S.A. Clauss, K.L. Wahl, and J.A. Campbell* \\ Advanced Organic Analytical Methods Group \\ Pacific Northwest National Laboratory \\ Richland, WA 99352
}

\section{Introduction}

Radioactive mixed hazardous wastes stored in 177 tanks at the Hanford Site in southeastern Washington contain substantial amounts of tri-n-butyl phosphate (TBP) ${ }^{1,2}$, which was used as a metal extractant to separate uranium, plutonium, and thorium in the reprocessing of spent nuclear fuel. Both thermal decomposition and radiolysis of TBP have generated dibutyl phosphate (DBP), monobutyl phosphate (MBP), and butanol. The chemistry of these processes has been described in great detail. ${ }^{3,4}$ Dibutyl phosphate has been of particular interest in terms of waste tank safety because of its high enthalpy.

Numerous analytical methods involving gas chromatography, several different types of liquid chromatography, infrared, visible, and ultraviolet spectroscopy, nuclear magnetic resonance, titrimetry, etc. exist to determine TBP. ${ }^{5}$ However, analytical methods for MBP and DBP have proven to be more elusive in the complex matrix found in the waste tanks. Bocek et al. have used high-speed isotachophoresis, a form of capillary electrophoresis with conductivity detection, to analyze for the degradation products of TBP in solutions containing nitrates and nitrites. ${ }^{6}$ Muller et al. have determined trace amounts of DBP and TBP in nuclear fuel reprocessing solutions by liquid chromatography. ${ }^{7}$ Wilkinson and Williams determined DBP and MBP by direct titration of irradiated TBP samples, ${ }^{8}$ and Krishramurthy and Sampathkumar have used titrimetry to determine dibutylphosphoric acid and monobutylphosphoric acid as degradation products in the twocomponent TBP-nitric acid system. ${ }^{9}$

Better methods are needed to separate and detect DBP and MBP in the highly basic complex waste mixtures found in radioactive waste storage tanks. Here we describe a method for determining DBP and MBP in simulant and actual waste mixtures by ion-pair chromatography with refractive index detection based on Muller et al. ${ }^{7}$ work with modifications and extensions. An ion-pairing agent was used (tetrahexylammonium bromide) to complex with all three phosphate species, MBP, $\mathrm{DBP}$, and TBP. Calibration graphs of area response vs. $\mathrm{mg} / \mathrm{mL}$ of $\mathrm{MBP}$ and $\mathrm{DBP}$ showed good 
linearity, and studies with spiked samples indicated that $80 \%$ of MBP and $90 \%$ of DBP could be recovered. In addition, this method was used to identify and quantify DBP in an actual tank waste sample.

\section{Experimental}

Standard solutions of DBP (Pfaltzgraph-Bauer Chemical Company) were prepared. Commercial DBP is a 64:36 DPB:MBP mixture. The DBP standards ranged from $0.24 \mathrm{mg} / \mathrm{mL}$ to $10.8 \mathrm{mg} / \mathrm{mL}$ in water. Above $10 \mathrm{mg} / \mathrm{mL}$, DBP does not dissolve well in aqueous solutions. Calibration graphs of area response vs. $\mathrm{mg} / \mathrm{mL}$ of the analyte were prepared for MBP and DBP.

Simulated waste samples ${ }^{10}$ were used to prepare samples. Table 1 shows the component breakdown for a typical simulant. Simulants subjected to 1) heat and radiation and 2) nonheated, non-irradiated were used. An aliquot of simulated waste was weighed $(0.50 \mathrm{~g})$, and $5.0 \mathrm{~mL}$ of Milli$\mathrm{Q}$ water was added quantitatively. The sample tube was capped, shaken, and vortexed, and centrifuged for 20 minutes at 1500 revolutions per minute (RPM). Twenty microliters of the aqueous layer were removed and injected into the high performance liquid chromatograph (HPLC) for analysis.

Relatively pure MBP and DBP can be obtained through a simple procedure outlined by Hardy et al. ${ }^{11}$ This method involves dissolving one volume mixed butyl phosphates (containing MBP) in four volumes of carbon tetrachloride $\left(\mathrm{CCl}_{4}\right)$ and extracting twice for 2 minutes with five volumes of water. The aqueous phases, which contain $98 \%$ of the MBP, are then combined. The $\mathrm{CCl}_{4}$ phase contains principally DBP. The $\mathrm{CCl}_{4}$ can be removed by nitrogen blow-down techniques after washing with $3 \mathrm{M} \mathrm{NaOH}$. Further purification is described, ${ }^{11}$ but these few steps provide a substantial amount of each analyte separately with only a few percent of the other analyte present as an impurity. These purified materials were used to spike waste samples to be sure which peaks were the MBP and DBP.

The original instrumentation included a Hewlett Packard series 1050 Isocratic HPLC pump, a Waters Associates Differential Refractometer R401 as the detector, and a Hewlett Packard HP3396 Series II integrator for collecting data. The analytical column was a Brownlee RP18, $25 \mathrm{~cm} \mathrm{x}$ $4.6 \mathrm{~mm}$, spheri-5 monofunctional $5 \mu \mathrm{C} 18$ with equivalent guard column. The mobile phase was $73 \%$ methanol and $27 \%$ water with $4 \times 10^{-3} \mathrm{M}$ tetrahexylammonium bromide (THA-Br) as the ionpairing agent. 
A preconcentration column procedure described by Muller et al. ${ }^{7}$ was used to clean up the waste-sample matrix. This research had suggested the possibility of separating and identifying at least DBP. The preconcentration column had seemed unnecessary because of the sizable amounts of DBP and TBP in the tank waste samples. However, the possibility of eliminating uranium, plutonium, fission products, nitric, phosphoric, and hydroflụoric acids, butanol, hydrazine, etc. through use of a preconcentration column and a less eluting mobile phase (retaining DBP and MBP) was deemed highly desirable. The preconcentration column used was a Rainin RP-18, $15 \times 3.2 \mathrm{~mm}, 7-\mu \mathrm{m}$ particle size, and was used in place of the standard 20- $\mathrm{L}$ sample loop connected to the Rheodyne injector. The preconcentration mobile phase consisted of $35 \%$ methanol, $65 \%$ water, and $2.0 \times 10^{-3} \mathrm{M}$ THABr. The preconcentration column was flushed with $1.00 \mathrm{~mL}$ of preconcentration mobile phase between each injection; $20 \mu \mathrm{L}$ of waste sample were injected onto this column. The other waste components were rinsed from the column with $1.0 \mathrm{~mL}$ of preconcentration mobile phase. Finally, the analytes were eluted from the preconcentration column and onto the main column by using a mobile phase consisting of the $73 \%$ methanol, $27 \% \mathrm{H}_{2} \mathrm{O}$, and $4.0 \times 10^{-3} \mathrm{M}$ THA-Br already described.

Recovery studies indicated that this method is quantitative for determining the analytes in simulated waste samples. Known standard solutions of DBP and MBP were spiked into simulant waste samples that contained only inorganics to simplify the initial experiment. The spiked samples were prepared by weighing $0.50 \mathrm{~g}$ of simulant into a screw-cap test tube. A $0.6-\mathrm{mL}$-aliquot of standard solution containing $10.1 \mathrm{mg} / \mathrm{mL}$ DBP/MBP and $10.23 \mathrm{mg} / \mathrm{mL}$ TBPwas added, $4: 4 \mathrm{~mL}$ of Milli-Q water were added, and the tube was capped, shaken, and vortexed. It was then centrifuged for 20 minutes at $1500 \mathrm{RPM}$, and $20 \mu \mathrm{L}$ of the aqueous layer were removed and injected onto the HPLC column for ion-pair chromatographic analysis.

Before testing actual Hanford tank waste samples, the majority of the radioactivity is removed, allowing additional sample preparation to be performed in a fume hood rather than a hot-cell. Two grams of waste from Tank 204-C were slurried with water and allowed to percolate through a bed of Dowex 50-X8 resin (sodium form) to reduce the radioactivity level. The column was rinsed with $1 \mathrm{~N}$ $\mathrm{NaOH}$ to remove fission cations. The resulting eluate was found to be practically devoid of residual activity and was used for analysis without the requirement for radiochemical protection. Samples were analyzed using the ion-pair HPLC chromatographic method with preconcentation cleanup and also by ion-chromatography with conductivity detection to determine the quantity of butylated phosphates present. 


\section{Results and Discussion}

Studies with the standards show that both MBP and DBP can be detected and separated, although the MBP peak is very close to a negative peak eluting just before it (see Figure 1). Tributyl phosphate was also spiked into the standard and could be detected as a late eluting peak (about 28 minutes). These results raised the possibility of detecting all three phosphate species in mixed hazardous waste. The MBP elutes before DBP, a surprising result, since MBP would have two sites for pairing with the THA-Br as opposed to just one for the DBP. However, molecular modeling studies show that the steric hindrance caused by two THA-Br attachments to MBP would be prohibitive. Therefore, it is likely that only one THA-Br pairs with MBP, leaving a negative charge on this species.

The calibration graphs of area response vs. $\mathrm{mg} / \mathrm{mL}$ of DBP and MBP are shown in Figures 2 and 3. These graphs show excellent linearity over the range for DBP and reasonable linearity for MBP.

Initial results with waste simulants demonstrated that DBP could be detected easily and was fairly well separated from other peaks due to butanol and other waste components. Monobutyl phosphate was frequently lost due to large negative peaks, undoubtedly caused by large quantities of nitrates and other salts in the waste matrix. The baseline was often negative for several minutes and barely rose to zero before DBP eluted. Furthermore, the retention time for DBP had a tendency to continually drift downward, perhaps indicating that column sites were being increasingly occupied by other waste species. These negative chromatographic separations were obtained before introducing the preconcentration column. When the preconcentration column procedure described under the Experimental section was introduced, a much cleaner chromatogram was obtained for the waste samples. The large negative peaks disappeared, except for the ones associated with the solvent front. Monobutyl phosphate was now detectable at about 7 to 9 minutes, and the retention time for DBP appeared to stabilize (about 17-19 minutes) instead of drifting downward (see Figure 4). Figure 5 is a chromatogram of a simulant containing MBP,DBP,andTBP. The results indicate the presence of all three phosphate'species. Muller et al. ${ }^{7}$ acidified the aqueous phase (after extraction with $\mathrm{NaOH}$ solution) to a pH of about 2.5. We have tried to acidify samples, but consistently less MBP and DBP are determined. This seems reasonable since an acidic medium would favor MBP to remain as $\mathrm{H}_{2} \mathrm{MBP}$, and DBP to occur as HDBP. Thus, ion pairing with THA-Br produces less effective neutral species. Therefore, the $\mathrm{pH}$ of the samples was not adjusted. The average $\mathrm{pH}$ of the waste samples was 12. 
Our studies show that TBP recovery is unreliable with this method. However, we have shown that extraction of TBP from actual waste with methylene chloride with subsequent analysis using GC/MS provides $>90 \%$ recovery ${ }^{(1,2)}$. The low recovery often seen can be attributed to the poor solubility of TBP in aqueous solutions. Monobutyl phosphate shows a recovery of $80 \%$ or better, and DBP is $90 \%$ or better. These figures are very sensitive to even slight changes in $\mathrm{pH}$ or mobilephase concentration. All solutions and samples were prepared and analyzed the same day to avoid equilibrium effects between the DBP and MBP and possible hydrolysis of the analytes.

Figure 6 is an ion-pair chromatogram of an actual waste sample from Tank 241-C-204. Dibutyl phosphate was identified with a retention time of $16.6 \mathrm{~min}$. The approximate concentration was $6.8 \mathrm{mg} / \mathrm{g}$ sample. Monobutyl phosphate was not found in this waste sample, a result confirmed by ion chromatography with conductivity detection. These results indicate clearly the applicability of ion-pair chromatography for the analysis of MBP and DBP in mixed hazardous wastes

\section{Acknowledgments}

This research was conducted at Pacific Northwest National Laboratory, which is operated for the U.S. Department of Energy by Battelle under Contract DE-AC06-76RLO 1830. 


\section{References}

1. J.A. CAMPBELL, R.M BEAN. 1995. Waste Tank Organic Safety Project: Analysis of Samples from Hanford Waste Tanks 241-C-102, 241-BY-108, and 241-C-103. PNL-10531, Pacific Northwest National Laboratory, Richland, Washington.

2. H. BABAD, B.A. CRAWFORD, R.D. SCHREIBER, J.A. CAMPBELL, G.M. MONG, S.A. BRYAN,

R.D. SCHEELE. 1996. Chemically and Chemically-Related Considerations Associated with Sluicing Tank C-106 Waste to Tank AY-102. WHC-SD-WM-TI-756, Revision A, Draft. Westinghouse Hanford Company and Pacific Northwest National Laboratory, Richland, Washington.

3. Science and Technology of Tri-Butyl Phosphate (Ed. by W.W. Schulz and J.D. Navratil). C.R.C. Press, Boca Raton (1984), Vol. 1.

4. M.V. KRISHNAMURTHY, A.T. SIPAHIMALANI. J. Radioanal. Nucl. Chem. Letter., 199 (3) (1995) $197-206$.

5. W. Davis, Jr., J.D. Navratil, A. Lásztity, and Z. Horvath, Science and Technology of Tri-pButyl Phosphate, (Ed. by W.W. Schulz and J.D. Navratil) C.R.C. Pess, Boca Raton (1984), Chapter 8.

6. P. BOCEK, V. DOLNIK, M. DEML, J. JANAK J. Chromatogr., 195 (1980) 303-305.

7. M.P. MULLER, J. COJEAN, A. DELOGE. Analysis, 13(4) (1985) 160-165.

8. W. WILKINSON, T.F. WILLIAMS. J. Chem. Soc. (1961) 4098.

9. M.V. KRISHNAMURTHY, R. SAMPATHKUMAR J. Radioanal. Nucl. Chem., Letters 166(5) (1992) 421-429.

10. D.M. CAMAIONI, W.D. SAMUELS, B.D. LENIHAN, S.A. CLAUSS, K.L. WAHL, J.A. CAMPBELL. 1994. Organic Waste Tank Safety Program, Waste Aging Studies. PNL-10161, Pacific Northwest National Laboratory, Richland, Washington.

11. C.J. HARDY, D. SEARGILL. J. Inorg..Nucl. Chem., 10 (1959) 323-325. 
Table 1. Composition of Simulant Waste Samples (From Reference 10)

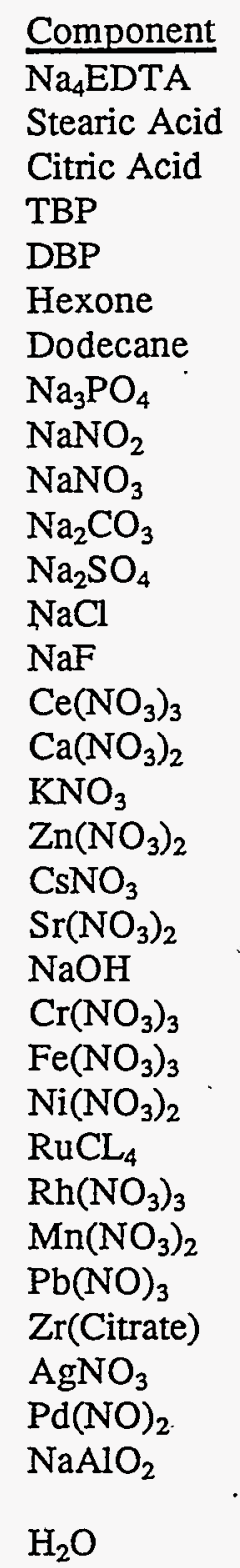

\begin{tabular}{cc} 
Weight $(\mathrm{g})$ & $\frac{\mathrm{mg} / \mathrm{g}}{22.81}$ \\
\hline 76.0412 & 16.23 \\
54.1017 & 16.23 \\
54.1132 & 15.98 \\
53.2622 & 12.60 \\
42.0007 & 6.012 \\
20.0403 & 10.218 \\
34.0598 & 24.59 \\
81.9590 & 152.3 \\
507.7 & 125.3 \\
417.5241 & 53.41 \\
178.0422 & 5.676 \\
18.9207 & 0.00 \\
0 & 0.0031 \\
0.0103 & 0.8078 \\
2.6926 & 1.31 \\
4.3549 & 8.091 \\
26.9705 & 0.06021 \\
0.2007 & 0.02094 \\
0.0698 & 0.001 \\
0.0034 & 56.44 \\
188.1429 & 30.30 \\
100.9953 & 1.938 \\
6.4608 & 0.7146 \\
2.381 & 0.022 \\
0.0717 & 0.019 \\
0.062 & 1.081 \\
3.6022 & 2.004 \\
6.6808 & 1.353 \\
4.5111 & 01001 \\
0.004 & 0.146 \\
0.4893 & \\
408.9299 & 122.7 \\
1039 & \\
& \\
& \\
11.7 \\
\hline
\end{tabular}




\section{Figure Captions}

Figure 1. Ion-Pair Chromatogram with Refractive Index Detection of MBP and DBP Standards

Figure 2. Calibration Curve for DBP

Figure 3. Calibration Curve for MBP

Figure 4. Ion-Pair Chromatogram of a Simulated Waste Spiked with DBP and MBP Using a Preconcentration Clean-Up Column

Figure 5. Ion-Pair Chromatogram of Simulated Waste Sample Containing TBP, DEP, and MBP Using a Preconcentration Column

Figure 6. Ion-Pair Chromatogram of Tank 241-C-204 Waste Sample 


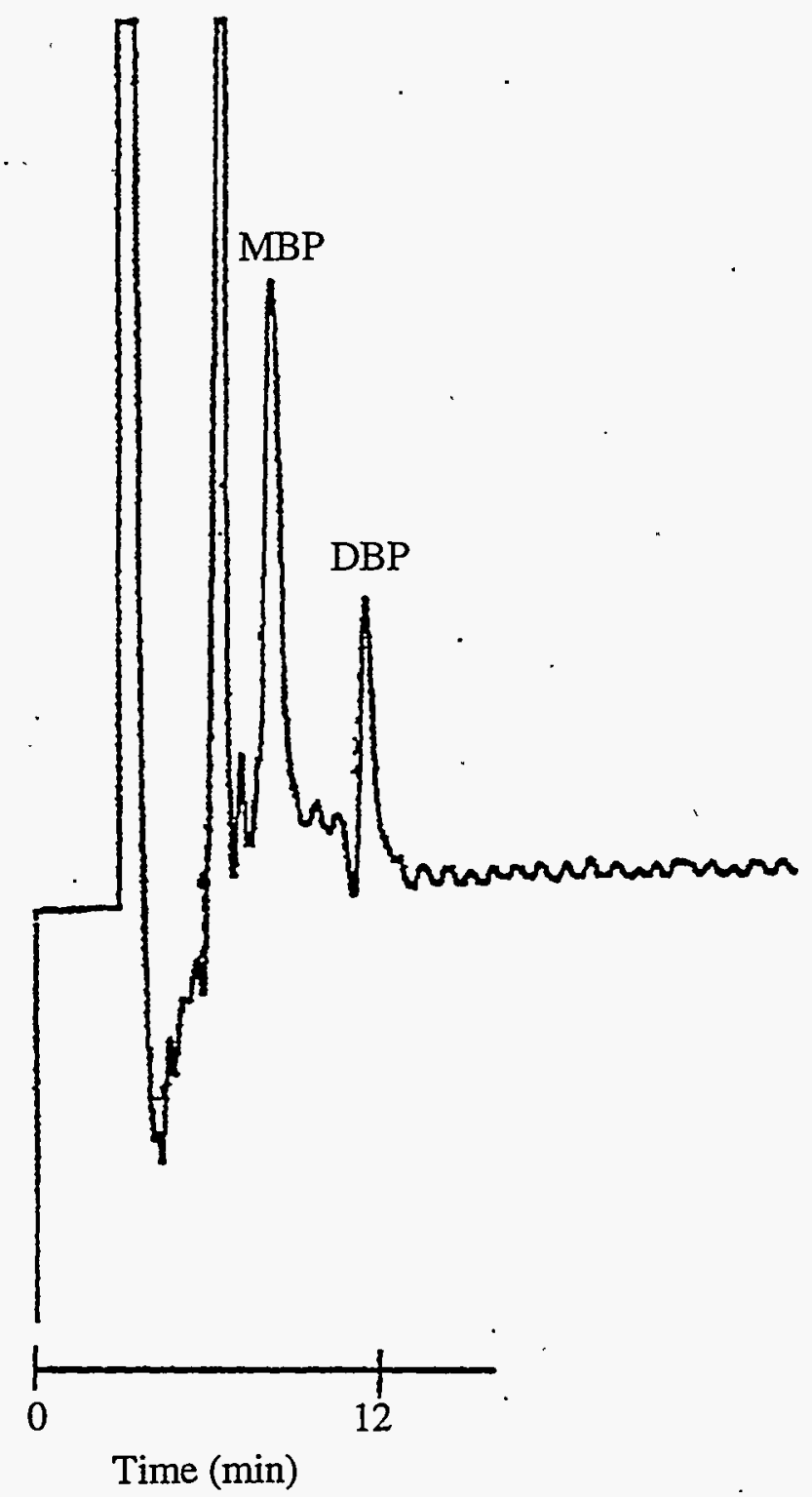

B. 12 


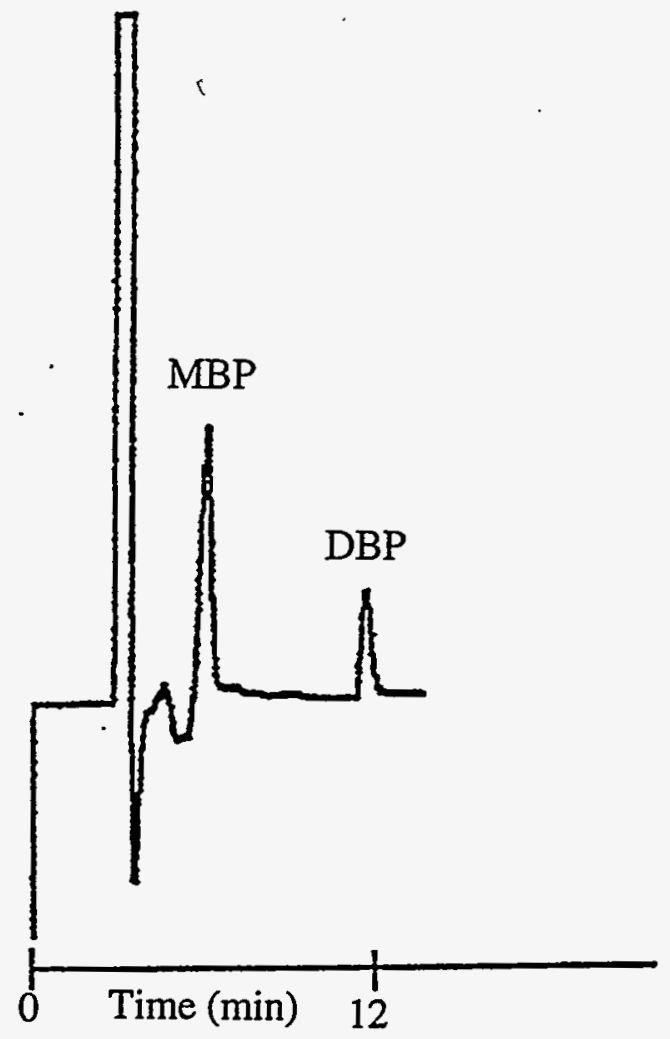

B.13 


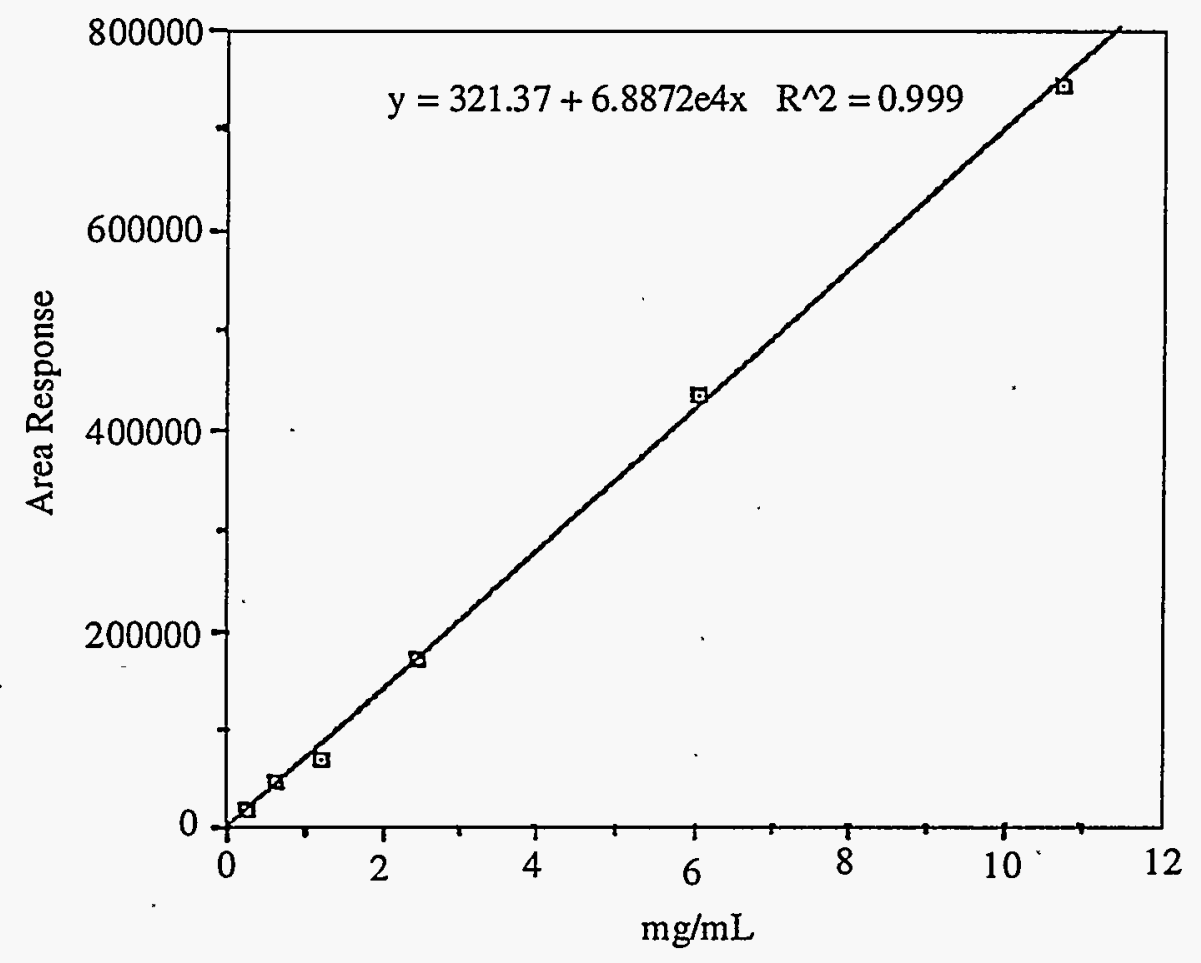

B. 14 


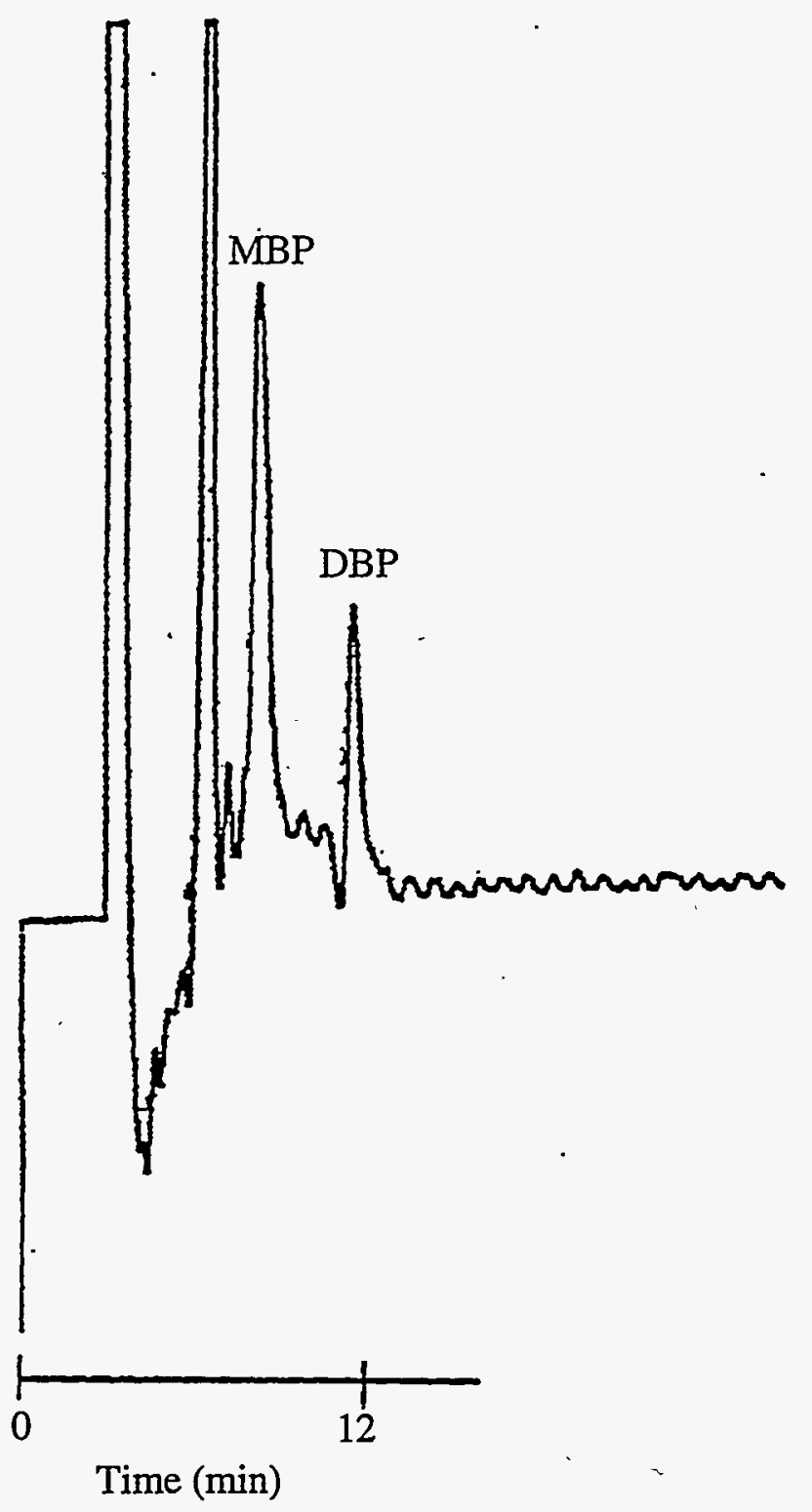

B. 15 


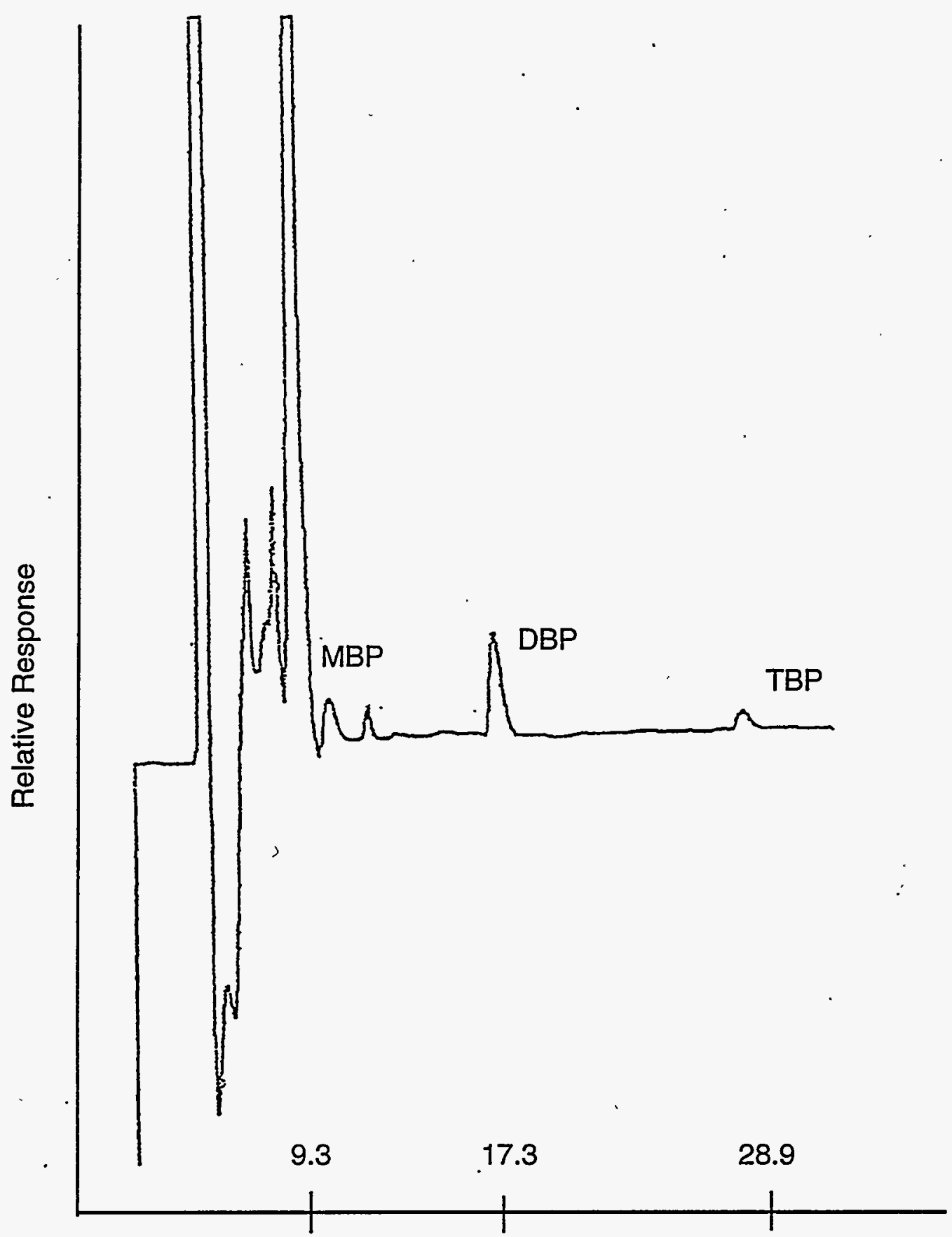

Retention Time (min)

9608230067.jac 


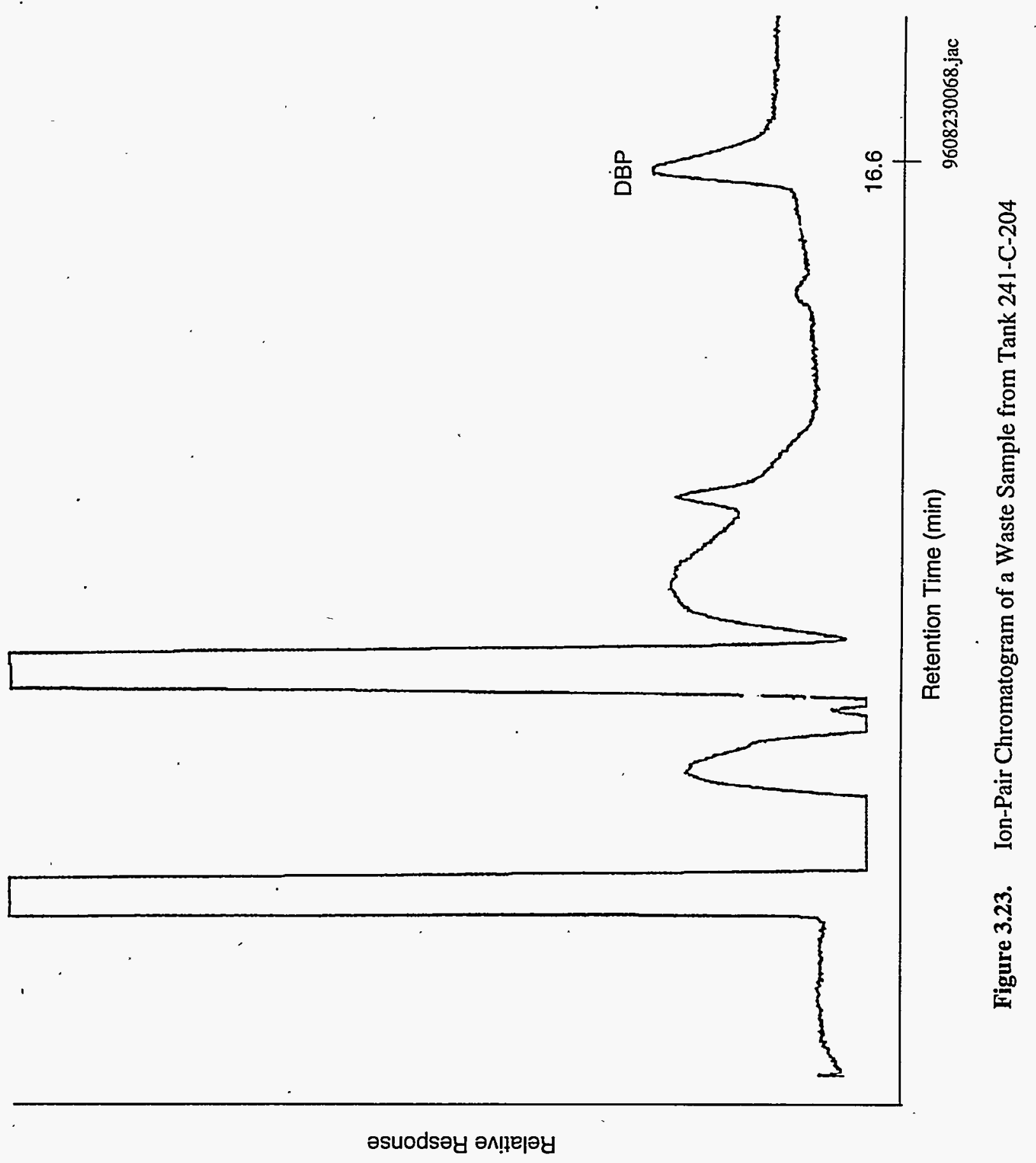

B. 17 


\section{Distribution}

No. of

Copies

\section{Offsite}

2 DOE/Office of Scientific and

Technical Information .

Steve F. Agnew

Los Alamos National Laboratory

P. O. Box 1663

CST-4MS-J586

Los Alamos, NM 87545

J. Antizzo

U.S. Department of Energy

EM-36/Trevion II

Germantown,-MD 20874

Dr. E. C. Ashby

School of Chemistry/Biochemistry

Georgia Institute of Technology

Atlanta, GA .30332-0400

Dr. E. K. Barefield

School of Chemistry/Biochemistry

Georgia Institute of Technology

Atlanta, GA 30332-0400

Ned Bibler

Westinghouse Savannah River

P. O. Box 616

Aiken, SC 29802

Jack Edwards

Los Alamos National Laboratory

P. O. Box 1663

Los Alamos, NM 87545

L. Kovach

NUCON

P. O. Box 29151

Columbus, $\mathrm{OH}$ 43229-0151
No. of

Copies
B. R. Kowalski
Chemistry Department, BG-10
University of Washington
Seattle, WA 98195
C. L. Liotta
School of Chemistry/Biochemistry
Georgia Institute of Technology
Atlanta, GA 30332-0400

\section{Offsite}

Dr. D. Meisel

Chemistry Division

Argonne National Laboratory

9700 South Cass Avenue

Argonne, IL 60439

H. M. Neumann

School of Chemistry/Biochemistry

Georgia Institute of Technology

Atlanta, GA 30332-0400

C. O'Dell

U. S. Department of Energy

EM 36/Trevion II

Germantown, MD 20874

H. Sutter

SAIC

20300 Century Boulevard

Germantown, MD 20874

\section{Onsite}

7 DOE Richard Operations Office
S. O. Branch
S7-54
R. F. Christensen,
S7-54
M. F. Jarvis,
S7-54
G. W. Roseriwald,
S7-54
Public Reading Room
RL Docket File (2)
B3-11

Dist. 1 
No. of

Copies

Onsite

FAI

M. G. Plys

H4-62

2 MACTEC

M. H. Campbell,

S7-73

S. T. Murff

S7-73

17 Westinghouse Hanford Company

H. Babad

S7-14

G. S. Barney

T5-12

G. A. Barnes

H5-09

D. B. Bechtold

T6-09

B. A. Crawford

T6-09

G. T. Dukelow

S7-14

K. A. Gasper

D. L. Herting

J. D. Hopkins

J. R. Jewett

G. D. Johnson

N. W. Kirch

J. C. Person

F. R. Reich

D. A. Reynolds

L. M. Stock

D. A. Turner

G3-21

T6-09

R2-11

T6-09

S7-14

R2-11

T6-09

L5-55

R2-11

S7-14

S7-14
No. of

Copies

\section{Onsite}

\section{Pacific Northwest National Laboratory}

G. H. Beeman

P7-75

J. W. Brothers (5)

K9-20

I. E. Burgeson

P7-25

S. A. Bryan

P7-25

D. M. Camaioni

$\mathrm{K} 2-44$

J. A. Campbell (10)

P8-08

C. D. Carlson

P7-25

S. A. Clauss

P8-08

P. A. Gauglitz

P7-41

M. A. Gerber

P8-38

S. C. Goheen

P8-08

R. T. Hallèn

P8-38

L. K. Holton

K9-73

D. W. Koppenaal

P7-07

Pacific Northwest National Laboratory

B. D. Lerner

M. A. Lilga

P. K. Melethil

G. M. Mong

L. R. Pederson

W. D. Samuels

R. D. Scheele

L. A. Schienbein

A. K. Sharma

C. W. Stewart

M. R. Thompson

J. M. Tingey

J. J. Toth

K. L. Wahl (10)

P8-08

P8-38

P7-22

P8-08

K2-44

K2-44

P7-25

K5-20

P8-08

K7-15

$\mathrm{K} 2-50$

P7-25

K7-94

P8-08

Organic Tank Project File K9-89

Publishing Coordination

Technical Report Files (5) 